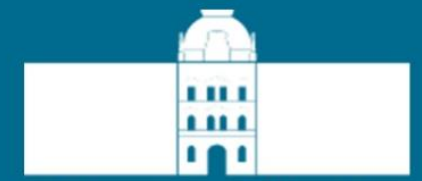

University of Maribor

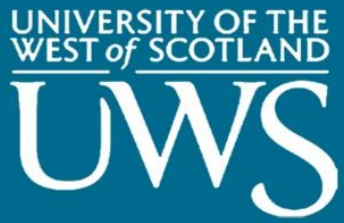

\title{
$10^{\mathrm{TH}}$ International Conference on Sustainable Energy and Environmental Protection:
}

\section{Water and Air Quality}

(June $27^{T H}-30^{T H}, 2017$, Bled, Slovenia)

(Conference Proceedings)

\section{Editors:}

Emeritus Prof. dr. Jurij Krope Prof. dr. Abdul Ghani Olabi Prof. dr. Darko Goričanec

Prof. dr. Stanislav Božičnik 
University of Maribor Press 


\title{
$10^{\mathrm{TH}}$ International Conference on Sustainable Energy and Environmental Protection
}

\author{
Water and Air Quality \\ (June 27 ${ }^{\mathrm{TH}}-30^{\mathrm{TH}}, 2017$, Bled, Slovenia) \\ (Conference Proceedings)
}

Editors:

Emeritus Prof. dr. Jurij Krope

Prof. dr. Abdul Ghani Olabi

Prof. dr. Darko Goričanec

Prof. dr. Stanislav Božičnik

June 2017 
Title: $\quad 10^{\mathrm{TH}}$ International Conference on Sustainable Energy and Environmental Protection (June $27^{\mathrm{TH}}-30^{\mathrm{TH}}, 2017$, Bled, Slovenia) (Conference Proceedings)

Subtitle: Water and Air Quality

Editors: Emeritus Prof. Jurij Krope, Ph.D. (University of Maribor, Slovenia), Prof. Abdul Ghani Olabi, Ph.D. (University of the West of Scotland, UK), Asso. Prof. Darko Goričanec, Ph.D. (University of Maribor, Slovenia), Asso. Prof. Stanislav Božičnik (University of Maribor, Slovenia).

Review: Prof. Željko Knez, Ph.D. (University of Maribor, Slovenia), Prof. Niko Samec, Ph.D. (University of Maribor, Slovenia).

Tehnical editors : Jan Perša (University of Maribor Press), Armin Turanović (University of Maribor Press).

Design and layout: University of Maribor Press

Conference: $\quad 10^{\mathrm{TH}}$ International Conference on Sustainable Energy and Environmental Protection

Honorary Committee:

Abdul Ghani Olabi, Ph.D. (Honorary President, University of the West of Scotland, United Kingdom), Igor Tičar, Ph.D (Rector of the University of Maribor, Slovenia), Niko Samec $\mathrm{Ph} . D$. (Pro-rector of University of Maribor, Slovenia), Zdravko Kravanja, Ph-D. (Dean of the Faculty of Chemistry and Chemical Engineering, University of Maribor, Slovenia).

Organising Committee:

Jurij Krope, Ph.D. (University of Maribor, Slovenia), Darko Goričanec, Ph.D. (University of Maribor, Slovenia), Stane Božičnik, Ph.D. (University of Maribor, Slovenia), Peter Trop, Ph.D. (University of Maribor, Slovenia), Danijela Urbancl, Ph.D. (University of Maribor, Slovenia), Sonja Roj (University of Maribor, Slovenia), Željko Knez, Ph.D. (University of Maribor, Slovenia), Bojan Štumberger, Ph.D. (University of Maribor, Slovenia), Franci Čuš, Ph.D. (University of Maribor, Slovenia), Miloš Bogataj, Ph.D. (University of Maribor, Slovenia), Janez Žlak, Ph.D (Mine Trbovlje Hrastnik, Slovenia), LL. M. Tina Žagar (Ministry of Economic Development and Technology), Igor Ivanovski, MSc. (IVD Maribor, Slovenia), Nuša Hojnik, Ph.D. (Health Center Maribor).

Programme Committee:

Prof. Abdul Ghani Olabi (UK), Emeritus Prof. Jurij Krope (Slovenia), Prof. Henrik Lund (Denmark), Prof. Brian Norton (Ireland), Prof. Noam Lior (USA), Prof. Zdravko Kravanja (Slovenia), Prof. Jirí Jaromír Klemeš (Hungary), Prof. Stane Božičnik (Slovenia), Prof. Bojan Štumberger (Slovenia), Prof. Soteris Kalogirou (Cyprus), Prof. Stefano Cordiner (Italy), Prof. Jinyue Yan (Sweden), Prof. Umberto Desideri (Italy), Prof. M.S.J. Hashmi (Ireland), Prof. Michele Dassisti (Italy), Prof. Michele Gambino (Italy), Prof. S. Orhan Akansu (Turkey), Dr. David Timoney (Ireland), Prof. David Kennedy (Ireland), Prof. Bekir Sami Yilbas (Saudi Arabia), Dr. Brid Quilty (Ireland), Prof. B. AbuHijleh (UAE), Prof. Vincenc Butala (Slovenia), Prof. Jim McGovern (Ireland), Prof. Socrates Kaplanis (Greece), Dr. Hussam Jouhara (UK), Prof. Igor Tičar (Slovenia), Prof. Darko Goričanec (Slovenia), Dr. Joseph Stokes (Ireland), Prof. Antonio Valero (Spain), Prof. Aristide F. Massardo (Italy), Prof. Ashwani Gupta (USA), Dr. Aoife Foley (UK), Dr. Athanasios Megartis (UK), Prof. Francesco Di Maria (Italy), Prof. George Tsatsaronis (Germany), Prof. Luis M. Serra (Spain), Prof. Savvas Tassou (UK), Prof. Luigi Alloca (Italy), Prof. Faek Diko (Germany), Dr. F. Al-Mansour (Slovenia), Dr. Artur Grunwald (Germany), Dr. Peter Trop (Slovenia), Prof. Philippe Knauth (France), Prof. Paul Borza (Romania), Prof. Roy Douglas (UK), Prof. Dieter Meissner (Austria), Dr. Danijela Urbancl (Slovenia), Prof. Daniel Favrat (Switzerland), Prof. Erik Dahlquist (Sweden), Prof. Eric Leonhardt (USA), Prof. GianLuca Rospi (Italy), Prof. Giuseppe Casalino (Italy), Prof. J. Dawson (USA), Dr. Josè Simoes (Portugal), Prof. Kadir Aydin (Turkey), Dr. Khaled Benyounis (Ireland), Prof. Laszlo Garbai (Hungary), Prof. Mariano Martin (Spain), Prof. Masahiro Ishida (Japan), Prof. Michael Seal (USA), Prof. Marco Spinedi (Italy), Prof. Michio Kitano (Japan), Prof. Milovan Jotanović (BiH), Prof. Nafiz Kahraman (Turkey), Prof. Na Zhang (China), Prof. Naotake Fujita (Japan), Prof. Niko Samec (Slovenia), Prof. Oleksandr Zaporozhets (Ukraine), Prof. Osama Al-Hawaj (Kuwait), Prof. Petar Varbanov (Hungary), Prof. Peter Goethals (Belgium), Prof. Qi Zhang (China), Prof. Rik Baert (The Netherlands), Prof. Rolf Ritz (USA), Dr. Stephen Glover (UK), Prof. Signe Kjelstrup (Norway), Dr. Sumsun Naher (UK), Prof. Sven Andersson (Sweden), Dr. Salah Ibrahim (UK), Prof. Sebahattin Unalan (Turkey), Prof. Sabah Abdul-Wahab Sulaiman (Oman), Prof. Somrat Kerdsuwan (Thailand), Prof. T. Hikmet Karakoç (Turkey), Prof. Tahir Yavuz (Turkey), Prof. Hon Loong Lam (Thailand), LL.M. Tina Žagar (Slovenia), Prof. A.M.Hamoda (Qatar), Prof. Gu Hongchen (China), Prof. Haşmet Turkoglu (Turkey), Dr. Hussam Achour (Ireland), Dr. James Carton (Ireland), Dr. Eivind Johannes (Norway), Prof. Elvis Ahmetović (BiH), Prof. 
D.G.Simeonov (Bulgaria), Prof. Abdelakder Outzourhit (Morocco), Prof. Bilge Albayrak Çeper (Turkey), Prof. Bekir Zühtü Uysal (Turkey), Prof. D. Bradley (UK), Dr. Silvia Tedesco (UK), Dr. Valentin Ivanov (Germany), Dr. Vincent Lawlor (Austria), Prof. Yonghua Cheng (Belgium), Prof. Yasufumi Yoshimoto (Japan), Prof. Yahya Erkan Akansu (Turkey), Prof. Yunus Ali Çengel (Turkey), Prof. Zeljko Knez (Slovenia), Prof. Zoltan Magyar (Hungary), Dr. William Smith (Ireland), Dr. Abed Alaswad (UK).

First published in 2017 by

University of Maribor Press

Slomškov trg 15, 2000 Maribor, Slovenia

tel. +386225042 42, fax +38622523245

http://press.um.si, zalozba@um.si

\section{Co-published by}

University of Maribor, Faculty of Chemistry and Chemical Engineering

Smetanova ulica 17,2000 Maribor, Slovenia

tel. +386 (0)2 2294 400, faks + $386(0) 22527774$

http://www.fkkt.um.si, fkkt@um.si

Published: 5. July 2017

\section{(C) University of Maribor Press}

All rights reserved. No part of this book may be reprinted or reproduced or utilized in any form or by any electronic, mechanical, or other means, now known or hereafter invented, including photocopying and recording, or in any information storage or retrieval system, without permission in writing from the publisher.

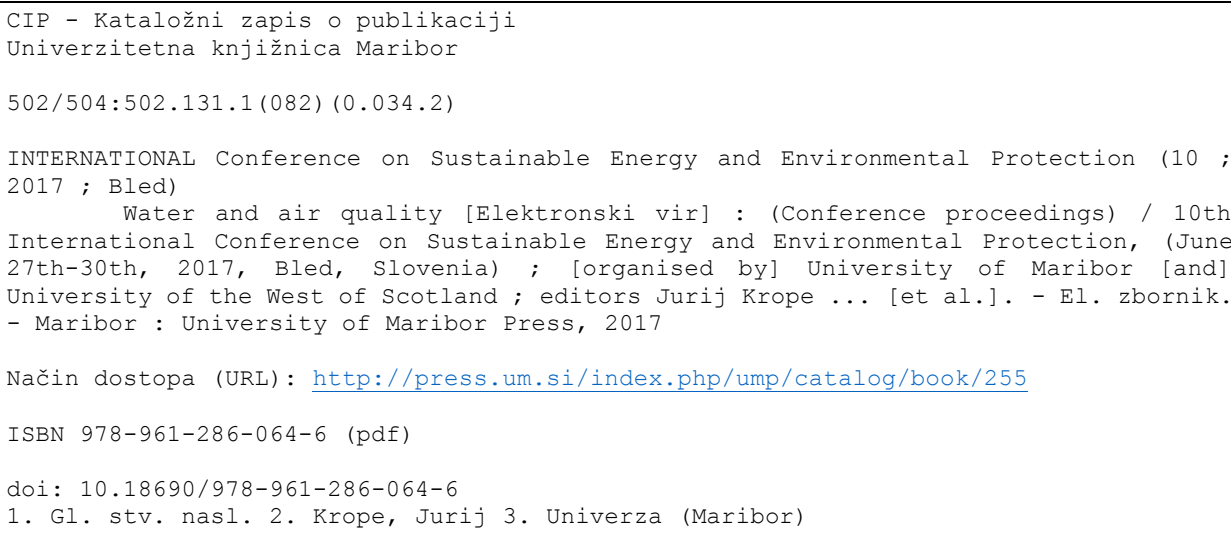

ISBN 978-961-286-064-6

DOI: https://doi.org/10.18690/978-961-286-064-6

Price: Free copy

For publisher: $\quad$ Prof. Igor Tičar, Ph.D., rector (University of Maribor) 
$10^{\mathrm{TH}}$ InTERNATIONAL CONFERENCE ON Sustainable ENERGy AND Environmental Protection (June 27 $7^{\mathrm{TH}}-30^{\mathrm{RD}}$, 2017, BLed, SLOVENIA), WATER AND AIR QUALITY

J. Krope, A.Ghani Olabi, D. Goričanec \& S. Božičnik

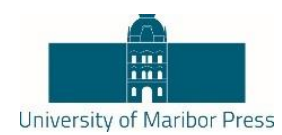

\section{Preface}

The $10^{\text {th }}$ International Conference on Sustainable Energy and environmental Protection SEEP 2017 was organised on June $27^{\text {th }}-30^{\text {th }} 2017$ in Bled, Slovenia, by:

- Faculty of Chemistry and Chemical Engineering, University of Maribor, Slovenia,

- University of the West of Scotland, School of Engineering and

The aim of SEEP2017 is to bring together the researches within the field of sustainable energy and environmental protection from all over the world.

The contributed papers are grouped in 18 sessions in order to provide access to readers out of 300 contributions prepared by authors from 52 countries.

We thank the distinguished plenary and keynote speakers and chairs who have kindly consented to participate at this conference. We are also grateful to all the authors for their papers and to all committee members.

We believe that scientific results and professional debates shall not only be an incentive for development, but also for making new friendships and possible future scientific development projects.

General chair

Emeritus Prof. dr. Jurij Krope
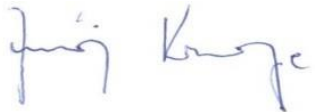
$10^{\mathrm{TH}}$ InTERNATIONAL CONFERENCE ON Sustainable ENERGY AND Environmental Protection (June 27 $7^{\mathrm{TH}}-30^{\mathrm{RD}}$, 2017, Bled, SLOVENIA), WATER AND AIR QUALITY

J. Krope, A.Ghani Olabi, D. Goričanec \& S. Božičnik

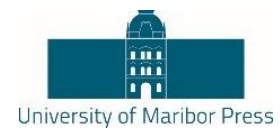

\title{
Plenary Talk on \\ The Relation between Renewable Energy and Circular Economy
}

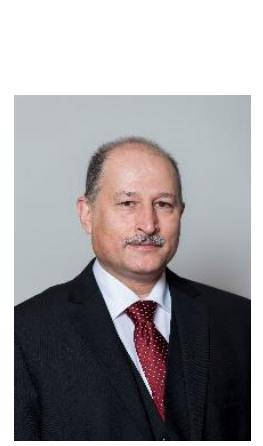

\author{
ABDUL GHANI OLABI - BIBLIOGRAPHY
}

Prof Olabi is director and founding member of the Institute of Engineering and Energy Technologies (www.uws.ac.uklieet) at the University of the West of Scotland. He received his M.Eng and Ph.D. from Dublin City University, since 1984 he worked at SSRC, HIAST, CNR, CRF, DCU and UWS. Prof Olabi has supervised postgraduate research students (10 M.Eng and 30PhD) to successful completion. Prof Olabi has edited 12 proceedings, and has published more than 135 papers in peer-reviewed international journals and about 135 papers in international conferences, in addition to 30 book chapters. In the last 12 months Prof Olabi has patented 2 innovative projects. Prof Olabi is the founder of the International Conference on Sustainable Energy and Environmental Protection SEEP, www.seepconference.co.uk

$\mathrm{He}$ is the Subject Editor of the Elsevier Energy Journal https://www.journals.elsevier.com/energy/editorial-board/abdul-ghani-olabi, also Subject editor of the Reference Module in Materials Science and Materials Engineering http://scitechconnect.elsevier.com/reference-module-material-science/ and board member of a few other journals. Prof Olabi has coordinated different National, EU and International Projects. He has produced different reports to the Irish Gov. regarding: Hydrogen and Fuel Cells and Solar Energy.

Correspondence AdDress: Abdul Ghani Olabi, Ph.D., Professor, University of the West of Scotland, School of Engineering and Computing, D163a, McLachlan Building, Paisley, United Kingdom, e-mail: Abdul.Olabi@uws.ac.uk. 
$10^{\mathrm{TH}}$ InTERNATIONAL CONFERENCE ON Sustainable ENERGy AND

Environmental Protection (June 27 $7^{\mathrm{TH}}-30^{\mathrm{RD}}$, 2017, Bled,

SLOVENIA), WATER AND AIR QUALITY

J. Krope, A.Ghani Olabi, D. Goričanec \& S. Božičnik

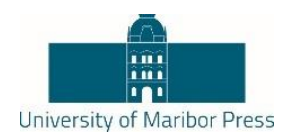

\title{
Plenary Talk on \\ Energy Footprints Reduction and Virtual Footprints Interactions
}

\author{
JIŘí JAROMÍR KLEMEŠ \& PETAR SABEV VARBANOV
}

Increasing efforts and resources have been devoted to research during environmental studies, including the assessment of various harmful impacts from industrial, civic, business, transportation and other economy activities. Environmental impacts are usually quantified through Life Cycle Assessment (LCA). In recent years, footprints have emerged as efficient and useful indicators to use within LCA. The footprint assessment techniques has provided a set of tools enabling the evaluation of Greenhouse Gas (GHG) - including $\mathrm{CO}_{2}$, emissions and the corresponding effective flows on the world scale. From all such indicators, the energy footprint represents the area of forest that would be required to absorb the GHG emissions resulting from the energy consumption required for a certain activity, excluding the proportion absorbed by the oceans, and the area occupied by hydroelectric dams and reservoirs for hydropower.

An overview of the virtual GHG flow trends in the international trade, associating the GHG and water footprints with the consumption of goods and services is performed. Several important indications have been obtained: (a) There are significant GHG gaps between producer's and consumer's emissions - US and EU have high absolute net imports GHG budget. (b) China is an exporting country and increasingly carries a load of GHG emission and virtual water export associated with consumption in the relevant importing countries. (c) International trade can reduce global environmental pressure by redirecting import to products produced with lower intensity of GHG emissions and lower water footprints, or producing them domestically.

To develop self-sufficient regions based on more efficient processes by combining neighbouring countries can be a promising development. A future direction should be focused on two main areas: (1) To provide the self-sufficient regions based on more efficient processes by combining production of surrounding countries. (2) To develop the shared mechanism and market share of virtual carbon between trading partners regionally and internationally.

CORRESPONDENCE AdDRESS: Jiř́i Jaromír Klemeš, DSc, Professor, Brno University of Technology - VUT Brno, Faculty of Mechanical Engineering, NETME Centre, Sustainable Process Integration Laboratory - SPIL, Technická 2896/2, 61669 Brno, Czech Republic, e-mail: klemes@fme.vutbr.cz. Petar Sabev Varbanov, Ph.D., Associate Professor, Brno University of Technology - VUT Brno, Faculty of Mechanical Engineering, NETME Centre, Sustainable Process Integration Laboratory - SPIL, Technická 2896/2, 61669 Brno, Czech Republic, e-mail: varbanov@fme.vutbr.cz. 
$10^{\mathrm{TH}}$ InTERNATIONAL CONFERENCE ON Sustainable ENERGY AND Environmental Protection (June 27 $7^{\mathrm{TH}}-30^{\mathrm{RD}}$, 2017, Bled, SLOVENIA), WATER AND AIR QUALITY

J. Krope, A.Ghani Olabi, D. Goričanec \& S. Božičnik

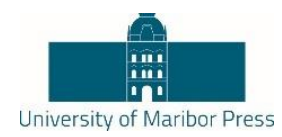

\section{JIŘÍ JAROMÍR KLEMEŠ - BIBLIOGRAPHY}

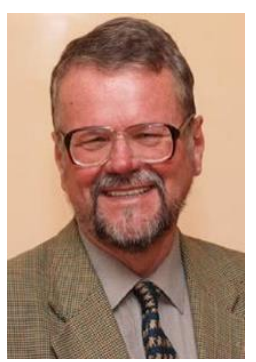

Head of "Sustainable Process Integration Laboratory - SPIL", NETME Centre, Faculty of Mechanical Engineering, Brno University of Technology - VUT Brno, Czech Republic and Emeritus Professor at "Centre for Process Systems Engineering and Sustainability", Pázmány Péter Catholic University, Budapest, Hungary.

Previously the Project Director, Senior Project Officer and Hon Reader at Department of Process Integration at UMIST, The University of Manchester and University of Edinburgh, UK. Founder and a long term Head of the Centre for Process Integration and Intensification - CPI2, University of Pannonia, Veszprém, Hungary. Awarded by the EC with Marie Curies Chair of Excellence (EXC). Track record of managing and coordinating 91 major EC, NATO and UK Know-How projects. Research funding attracted over $21 \mathrm{M€}$.

Co-Editor-in-Chief of Journal of Cleaner Production ( $\mathrm{IF}=4.959)$. The founder and President for 20 $\mathrm{y}$ of PRES (Process Integration for Energy Saving and Pollution Reduction) conferences. Chairperson of CAPE Working Party of EFCE, a member of WP on Process Intensification and of the EFCE Sustainability platform.

He authored nearly 400 papers, h-index 40. A number of books published by McGraw-Hill; Woodhead; Elsevier; Ashgate Publishing Cambridge; Springer; WILEY-VCH; Taylor \& Francis).

Several times Distinguished Visiting Professor for Universiti Teknologi Malaysia, Xi'an Jiaotong University; South China University of Technology, Guangzhou; Tianjin University in China; University of Maribor, Slovenia; University Technology Petronas, Malaysia; Brno University of Technology and the Russian Mendeleev University of Chemical Technology, Moscow. Doctor Honoris Causa of Kharkiv National University "Kharkiv Polytechnic Institute" in Ukraine, the University of Maribor in Slovenia, University POLITEHNICA Bucharest, Romania. "Honorary Doctor of Engineering Universiti Teknologi Malaysia", "Honorary Membership of Czech Society of Chemical Engineering", "European Federation of Chemical Engineering (EFCE) Life-Time Achievements Award" and "Pro Universitaire Pannonica" Gold Medal.

CORRESPONDENCE AdDRESS: Jiří Jaromír Klemeš, DSc, Professor, Brno University of Technology - VUT Brno, Faculty of Mechanical Engineering, NETME Centre, Sustainable Process Integration Laboratory - SPIL, Technická 2896/2, 61669 Brno, Czech Republic, e-mail: klemes@fme.vutbr.cz. 
$10^{\mathrm{TH}}$ InTERNATIONAL CONFERENCE ON Sustainable ENERGy AND

Environmental Protection (June 27 $7^{\mathrm{TH}}-30^{\mathrm{RD}}$, 2017, Bled,

SLOVENIA), WATER AND AIR QUALITY

J. Krope, A.Ghani Olabi, D. Goričanec \& S. Božičnik

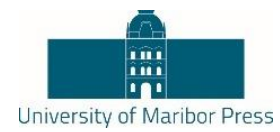

\title{
Plenary Talk on \\ Renewable energy sources for environmental protection
}

\author{
HAKAN SERHAD SOYHAN
}

Development in energy sector, technological advancements, production and consumption amounts in the countries and environmental awareness give shape to industry of energy. When the dependency is taken into account in terms of natural resources and energy, there are many risks for countries having no fossil energy sources. Renewable and clean sources of energy and optimal use of these resources minimize environmental impacts, produce minimum secondary wastes and are sustainable based on current and future economic and social societal needs. Sun is one of the main energy sources in recent years. Light and heat of sun are used in many ways to renewable energy. Other commonly used are biomass and wind energy. To be able to use these sources efficiently national energy and natural resources policies should be evaluated together with the global developments and they should be compatible with technological improvements. Strategic plans with regard to energy are needed more intensively and they must be in the qualification of a road map, taking into account the developments related to natural resources and energy, its specific needs and defining the sources owned by countries. In this presentation, the role of supply security was evaluated in term of energy policies. In this talk, new technologies in renewable energy production will be shown and the importance of supply security in strategic energy plan will be explained.

Correspondence Address: Hakan Serhad Soyhan, Ph.D., Professor, Sakarya University, Engineering Faculty, Esentepe Campus, M7 Building, 54187 - Esentepe /Sakarya, Turkey, e-mail: hsoyhan@sakarya.edu.tr. 
$10^{\mathrm{TH}}$ InTERNATIONAL CONFERENCE ON Sustainable ENERGY AND Environmental Protection (June 27 $7^{\mathrm{TH}}-30^{\mathrm{RD}}$, 2017, Bled, SLOVENIA), WATER AND AIR QUALITY

J. Krope, A.Ghani Olabi, D. Goričanec \& S. Božičnik

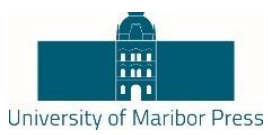

\section{HAKAN SERHAD SOYHAN - BIBLIOGRAPHY}

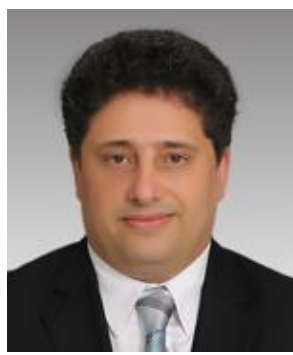

Professor at Sakarya University, Engineering Faculty. $50 \%$ fot teaching and the rest for reasearch activities.

Teaching, courses taught:

Graduate courses:

- Combustion technology;

- Modelling techniques;

Undergraduate courses:

- Combustion techniques;

- Internal combustion engines;

- Fire safety.

Tehnical skills and competences professional societies:

- 25 jurnal papers in SCI Index. 23 conference papers;

- $\quad$ Editor at FCE journal. Co-editor at J of Sakarya University;

- Head of Local Energy Research Society (YETA);

- Member od American Society of Mechanical engineers (ASME);

- Member of Turkish Society of Mechanical Engineers (TSME).

Correspondence AdDress: Hakan Serhad Soyhan, Ph.D., Professor, Sakarya University, Engineering Faculty, Esentepe Campus, M7 Building, 54187 - Esentepe /Sakarya, Turkey, e-mail: hsoyhan@sakarya.edu.tr. 

$10^{\mathrm{TH}}$ InTERnAtional CONFERENCE ON Sustainable ENERGy AND Environmental Protection (June 27 $7^{\mathrm{TH}}-30^{\mathrm{RD}}$, 2017, Bled, SLOVENIA), WATER AND AIR QUALITY

J. Krope, A.Ghani Olabi, D. Goričanec \& S. Božičnik

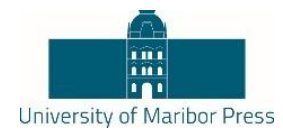

\section{Table of Contents}

\section{CONFERENCE PROCEEDINGS}

Capturing Sulfur Dioxide from Flue Gas by Iron (II)

Hydroxide

Özgü Yörük, Duygu Uysal \& Bekir Zühtü Uysal

Total Carbon Dioxide Absorption Capacity of Calcium Acetate Solution

Duygu Uysal, Javid Safarov, Özkan Murat Doğan, Egon Hassel \& Bekir Zühtü Uysal

Heat Capacity and Speed of Sound of 1-Butyl-3Methylimidazolium Hex-afluoro $\neg$ phosphate and 1-Butyl-3Methylimidazolium Trifluoro-Methanesulfonate Over Wide Range of Temperature

Khagani Suleymanli, Duygu Uysal, Rena Hamidova, Abilgani Aliyev, Javid Sa-farov, Astan Shahverdiyev \& Egon Hassel

Permeable and Hygroscopic Building Envelopes:

Hygrothermal Simulations of "Det Naturlige Hus"

Diane Bastien \& Martin Winther-Gaasvig

Water Quality Monitoring Using a Wireless Sensor Network

- A Brief Review

Rubens Z. Sakiyama, Paulo Henrique Soares, Linnyer B.R. Aylon \& Cid Marcos Goncqlues Andrade

Effects of Climate Change on the Health of Citizens Modelling Urban Weather and Air Pollution

Roberto San José, Juan L. Pérez, Libia Pérez \& Rosa Maria Gonzalez Barras

A Platform for Air Quality Monitoring Using Wireless Sensor Network - A Brief Review

Paulo Henrique Soares, Rubens Z. Sakiyama \& Cid Marcos Goncalves Andrade 
Zdravko Praunseis, Sebastijan Seme, Bojan Štumberger \& Miralem Hadžiselimović

Pm from the Combustion of Heavy Fuel Oils

Abdulrahman Alkhateeb, Ayman M. Elbaz, Jianguo Du \& William. L.

Roberts

Removal of As3+ Ions from Water Solutions in Column by Adsorption on Activted Carbon

Milena Stojiljković, Sanja Petrović, Saša Savić, Staniša Stojiljković \& Bratislav Todorović 
$10^{\mathrm{TH}}$ InTERnational CONFERENCE ON Sustainable ENERgy AND ENVIRONMENTAL PRotection (June $27^{\mathrm{TH}}-30^{\mathrm{RD}}$, 2017, BLed, SLOVENIA), WATER AND AIR QuALITY

J. Krope, A.Ghani Olabi, D. Goričanec \& S. Božičnik

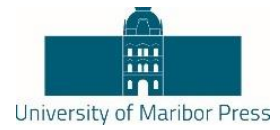

\title{
Capturing Sulfur Dioxide from Flue Gas by Iron (II) Hydroxide
}

\author{
ÖZGÜ YÖRÜK, DUYGU UYSAL \& BEKIR ZÜHTÜ UYSAL
}

\begin{abstract}
The possibility of utilization of iron (II) hydroxide slurry in wet flue gas desulfurization (WFGD) was investigated. The most important feature for selecting iron (II) hydroxide as the sorbent was that iron sulfate formed by sulphur dioxide capture can easily be converted back into iron (II) hydroxide with sodium hydroxide. Thus, it is a reusable chemical system. An $80 \mathrm{~mm}$ diameter bubble column with active liquid height of $600 \mathrm{~mm}$ was used in the experimental study. The experiments were carried out at atmospheric pressure and room temperature. The system was operated continuously with respect to both liquid and gas. Air containing $500 \mathrm{ppm}$ sulfur dioxide was used as the gas phase and its velocity was changed between $3.58-11.60 \mathrm{~L} / \mathrm{min}$. The liquid phase was iron (II) hydroxide-water slurry $(0.4 \mathrm{wt} \%)$ and its velocity was varied between 0.5 and $1.5 \mathrm{~L} / \mathrm{min}$. The sulfur dioxide concentration in the outlet gas was measured by a gas chromatograph. Liquid samples were analyzed by a calibrated spectrophotometer at $420 \mathrm{~nm}$ wavelength. Using the experimental data, the amount of absorbed SO2 was determined, the overall mass transfer coefficients were calculated and a correlation for mass transfer coefficient was developed.
\end{abstract}

Keywords: • sulfur dioxide • flue gas desulfurization • iron (II) hydroxide - bubble column $\bullet$ mass transfer coefficient $\bullet$.

CORRESPONDENCE AdDRESS: Özgü Yörük, M.Sc., Student, Gazi University, Faculty of Engineering, Dept. of Chemical Engineering, Dögol Street 06100 Tandoğan, 06570 Ankara, Turkey, e-mail: ozguyoruk@gmail.com. Duygu Uysal, Ph.D., Assistant, Gazi University, Faculty of Engineering, Dept. of Chemical Engineering, Dögol Street 06100 Tandoğan, 06570 Ankara, Turkey, e-mail: duysal@gazi.edu.tr. Bekir Zühtü Uysal, Ph.D., Professor, Gazi University, Faculty of Engineering, Dept. of Chemical Engineering, Dögol Street 06100 Tandoğan, 06570 Ankara, Turkey, e-mail: bzuysal@gazi.edu.tr.

https://doi.org/10.18690/978-961-286-064-6.1 ISBN 978-961-286-064-6

(C) 2017 University of Maribor Press

Available at: http://press.um.si. 


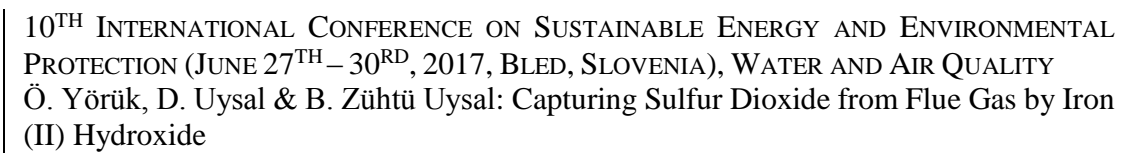

The air pollution caused by increasing energy consumption is a global problem. Sulfur dioxide emitted from the combustion of fossil fuels like coal, petroleum and other factory combustibles is one of the major causes of air pollution [1]. Sulfur dioxide is toxic, harmful to human health and causes serious air and environmental pollution. Hence, removal of sulfur dioxide from flue gas is very important in controlling air pollution. Its importance is constantly increasing with lowered legal emission limit values specified for air pollution control.

To control the sulfur dioxide emission, various flue gas desulfurization (FGD) processes have been developed and applied worldwide as post-combustion desulfurization processes. Among different methods, wet flue gas desulfurization (WFGD) is more common technology and widely used because of the high desulfurization efficiency, reliability and its capability of capturing particulates as well [2].

Lime slurries which are calcium-based absorbents are most commonly employed in WFDG systems all over the world for its high $\mathrm{SO}_{2}$ absorption efficiency [3]. Another big advantage of systems using lime slurries is that it is a cheap and easily available material. However, the disadvantages of such systems are that it is non regenerative, and that the formed slag and other wastes cannot be safely removed [4]. Therefore, the development of technologies for $\mathrm{SO}_{2}$ capture with reusable chemicals has attracted much attention.

In this work, a different solution was used, which was not tried before, and the absorption of sulfur dioxide to the iron (II) hydroxide solution was carried out. Absorption of sulfur dioxide into the iron (II) hydroxide solution is a chemical absorption, which takes place according to the reaction given below.

$\mathrm{SO}_{2}+\mathrm{Fe}(\mathrm{OH})_{2}+1 / 2 \mathrm{O}_{2} \rightarrow \mathrm{FeSO}_{4}+\mathrm{H}_{2} \mathrm{O}$

The most important factor in selecting iron (II) hydroxide is the recycling property and reusability of iron (II) hydroxide. The recycling reaction is given below.

$\mathrm{FeSO}_{4}+2 \mathrm{NaOH} \rightarrow \mathrm{Fe}(\mathrm{OH})_{2}+\mathrm{Na}_{2} \mathrm{SO}_{4}$

Another important factor affecting the choice of iron (II) hydroxide is its anticipated capability of utilization of magnetic field in effort of improving its $\mathrm{SO}_{2}$ capture efficiency. This will be investigated in the next stage of the present research. 


\section{$2 \quad$ Materials and Methods}

\subsection{Experimental setup}

Experimental studies for the absorption of sulfur dioxide into the iron (II) hydroxide slurry were carried out in a bubble column (Figure 1). The diameter of the bubble column used was $80 \mathrm{~mm}$ and the liquid height was $600 \mathrm{~mm}$. The system was operated continuously with respect to both liquid and gas in countercurrent mode. The liquid velocity was changed as $0.54,0.83,1.12$ and $1.50 \mathrm{~L} / \mathrm{min}$. The gas velocity was changed as $10,15,20,25$ and $30 \mathrm{~L} / \mathrm{min}$. Air containing $500 \mathrm{ppm}$ sulfur dioxide was used as the gas phase. The sulfur dioxide concentration in the outlet gas was measured by using SRI$310 \mathrm{C}$ gas chromatography device. Porapak-Q column was used and helium was used as carrier gas in the gas chromatography. Liquid samples were analyzed by a calibrated spectrophotometer, which was Optima SP-300, at $420 \mathrm{~nm}$ wavelength. The mass balance was verified by both gas and liquid analyses.

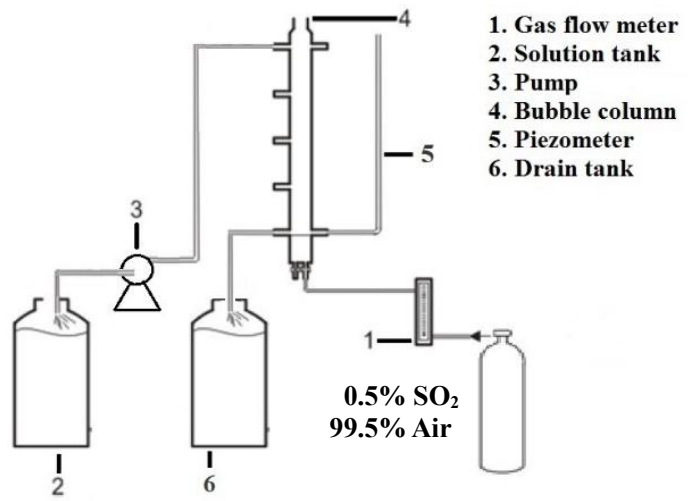

Figure 1. Experimental Setup

\subsection{Estimation of overall mass transfer coefficient}

The overall volumetric mass transfer coefficient based on gas phase was calculated from the data obtained experimentally using the following equations [5]. Firstly, mass balance for $\mathrm{SO}_{2}$ can be written as follows,

$\mathrm{V}_{\mathrm{L}} \cdot \mathrm{dC}_{\mathrm{L}}=\mathrm{V}_{\mathrm{G}} \cdot \mathrm{dC}_{\mathrm{G}}=\mathrm{W}$

$\mathrm{W}$ is $\mathrm{SO}_{2}$ absorption rate $(\mathrm{mol} / \mathrm{s}) . \mathrm{V}_{\mathrm{L}}$ and $\mathrm{V}_{\mathrm{G}}$ are the volumetric flow rates of liquid and gas, respectively, in $\left(\mathrm{m}^{3} / \mathrm{s}\right)$, and $\mathrm{C}_{\mathrm{L}}$ and $\mathrm{C}_{\mathrm{G}}$ are concentrations of $\mathrm{SO}_{2}$ in liquid and in gas, respectively, in $\left(\mathrm{mol} / \mathrm{m}^{3}\right)$.

The absorption rate can be related to the average mass transfer flux as, 

Protection (June 27 $7^{\mathrm{TH}}-30^{\mathrm{RD}}, 2017$, Bled, Slovenia), WATER AND Air QuAlity Ö. Yörük, D. Uysal \& B. Zühtü Uysal: Capturing Sulfur Dioxide from Flue Gas by Iron (II) Hydroxide

$\mathrm{V}_{\mathrm{G}} \cdot \mathrm{dC}_{\mathrm{G}}=\overline{\mathrm{N}}_{\mathrm{SO}_{2}} \mathrm{aS}_{\mathrm{c}} \mathrm{dz}$

Where, a is the interfacial area $\left(\mathrm{m}^{2} / \mathrm{m}^{3}\right.$ column), $\overline{\mathrm{N}}_{\mathrm{SO}_{2}}$ is the average mass transfer flux $\left(\mathrm{mol} / \mathrm{m}^{2} . \mathrm{s}\right), \mathrm{S}_{\mathrm{c}}$ is the cross-sectional area of the column $\left(\mathrm{m}^{2}\right)$. The average mass transfer flux can be expressed in terms of the overall mass transfer coefficient $(\mathrm{m} / \mathrm{s})$ as given below.

$\overline{\mathrm{N}}_{\mathrm{SO}_{2}}=\mathrm{K}_{\mathrm{C}}\left(\mathrm{C}_{\mathrm{G}}-\mathrm{C}^{*}\right)$

$\mathrm{C}^{*}$ is the concentration of solute $\left(\mathrm{SO}_{2}\right)$ in gas which would be in equilibrium with $\mathrm{C}_{\mathrm{L}}$. For a fast chemical reaction such as the one shown by Equation (1), it can reasonably be assumed that $\mathrm{SO}_{2}$ concentration in liquid will be zero $\left(\mathrm{C}_{\mathrm{L}}=0\right)$. The concentration of solute in gas in equilibrium with zero concentration in liquid will also be zero. Hence, Equation (5) reduces to

$\overline{\mathrm{N}}_{\mathrm{SO}_{2}}=\mathrm{K}_{\mathrm{C}} \mathrm{C}_{\mathrm{G}}$

Substitution of Equation (6) into Equation (4) and integration yield the following expression for the overall volumetric mass transfer coefficient $\left(\mathrm{K}_{\mathrm{c}} \mathrm{a}\right)$.

$\mathrm{K}_{\mathrm{c}} \mathrm{a}=\frac{\mathrm{V}_{\mathrm{G}}}{\mathrm{H} \cdot \mathrm{S}_{\mathrm{c}}} \ln \frac{\mathrm{C}_{\mathrm{G}_{\text {in }}}}{\mathrm{C}_{\mathrm{G}_{\text {out }}}}$

where, $\mathrm{H}$ is the active liquid height.

\section{$3 \quad$ Results}

Absorption of sulfur dioxide was carried out at different gas and liquid velocities using a $0.4 \%$ iron (II) hydroxide slurry to determine the overall mass transfer coefficient in the bubble column. The effects of gas and liquid velocities on the overall mass transfer coefficient are shown in Figure 2. 


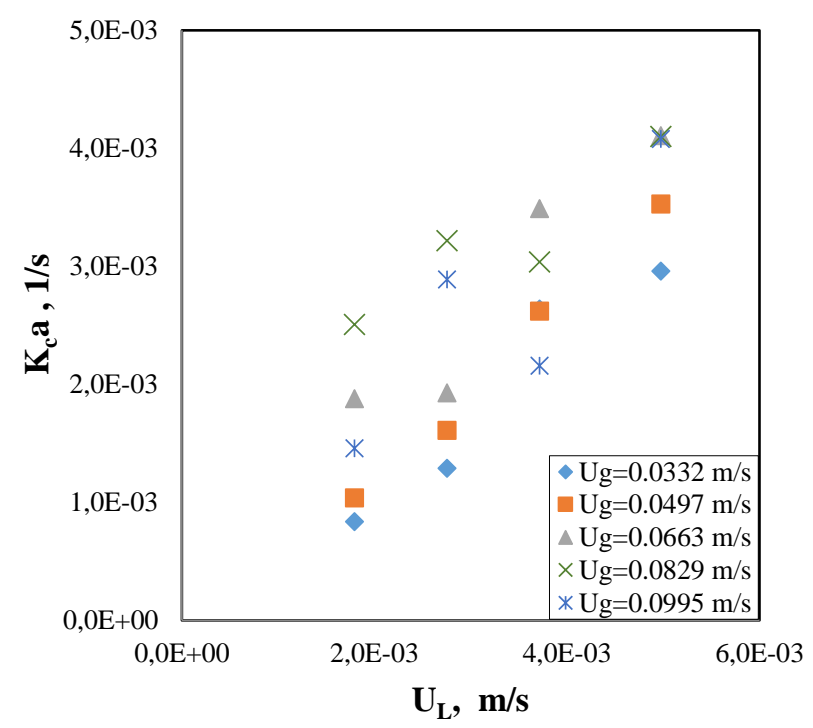

Figure 2. Effect of gas and liquid velocities on volumetric mass transfer coefficient

As can be seen from Figure 2, the experimental data is scattered considerably due to the hydrodynamic effects in the bubble column. The velocities employed in this research fall in the smoothly homogeneous bubbling and transition regimes for bubble columns (Figure 3) [6-8]. While the behavior of the column is smooth at low gas velocities in the homogeneous bubbling regime, the hydrodynamic behavior becomes vigorous and more intense in the transition regime towards slug flow regime with the increase in gas velocity. But, Figure 2 shows that the overall mass transfer coefficient is clearly affected by both gas and liquid velocities, and the overall mass transfer coefficient shows an increase as the gas and liquid velocities increase.

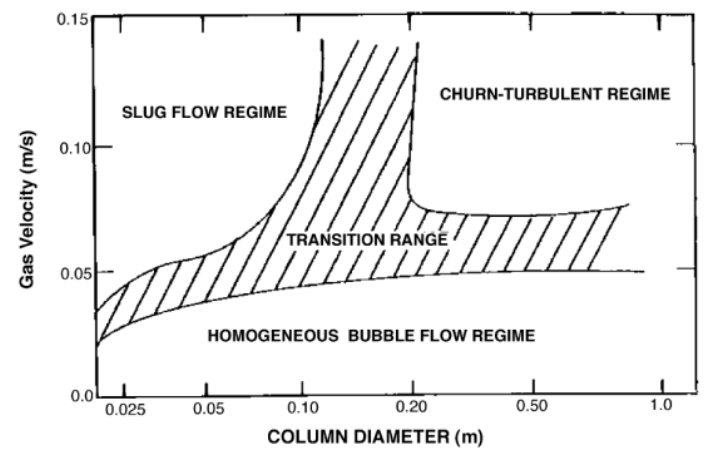

Figure 3. Flow regime map for bubble columns [6] 
$10^{\text {TH }}$ International Conference on Sustainable Energy and Environmental Protection (June $27^{\mathrm{TH}}-30^{\mathrm{RD}}, 2017$, Bled, SLovenia), WATER AND Air Quality Ö. Yörük, D. Uysal \& B. Zühtü Uysal: Capturing Sulfur Dioxide from Flue Gas by Iron (II) Hydroxide

Using the data obtained from the experimental work, a correlation was developed for the calculated overall mass transfer coefficients for the capture of sulfur dioxide into the iron (II) hydroxide slurry. The correlation is expressed in terms of gas and liquid velocities and is given below. $\left(\mathrm{r}=0.88, \mathrm{U}_{\mathrm{G}}\right.$ and $\left.\mathrm{U}_{\mathrm{L}}: \mathrm{m} / \mathrm{s}\right)$

$\mathrm{K}_{\mathrm{c}} \mathrm{a}=0.8648 \mathrm{U}_{\mathrm{G}}^{0.3157} \mathrm{U}_{\mathrm{L}}^{0.8644}$

Figure 4 is prepared to show the variation of overall mass transfer coefficient more explicitly with gas and liquid velocities according to the correlation developed (Equation (8)).

The comparison of the overall mass transfer coefficients calculated from the correlation (Equation 8) and those calculated from the experimental data is given in Figure 5.

As the hydrodynamics of the column is distinctly different at low gas velocities, another correlation was also developed for homogeneous bubbling regime $\left(\mathrm{U}_{\mathrm{G}}\right.$ : 0.0332 and $0.0497 \mathrm{~m} / \mathrm{s}) .\left(\mathrm{r}=0.995, \mathrm{U}_{\mathrm{G}}\right.$ and $\left.\mathrm{U}_{\mathrm{L}}: \mathrm{m} / \mathrm{s}\right)$

$\mathrm{K}_{\mathrm{c}} \mathrm{a}=10.7057 \mathrm{U}_{\mathrm{G}}^{0.4567} \mathrm{U}_{\mathrm{L}}^{1.25}$

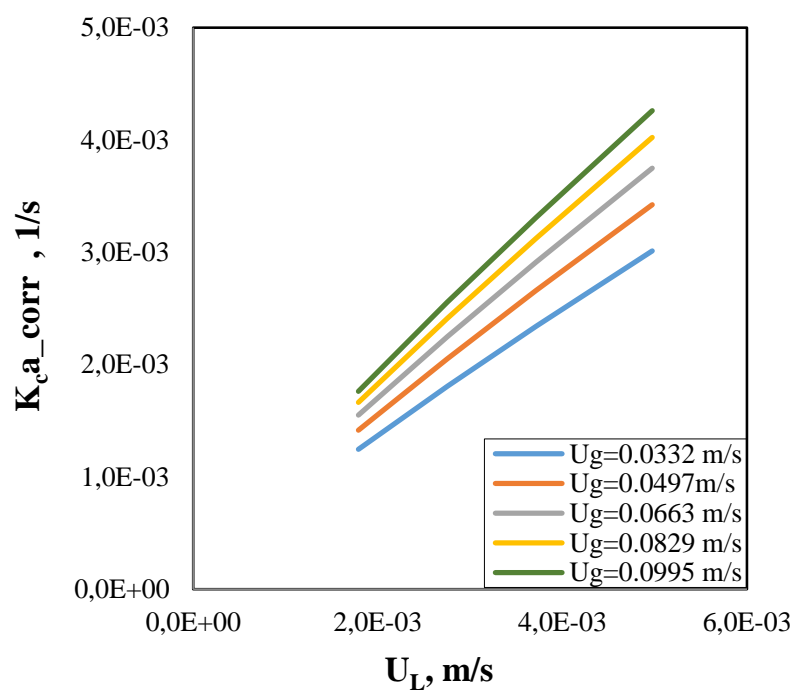

Figure 4. Plot of Equation (8) 

Protection (June 27 $7^{\mathrm{TH}}-30^{\mathrm{RD}}, 2017$, Bled, Slovenia), WATER AND Air Quality Ö. Yörük, D. Uysal \& B. Zühtü Uysal: Capturing Sulfur Dioxide from Flue Gas by Iron (II) Hydroxide

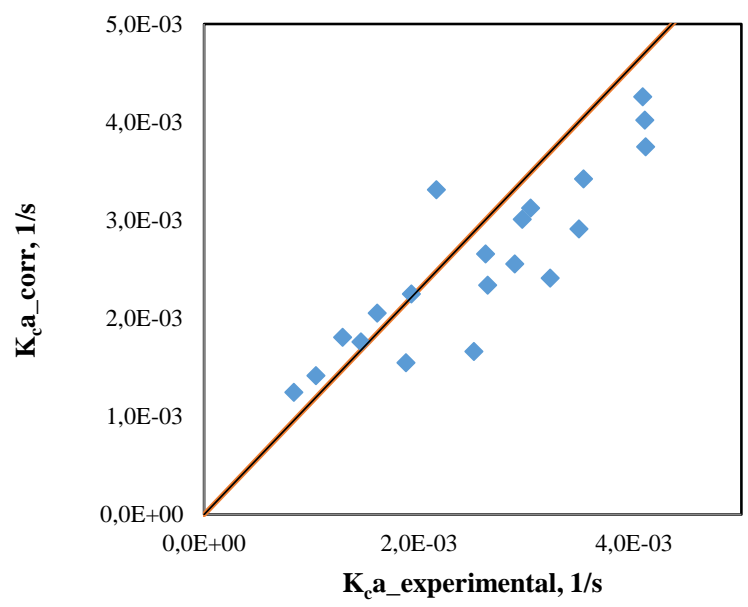

Figure 5. Comparison of the calculated $\mathrm{K}_{\mathrm{c}}$ a values from the correlation (Equation 8) with the experimental data

Figure 6 shows the variation of overall mass transfer coefficient at low gas velocities. The curves correspond to the predictions made by the correlation developed (Equation 9).

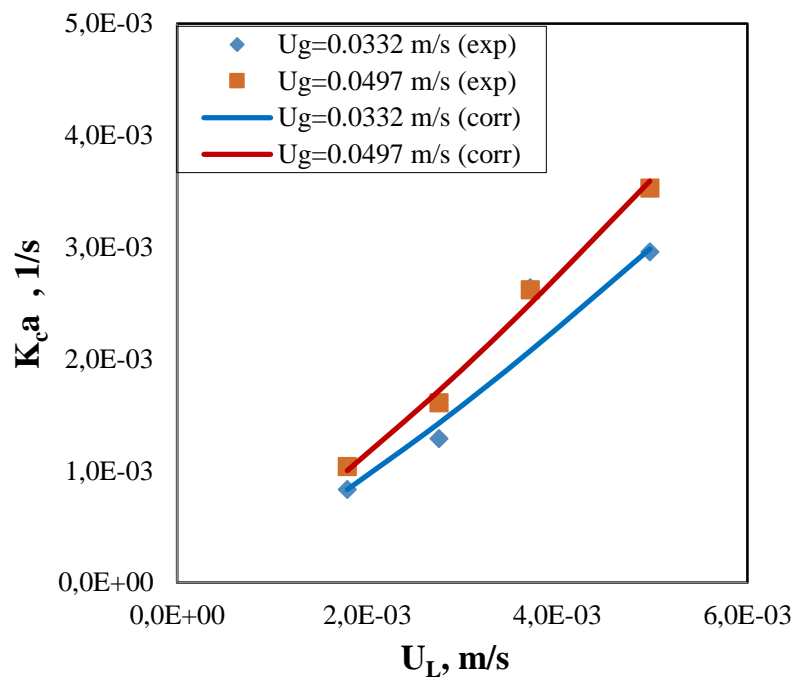

Figure 6. Volumetric mass transfer coefficient at low gas velocities and plot of Equation (9) 

Protection (June $27^{\mathrm{TH}}-30^{\mathrm{RD}}, 2017$, Bled, SLovenia), WATER AND Air Quality Ö. Yörük, D. Uysal \& B. Zühtü Uysal: Capturing Sulfur Dioxide from Flue Gas by Iron (II) Hydroxide

When the experimental work carried out is evaluated, it can be stated that sulfur dioxide, which causes air pollution and acid rain, can be captured at atmospheric conditions with iron (II) hydroxide slurry by chemical absorption.

\section{Conclusions}

In this work, absorption of sulfur dioxide in a bubble column was investigated using iron (II) hydroxide-water slurry. The effects of gas and liquid velocities on the overall mass transfer coefficient were investigated. The main conclusions derived are as follows:

- It has been observed that sulfur dioxide can be captured effectively by the iron (II) hydroxide slurry by chemical absorption at low temperatures at atmospheric pressure.

- As the gas and liquid velocities increase, the overall mass transfer coefficient increases.

- A correlation was developed for the overall mass transfer coefficient in terms of gas and liquid velocities over the ranges covered in the experiments.

- Another correlation was also developed for the overall mass transfer coefficient which is valid for low gas velocities in homogeneous flow regime in bubble columns.

\section{References}

[1] K. Wark, C.F. Warner, W.T. Davis, Air Pollution-Its Origin and Control, $3^{\text {rd }}$ edition, New York: Addison-Wesley, 1998.

[2] B. Dou, W. Pan, Q. Jin, W. Wang, Y. Li, "Prediction of $\mathrm{SO}_{2}$ removal efficiency for wet flue gas desulfurization", Energy Conversion and Management, vol. 50, 2547-2553, 2009.

[3] R.K. Srivastava, "Controlling $\mathrm{SO}_{2}$ emissions: A review of technologies", United States Environmental Protection Agency, Office of Research and Development, Washington, 2000 .

[4] B.K. Dutta, R.K. Basu, A. Pandit, P. Ray, “Absorption of $\mathrm{SO}_{2}$ in Citric Acid-Sodium Citrate Buffer”, Ind. Eng. Chem. Res., vol. 26, 1291-1296, 1987.

[5] B.Z. Uysal, Fundamentals of Mass Transfer and Its Applications (in Turkish: Kütle Transferi Esaslart ve Uygulamaları), $2^{\text {nd }}$ Edition, Ankara: Alp Yayınevi, 2003.

[6] W.D. Deckwer, Y. Louisi, A. Zaidi, M. Ralek, "Hydrodynamic properties of the FischerTropsch slurry process", Ind. Eng. Chem. Process Des. Dev, vol. 19, 699-708, 1980.

[7] C.L. Hyndman, F. Larachi, C. Guy, "Understanding gas-phase hydrodynamics in bubble columns: a convective model based on kinetic theory", Chem. Eng. Sci., vol. 52, 63-77 1997.

[8] N. Kantarci, F. Borak, K.O. Ulgen, "Bubble column reactors", Process Biochemistry, vol. 40, 2263-2283, 2005. 
$10^{\mathrm{TH}}$ InTERnational CONFERENCE ON Sustainable ENERgy AND ENVIRONMENTAL PRotection (June $27^{\mathrm{TH}}-30^{\mathrm{RD}}$, 2017, BLed, SLOVENIA), WATER AND AIR QUALITY

J. Krope, A.Ghani Olabi, D. Goričanec \& S. Božičnik

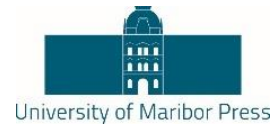

\title{
Total Carbon Dioxide Absorption Capacity of Calcium Acetate Solution
}

\author{
DUYGU UYSAL, JAVID SAFAROV, ÖZKAN MURAT DOĞAN, EGON HASSEL \& BEKIR \\ ZÜHTÜ UYSAL
}

\begin{abstract}
The main reason of global warming is the increase in concentration of greenhouse gases in atmosphere, especially $\mathrm{CO} 2$, which is mostly emitted from power plants. There are several systems conventionally used to prevent this increment like absorption of $\mathrm{CO} 2$ from flue gases with ammonia or amine solutions. The drawback of these conventional systems is that they require so much energy to operate due to pressures and temperatures involved, resulting in the decrease of overall power plant efficiency. Calcium acetate could be an alternative sorbent due to its alkaline nature and the ability to react with $\mathrm{CO} 2$. In this work, the total $\mathrm{CO} 2$ absorption capacities of calcium acetate solutions were investigated. In the experiments, calcium acetate (Sigma-Aldrich BASF Quality, $\geq 99 \%$ ) binary solutions with 8 different concentrations (ranging between 0.7719-22.3204 wt-\%) in water were used. The experiments were performed in a stainless steel measuring cell in equilibrium by using the isochoric method at 3 different pressures $(0.485$ $\mathrm{MPa}, 0.988 \mathrm{MPa}, 1.530 \mathrm{MPa}$ ) and 4 different temperatures (ranging between 273 $333 \mathrm{~K})$. It was found out that with increasing pressure and decreasing temperature, the absorption capacity of the solutions increased. The pressure, however, was observed to have less profound effect at high values.
\end{abstract}

Keywords: $\bullet$ carbon dioxide $\bullet$ absorption capacity $\bullet$ calcium acetate $\bullet \mathrm{CO}_{2} \bullet$ experiments $\bullet$.

Correspondence AdDress: Duygu Uysal, Ph.D., Assistant, Gazi University, Faculty of Engineering, Dept. of Chemical Engineering, Dögol Street 06100 Tandoğan, 06570 Ankara, Turkey, e-mail: duysal@gazi.edu.tr. Javid Safarov, Ph.D., Assoc. Professor, Lehrstuhl für Technische Thermodynamik, Universität Rostock, Albert-Einstein-Str.2, D-18059, Rostock, Germany, e-mail: javid.safarov@uni-rostock.de. Özkan Murat Doğan, Ph.D., Professor, Gazi University, Faculty of Engineering, Dept. of Chemical Engineering, Dögol Street 06100 Tandoğan, 06570 Ankara, Turkey, e-mail: mdogan@gazi.edu.tr. Egon Hassel, Ph.D., Professor, Lehrstuhl für Technische Thermodynamik, Universität Rostock, Albert-Einstein-Str.2, D-18059, Rostock, Germany, e-mail: egon.hassel@uni-rostock.de. Bekir Zühtü Uysal, Ph.D., Professor, Gazi University, Faculty of Engineering, Dept. of Chemical Engineering, Dögol Street 06100 Tandoğan, 06570 Ankara, Turkey, e-mail: bzuysal@ gazi.edu.tr.

https://doi.org/10.18690/978-961-286-064-6.2 ISBN 978-961-286-064-6

(C) 2017 University of Maribor Press

Available at: http://press.um.si. 
$10^{\mathrm{TH}}$ InTERnAtional CONFERENCE ON Sustainable ENERGy AND ENVIRONMENTAL Protection (June $27^{\mathrm{TH}}-30^{\mathrm{RD}}, 2017$, Bled, Slovenia), WATER AND Air Quality

D. Uysal, J. Safarov, Ö. Murat Doğan, E. Hassel \& B. Zühtü Uysal: Total Carbon

Dioxide Absorption Capacity of Calcium Acetate Solution

Global warming, being one of the most important issues of the world, is a current threat for the environment [1]. It is proven that the greatest factor of global warming is the carbon dioxide gas concentration in the atmosphere [2]. Thus, currently it is important to prevent the increment of carbon dioxide amount in the atmosphere. This should be done by capturing the carbon dioxide from point sources, i.e., from the flue gases of plants $[3,4]$. There are many researches and projects about capturing and sequestrating carbon dioxide from flue gases; but the conventional systems require so much energy that the CCS (carbon dioxide capture and storage) unit in a power plant decreases the overall efficiency of that plant by approximately $2 \%$ which is a non-negligible value regarding the amount of total energy being produced [4-6].

Arising from these problems, there is an inevitable need for a new alternative solution for carbon dioxide capture systems. Calcium acetate, a benign material, can be the answer for this problem. Calcium acetate is an environment-friendly, noncorrosive and relatively inexpensive material. The biggest advantage of this system is the solubility of it in water being high thus making it possible to be used in absorption systems (preferred to $\mathrm{CaCO}_{3}$ and $\mathrm{Ca}(\mathrm{OH})_{2}$ because they are slurry systems). Moreover, it is an inorganic system; thus decomposition is not a concern. Furthermore, it is an inexpensive chemical. All of these advantages of calcium acetate are making itself a perfect candidate for the alternative solution being sought.

In this work, the total absorption capacity of calcium acetate solutions with different concentrations were investigated at elevated pressures and different tempreatures.

\section{$2 \quad$ Materials and Methods}

\subsection{Preparation of calcium acetate-water binary solutions}

In order to investigate the total carbon dioxide absorption capacity of calcium acetate solution at elevated pressures and different temperatures, firstly calcium acetate - water binary solutions with different concentrations were prepared.

To prepare these binary solutions, calcium acetate powder (Sigma Aldrich BASF Quality, $\geq 99 \%$ ) was dehydrated due its to the hydrophilic nature in a closed flask, under vacuum for 24 hours. Also distilled water was degassed by applying vaccum to its flask, in order to get rid of any dissolved gases. Then the dehyrated calcium acetate powder and degassed distilled water were combined in a special apparatus under vacuum to obtain calcium acetate-water binary solution.

\subsection{Experimental setup}

The experiments for the determination of total $\mathrm{CO}_{2}$ absorption capacity of calcium acetate solution were done with the experimental setup shown in Figure 1. 
Here, calcium acetate solution with previously measured volume was poured into the measuring cell. Then, after sealing up the system, $\mathrm{CO}_{2}$ in the gas chambers at certain pressure was sent to measuring cell. Whilst the operation, the pressure inside the cell was measured continuosly. As $\mathrm{CO}_{2}$ was absorbed by the solution, the pressure inside the cell decreased until the equilibrium was reached. By the pressure point at which the equilibrium was reached, it was possible to calculate the $\mathrm{CO}_{2}$ absorption capacity of the solution at that certain pressure and temperature. When the equilibrium was reached for that certain pressure, the temperature was decreased at the same chamber pressure.

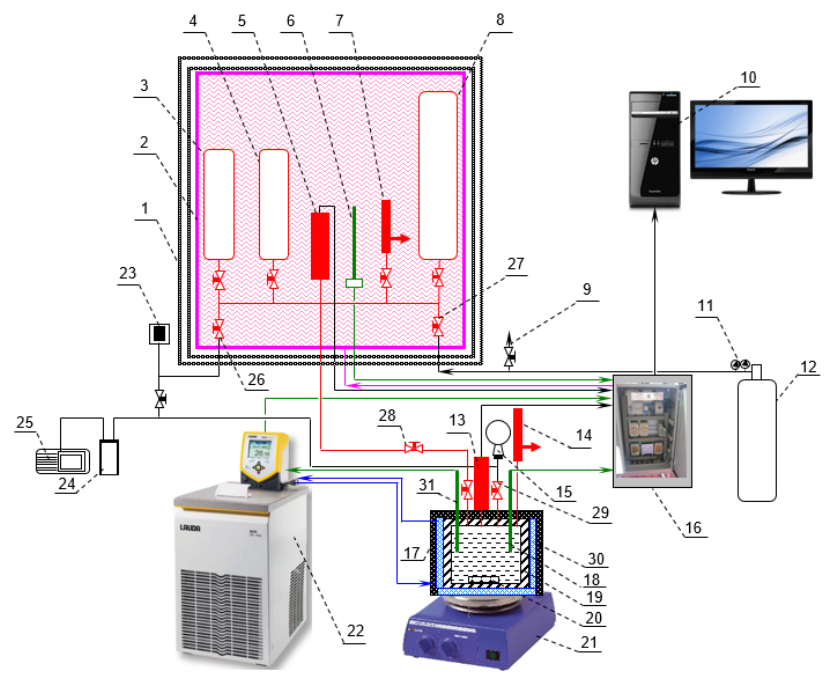

1 - Gas reservoir, 2 - Heating, 3, 4 - Gas chambers $\left(150 \mathrm{~cm}^{3}\right), 5$ - Pressure transducer, 6,18 - PT100 Rod Sensor, 7 - Emergence valve, 8 - Gas balloon $\left(300 \mathrm{~cm}^{3}\right), 9-$ Connection for the evacuation of gas from system, 10 - PC, 11 - Reducer, 12 - External $\mathrm{CO}_{2}$ gas cylinder, 13 - Pressure transducer of measuring cell, 14 - Emergence valve of measuring cell, 15 - Coble with the filled sample, 16 -Electronic tracking system, 17 Isolation, 19 - Measuring cell, 20 - Magnetic coupling, 21 - Magnet, 22 - Thermostat, 23 - Vacuum indicator, 24 - Liquid nitrogen trap, 25 - Vacuum pump, 26,27,28,29 Valve, 30 - Metal reservoir for heating of measuring cell.

Figure 1. Experimental setup

By this method, the total absorption capacities of 8 different calcium acetate solutions $(0.7719,1.4598,3.6274,5.4390,11.9642,14.4661,17.6164$ and $22.3204 \mathrm{wt}-\%)$ were obtained at 3 different pressures ( $0.485 \mathrm{MPa}, 0.988 \mathrm{MPa}$, and $1.530 \mathrm{MPa})$ and 4 different temperatures $(273.15,293.15,313.15$ and $333.15 \mathrm{~K})$.

These calcium acetate-water binary solutions were prepared regarding the maximum solubility of calcium acetate in water which is $24.8 \mathrm{~g}$ calcium acetate/ $100 \mathrm{~g}$ solution $[7,8]$. 
The reason of selecting the highest temperature as $333.15 \mathrm{~K}$ was that the maximum operating temperature of the conventional absorption system is $60^{\circ} \mathrm{C}$.

In Figure 2, an example data graph for single experiment can be seen.

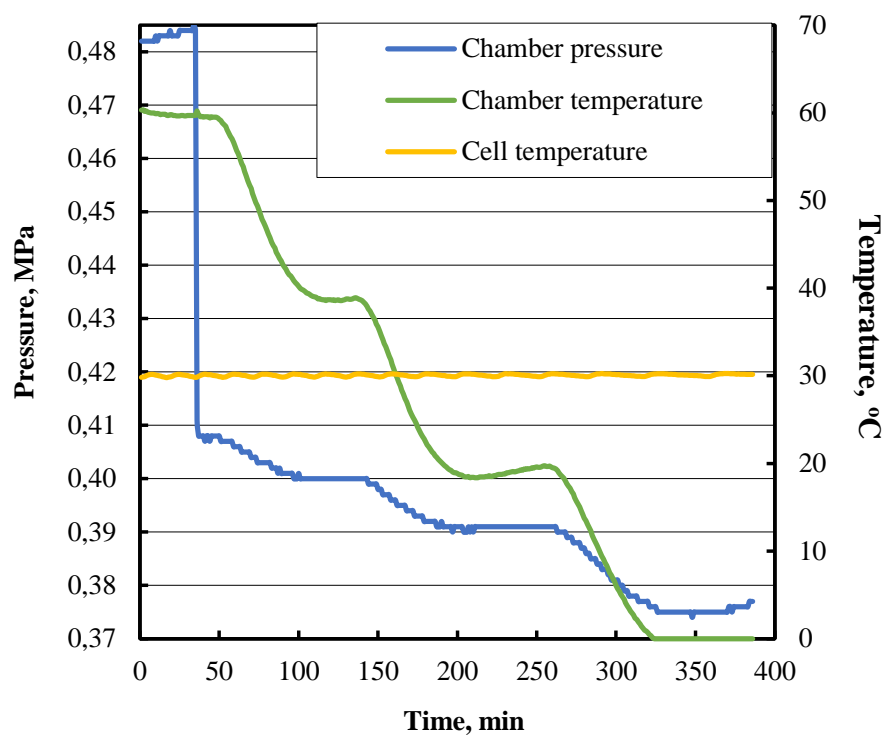

Figure 2. Experimental data graph (calcium acetate solution concentration: 0.7719 wt$\%$, initial chamber pressure: $0.482 \mathrm{MPa}$ )

As it can be clearly seen from the figure, the initial conditions for the experiments were adjusted as the chamber pressure (which was selected as $0.485 \mathrm{MPa}, 0.988 \mathrm{MPa}$, and 1.530 MPa, as mentioned before) and the highest temperature (which is $333.15 \mathrm{~K}$ or $60^{\circ} \mathrm{C}$ ). When there was not any decrement in pressure, the temperature was then decreased to $313.15 \mathrm{~K}$ (or to $40^{\circ} \mathrm{C}$ ). As the solubility of the gases increases with decreasing temperature, at a lower value of temperature than previous, the absorption process proceeded and a new equilibrium pressure point was reached. As a result, it was possible to calculate the total absorption capacities for different temperatures at different pressures.

\section{$3 \quad$ Results}

In order to investigate the total carbon dioxide absorption capacity of calcium acetate solutions, the experiments were done with 8 different calcium acetate solution concentrations at 3 different pressures and 4 different temperatures. The result for the effect of pressure at different temperatures can be seen in Figure 3.

As it is clearly seen from the figure, as the pressure increases, the absorption capacity of the solution also increases. The absorption capacity values are very close to each other at 
higher pressures while there is a big gap between the capacity values obtained at approximately $0.5 \mathrm{MPa}$ and $1 \mathrm{MPa}$ and particularly at lower temperatures. Regarding the results, it is reasonable to say that, it may not be worth to operate the absorption system at high pressures as the increase in the capacity (thus the yield of unit) may not compensate the increase in operating costs. The importance of pressure increment becomes unimportant at higher temperatures, due to the fact that the solution of gases in liquids decrease with increasing temperature.

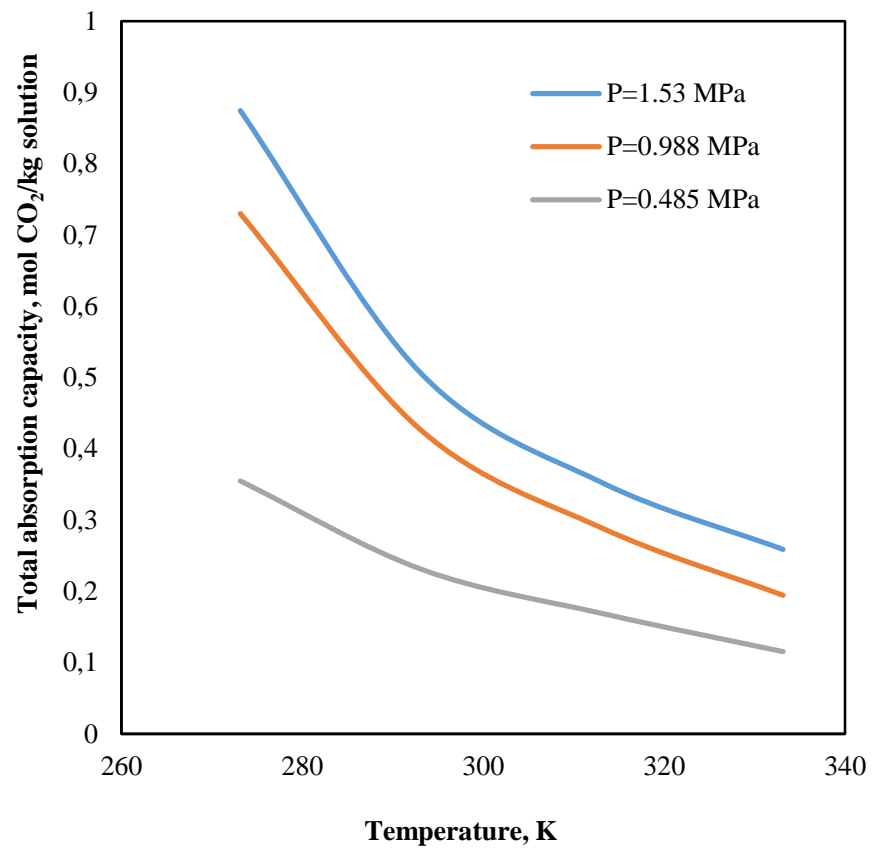

Figure 3. The change in the total $\mathrm{CO}_{2}$ absorption of constant calcium acetate solution concentration $(0.7719 \mathrm{wt}-\%)$ with respect to temperature at different pressures 

Protection (June $27^{\mathrm{TH}}-30^{\mathrm{RD}}, 2017$, Bled, Slovenia), WATER AND Air Quality D. Uysal, J. Safarov, Ö. Murat Doğan, E. Hassel \& B. Zühtü Uysal: Total Carbon Dioxide Absorption Capacity of Calcium Acetate Solution

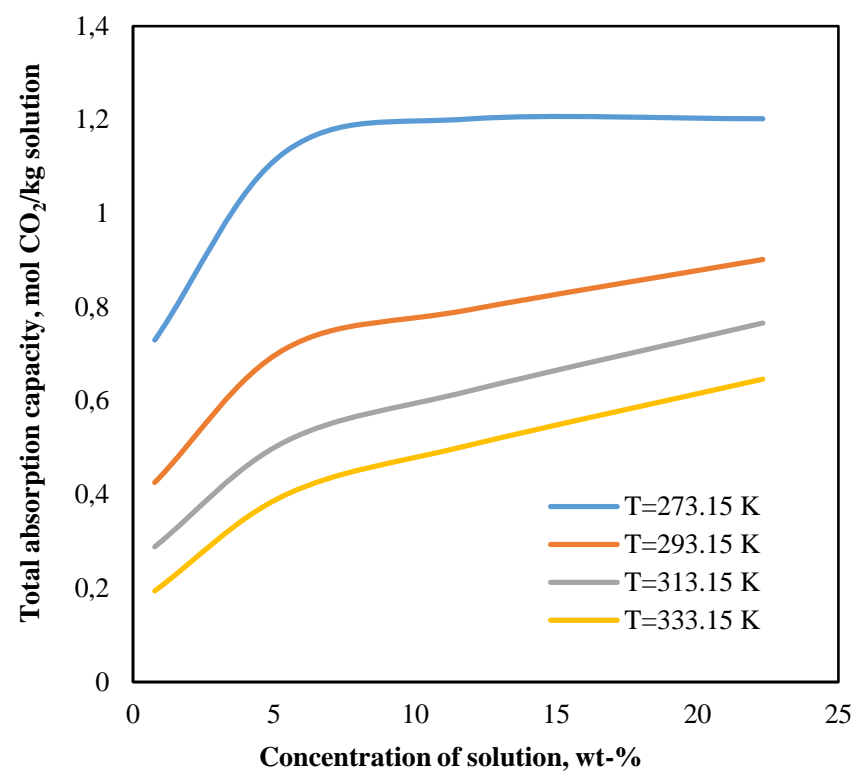

Figure 4. The change in the total $\mathrm{CO}_{2}$ absorption at constant chamber pressure (1 $\left.\mathrm{MPa}\right)$ with respect to concentration of solution at different temperatures

As it is seen from Figure 4 and Figure 5, as the concentration of the calcium acetate solution increases, the total absorption capacity of it also increases. Again as seen in Figure 4, it is better to operate the system at lower temperatures. As calcium acetate lowers the freezing point of water, operating the system at lower temperatures would not cause any problem. But the lower the temperature is (than the ambient temperature), the higher the operating cost would be. It is also clearly seen from the figure that the slope of increase in the absorption capacity at lower concentrations is higher than that of at higher concentrations. So selecting an optimum value of concentration rather than operating the system with saturated calcium acetate solution would be feasible. 


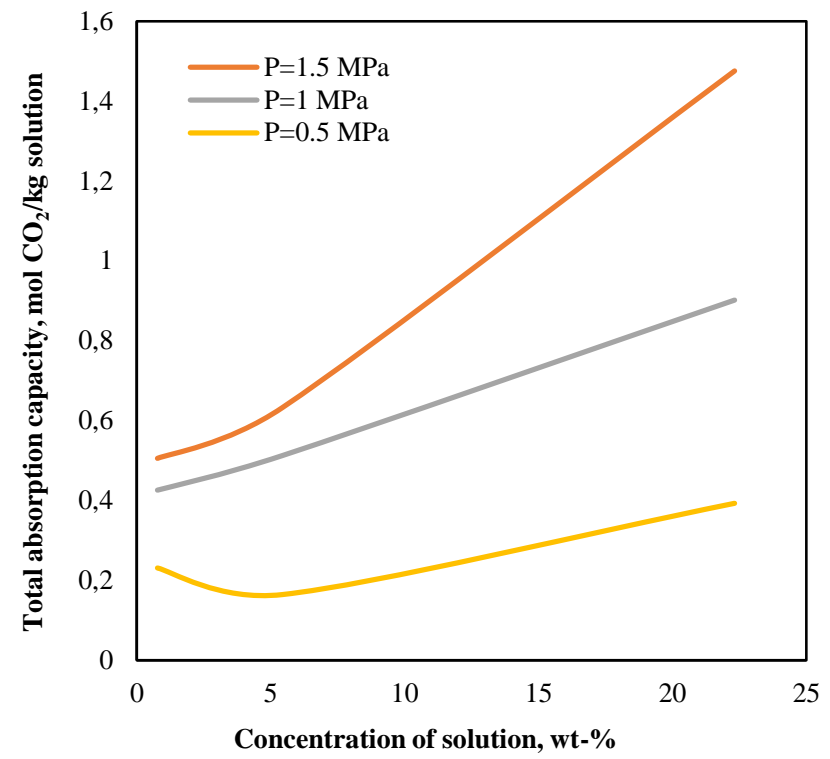

Figure 5. The change in the total $\mathrm{CO}_{2}$ absorption for constant temperature $(293.15 \mathrm{~K})$ with respect to concentration of solution at different pressures

The same result can be said for the results presented in Figure 5. The increment in pressure result in higher absorption capacity, but it also results in higher operating costs. So, when adapting these experimental results to $\mathrm{CO}_{2}$ capture unit, the optimum values should be determined for the parameters regarding the operational costs and the efficiency of the unit.

\section{$4 \quad$ Conclusions}

In this work, the total carbon dioxide absorption capacity of calcium acetate solution was investigated. The experiments were done at elevated pressures at several temperatures with different calcium acetate solution concentrations and the effects of these parameters were discussed. The main conclusion is that, the capacity of carbon dioxide absorption of calcium acetate solutions increases with increasing pressure, solution concentration and with decreasing temperature. The important point here is that, the effect of these parameters on operating cost should be considered in optimization.

\section{Acknowledgement}

The authors would like to thank to TUBITAK for granting this project. 
$10^{\mathrm{TH}}$ InTERnATIONAL CONFERENCE ON Sustainable ENERgy AND ENVIRONMENTAL Protection (June $27^{\mathrm{TH}}-30^{\mathrm{RD}}, 2017$, Bled, Slovenia), WATER AND Air Quality

D. Uysal, J. Safarov, Ö. Murat Doğan, E. Hassel \& B. Zühtü Uysal: Total Carbon Dioxide Absorption Capacity of Calcium Acetate Solution

\section{References}

[1] IPCC Synthesis Report, Climate Change 2007: Synthesis Report, An Assessment of the Intergovernmental Panel on Climate Change, 2007.

[2] IPCC Synthesis Report, Climate Change 2014: Synthesis Report, A report of the Intergovernmental Panel on Climate Change, 2014.

[3] B. Smit, J.A. Reimer, C.M. Oldenburg, I.C Bourg, Introduction to carbon capture and sequestration, The Berkeley Lectures on Energy - vol 1., Imperial College Press, London, 2014.

[4] M. Wang, A. Lawal, P. Stephenson, J. Sidders, C. Ramshaw, "Post-combustion $\mathrm{CO}_{2}$ capture with chemical absorption: a state-of-art review", Chemical Engineering Research and Design, 89, 1609-1624, 2011.

[5] K.P. Resnik, J.T. Yeh, H.W. Pennline, "Aqua ammonia process for simultaneous removal of $\mathrm{CO}_{2}, \mathrm{SO}_{2}$ and $\mathrm{NO}_{x}$ ", International Journal of Environmental Technology and Management, 4, 89-104, 2004.

[6] Z. Feng, F. Cheng-Gang, W. You-Ting, W. Yuan-Tao, L. Ai-Min, Z. Zhi-Bing, "Absorption of $\mathrm{CO}_{2}$ in the aqueous solutions of functionalized ionic liquids and MDEA", Chemical Engineering Journal, 160, 691-697, 2010.

[7] D. B. Leineweber, Production of Calcium Magnesium Acetate (CMA) from Dilute Aqueous Solutions of Acetic Acid, M.Sc. Thesis, University of Wisconsin, Madison 2002.

[8] C. Saury, R. Boistelle, F. Dalemat, J. Bruggeman, "Solubilities of calcium acetates in the temperature range 0-100 ${ }^{\circ}$ ", Journal of Chemical Engineering Data, 38, 56-59, 1993. 
$10^{\mathrm{TH}}$ InTERnational CONFEREnCE ON Sustainable ENERgy AND ENVIRONMENTAL PRotection (June $27^{\mathrm{TH}}-30^{\mathrm{RD}}$, 2017, BLed, SLOVENIA), WATER AND AIR QUALITY

J. Krope, A.Ghani Olabi, D. Goričanec \& S. Božičnik

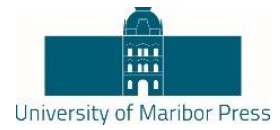

\title{
Heat Capacity and Speed of Sound of 1-Butyl-3- Methylimidazolium Hex-afluoro $\neg$ phosphate and 1-Butyl-3- Methylimidazolium Trifluoro-Methanesulfonate Over Wide Range of Temperature
}

\author{
Khagani Suleymanli, Duygu Uysal, Rena Hamidova, Abilgani Aliyev, JaVid \\ SA-FAROV, ASTAN SHAHVERDIYEV \& EGON HASSEL
}

\begin{abstract}
Ionic liquids are interesting to be useful in various branches of chemical industry. The wide range of application of them requires high quality thermophysical properties of them. In this work, we present the heat capacity and speed of sound measurements of 1-butyl-3-methylimidazolium hexafluorophosphate $[\mathrm{BMIM}]\left[\mathrm{PF}_{6}\right]$ and 1-butyl-3-methylimidazolium trifluoromethanesulfonate [BMIM][TFO] at the wide range of temperature. The constant pressure heat capacity $c_{p}\left(p_{0}, T\right) / \mathrm{J} \cdot \mathrm{kg}^{-1} \cdot \mathrm{K}^{-1}$ of these IL's measured at ambient pressure and at wide range of temperature $T=(273.15$ to 413.15$) \mathrm{K}$ using the Pyris 1 DSC Differential Scanning Calorimeter. The accuracy of evaluation of constant pressure specific heat capacity $c_{p}\left(p_{0}, T\right)$ is $\pm 0.1 \%$. The speed of sound values $u\left(p_{0}, T\right) / \mathrm{m} \cdot \mathrm{s}^{-1}$ at ambient pressure and temperatures at $T=(278.15$ to 343.15$) \mathrm{K}$ are investigated using the Anton Paar DSA 5000M vibration tube densimeter and sound velocity meter within an uncertainty of $\Delta u= \pm 0.1 \mathrm{~m} \cdot \mathrm{s}^{-1}$. The obtained experimental values of constant pressure heat capacity $c_{p}\left(p_{0}, T\right)$ and speed of sound values $u\left(p_{0}, T\right)$ are compared with the available literature values.
\end{abstract}

Keywords: - ionic liquid - heat capacity - Differential Scanning Calorimeter $\bullet$ speed of sound $\bullet$ velocity meter $\bullet$.

CORRESPONDENCE ADDRESS: Khagani Suleymanli, Azerbaijan Technical University Department of Heat Energy, H. Javid Avn. 25, AZ-1073 Baku, Azerbaijan, e-mail: khagani.suleymanli@mail.ru. Duygu Uysal, Ph.D., Assistant, Gazi University, Faculty of Engineering, Dept. of Chemical Engineering, 06570 Ankara, Turkey, e-mail: duysal@gazi.edu.tr. Rena Hamidova, Azerbaijan Technical University, Department of Heat En-ergy, H. Javid Avn. 25, AZ-1073 Baku, Azerbaijan, e-mail: rqamidova81@mail.ru. Abilgani Aliyev, Azerbaijan Technical University, Department of Heat Energy, H. Javid Avn. 25, AZ-1073 Baku, Azerbaijan, Javid Safarov, Ph.D., Assoc. Professor, Lehrstuhl für Technische Thermodynamik, Universität Rostock, Albert-Einstein-Str.2, D-18059, Rostock, Germany, e-mail: javid.safarov@uni-rostock.de. Astan Shahverdiyev, Azerbaijan Technical University, Department of Heat Energy, Azerbaijan, H. Javid Avn. 25, AZ-1073 Baku, Azerbaijan, e-mail: astanshahverdiyev205@gmail.com. Egon Hassel, Ph.D., Professor, Lehrstuhl für Technische Thermodynamik, Universität Ros-tock, Albert-Einstein-Str.2, D-18059, Rostock, Germany, e-mail: egon.hassel@uni-rostock.de.

https://doi.org/10.18690/978-961-286-064-6.3 ISBN 978-961-286-064-6

(C) 2017 University of Maribor Press

Available at: http://press.um.si. 
$10^{\mathrm{TH}}$ InTERnATIONAL CONFERENCE ON Sustainable ENERgy AND ENVIRONMENTAL Protection (June $27^{\mathrm{TH}}-30^{\mathrm{RD}}, 2017$, Bled, Slovenia), WATER AND Air Quality

K. Suleymanli, D. Uysal, R. Hamidova, A. Aliyev, J. Safarov, A. Shahverdiyev \& E. Hassel: Heat Capacity and Speed of Sound of 1-Butyl-3-Methylimidazolium Hexafluoro $\neg$ phosphate and 1-Butyl-3-Methylimidazolium Trifluoro-Methanesulfonate Over Wide Range of Temperature

\section{$1 \quad$ Introduction}

Room temperature ionic liquids (IL's) are salts that are liquids at ambient temperatures and have a stable liquid range of over $300 \mathrm{~K}$. They are excellent solvents for a broad range of polar organic compounds and show partial miscibility with aromatic hydrocarbons. An expanding interest in ionic liquids has been observed during the last decade. IL's are composed of bulky ions, have very small vapor pressure, low melting point, high solvating capacity, high ionic conductivity, which make them attractive for practical applications. IL's have been suggested as potentially "green" replacements for conventional organic solvents since they are nonvolatile, nonflammable and recyclable.

While scientific and technological interest in the properties of room-temperature IL's and their mixture with other fluids are rapidly increasing [1-4], their thermodynamical and structural properties have not yet been studied systematically [3-6]. The thermodynamic and reaction kinetics processes in IL's are different from those in conventional media [7]. This creates new opportunities for reaction, separation, photochemical and electrochemical processes. Binary mixtures of IL's and other fluids have been used for electrochemical applications (solar cells) and considerable improved the performance in the device $[8,9]$. ILs also has thermophysical properties that very suitable for heat transfer and short heat term storage in power plants (Valkenburg et al. [10]).

Before the measurements, we have analysed the literature results of these IL's and the results of heat capacity measurements of $[\mathrm{BMIM}]\left[\mathrm{PF}_{6}\right]$ and $[\mathrm{BMIM}][\mathrm{TFO}]$ in literature were summarized in Table 1-2, where are listed information on heat capacity and speed of sound measurements with temperatures or temperature ranges of this investigations, the techniques used and short characteristics of substances.

Table 1: Summary of the heat capacity measurements for [BMIM][PF6]

\begin{tabular}{|c|c|c|c|c|c|c|c|c|}
\hline First author & Year & Method & Properties & $\begin{array}{l}\text { Temperature, } \\
T / K\end{array}$ & $\begin{array}{r}\text { Pressure, } \\
p / \mathrm{MPa}\end{array}$ & $\begin{array}{l}\text { Uncertainty, } \\
\Delta \rho\end{array}$ & Purity & Company of Purchase \\
\hline Fredlake & 2004 & MTDSC & $\rho, T, c_{p}$ & 298.15 to 323.15 & 0.101 & $(2.5$ to 4$) \%$ & $99.9 \%$ & NA \\
\hline Kabo & 2004 & $\mathrm{AC}$ & $\rho, T, c_{p}$ & 196.80 to 311.31 & 0.101 & $\pm 0.4 \%$ & $99.56 \%$ & Covalent Associates, Inc. \\
\hline Azevedo & 2005 & Calc. & $T, \rho, p, u$ & 298.15 to 323.15 & 0.1 to 100 & $\pm 0.2 \%$ & Water $<75 \mathrm{ppm}$ & Quill laboratory \\
\hline Troncoso & 2006 & DSC & $\rho, T, c_{p}$ & 283.15 to 328.15 & 0.101 & $\pm 0.2 \%$ & $99.8 \%$ & Quill laboratory \\
\hline $\mathrm{Yu}$ & 2009 & DSC & $T, c_{p}$ & 293.2 to 358.2 & 0.101 & $\pm 1 \%$ & $\geq 0.981$ & TCI Co. \\
\hline Nieto De Castro & 2010 & DSC & $T, c_{p}$ & 308.16 to 423.22 & 0.101 & $\pm 1 \%$ & Chloride $<5 \cdot 10^{-6}$ mass $\mathrm{fr}$. & Quill laboratory \\
\hline Suleymanli & 2017 & DSC & $T, c_{p}$ & 283.15 to 413.15 & 0.101 & $0.1 \%$ & $40 \mathrm{ppm}$ & Merck \\
\hline
\end{tabular}


$10^{\text {TH }}$ INTERNATIONAL CONFERENCE ON SUSTAINABLE ENERGY AND ENVIRONMENTAL Protection (June $27^{\mathrm{TH}}-30^{\mathrm{RD}}, 2017$, Bled, SLOVEniA), WATER AND Air QuAlity

K. Suleymanli, D. Uysal, R. Hamidova, A. Aliyev, J. Safarov, A. Shahverdiyev \& E. Hassel: Heat Capacity and Speed of Sound of 1-Butyl-3-Methylimidazolium Hexafluoro $\neg$ phosphate and 1-Butyl-3-Methylimidazolium Trifluoro-Methanesulfonate

Over Wide Range of Temperature

Table 2: Summary of the heat capacity measurements for [BMIM][TFO]

\begin{tabular}{|c|c|c|c|c|c|c|c|c|}
\hline First author & Year & Method & Properties & $\begin{array}{l}\text { Temperature, } \\
T / K\end{array}$ & $\begin{array}{r}\text { Pressure, } \\
p / \mathrm{MPa} \\
\end{array}$ & $\begin{array}{l}\text { Uncertainty, } \\
\Delta \rho\end{array}$ & Purity & Company of Purchase \\
\hline Fredlake & 2004 & MTDSC & $\rho, T, c_{p}$ & 298.15 to 327.19 & 0.101 & (2.5 to 4$) \%$ & $99.9 \%$ & NA \\
\hline Diedrichs & 2006 & TSM & $T, c_{p}$ & 315 to 425 & 0.3 & $\pm 5 \%$ & NA & Merck \\
\hline García-Miaja & 2008 & DSC & $\rho, T, c_{p}$ & 293.15 to 318.15 & 0.101 & $\pm 0.3 \%$ & 0.999 & Solvent Innovation \\
\hline $\mathrm{Ge}$ & 2008 & DSC & $T, c_{p}$ & 293 to 358 & 0.101 & $2.9 \%$ & $>98 \%$ & Merck \\
\hline García-Miaja & 2009 & $\mathrm{CM}$ & $\rho, T, c_{p}$ & 293.15 to 318.15 & 0.101 & $\pm 0.1 \mathrm{~kg}^{-3}$ & NA & Solvent Innovation \\
\hline Garcia-Miaja & 2009 & DSC & $\rho, T, u, c_{p}$ & 293.15 to 318.15 & 0.101 & $\pm 0.1 \mathrm{~kg} \cdot \mathrm{m}^{-3}$ & $>0.985$ & Solvent Innovation \\
\hline Lin & 2009 & DSC & $T, u, c_{p}$ & 303.2 to 353.2 & 0.101 & $\pm 2 \%$ & $\leq 0.009$ & TCI Co. \\
\hline $\mathrm{Yu}$ & 2009 & DSC & $\sigma, T, c_{p}$ & 303.2 to 358.2 & 0.101 & $\pm 2 \%$ & $\geq 0.981$ & TCI Co. \\
\hline Paulechka & 2010 & $\mathrm{AC}$ & $\rho, T, c_{p}$ & 292.86 to 367.78 & 0.101 & $\pm 0.4 \%$ & 99.6 & $\mathrm{NA}$ \\
\hline Valderrama & 2011 & $\mathrm{GCM}$ & $T, c_{p}$ & 250 to 425 & 0.101 & $\mathrm{NA}$ & $\mathrm{NA}$ & $\mathrm{NA}$ \\
\hline Calvar & 2013 & DSC & $T, c_{p}$ & 298.15 to 323.15 & 0.101 & $\pm 5 \%$ & $>0.98$ & IoliTec \\
\hline Farahani & 2013 & DSC & $T, c_{p}$ & 188.06 to 663.10 & 0.101 & $3.6 \%$ & $\mathrm{NA}$ & $\mathrm{NA}$ \\
\hline Suleymanli & 2017 & DSC & $T, c_{p}$ & 283.15 to 413.15 & 0.101 & $0.1 \%$ & $40 \mathrm{ppm}$ & Merck \\
\hline
\end{tabular}

MTDSC; Mettler-Toledo differential scanning calorimeter; TSM, Three-step method; DSC, differential scanning calorimeter; CM, Calvet microcalorimeter; AC, adiabatic calorimetry; GCM, group-contribution method; $\rho$, density; T, temperature; $\mathrm{cp}$, heat capacity at constant pressure; $u$, speed of sound; $\sigma$; surface tension; NA, not available;

\section{Experiments}

1-butyl-3-methylimidazolium hexafluorophosphate [BMIM][PF 6$]$ (CAS No 174501-645, chemical formula $\mathrm{C}_{8} \mathrm{H}_{15} \mathrm{~N}_{2} \mathrm{~F}_{6}$, product number 4900500100, purity $\geq 98 \%$, $\left.\mathrm{M}_{\mathrm{w}}=0.28418 \mathrm{~kg} \cdot \mathrm{mol}^{-1}\right)$ and 1-butyl-3-methylimidazolium trifluoromethanesulfonate [BMIM][TFO] (CAS: 174899-66-2, chemical formula $\mathrm{C}_{9} \mathrm{H}_{15} \mathrm{~F}_{3} \mathrm{~N}_{2} \mathrm{O}_{3} \mathrm{~S}$, product number 4900240100 , purity $\geq 98 \%, \mathrm{M}_{\mathrm{w}}=0.28829 \mathrm{~kg} \cdot \mathrm{mol}^{-1}$ ) were purchased from Merck. In order to remove all volatile impurities the sample was dried under vacuum during 48 hours at temperature $T=423.15 \mathrm{~K}$. Mass fraction of water determined after drying by means of Karl-Fisher titration was less than $40 \mathrm{ppm}$.

The constant pressure heat capacity $c_{p}\left(p_{0}, T\right)$ measurements of $[\mathrm{BMIM}]\left[\mathrm{PF}_{6}\right]$ and [BMIM][TFO] at ambient pressure and experimental temperature interval of $(p, \rho, T)$ measurements for the calculation of other thermophysical properties, like as heat capacities at constant pressure $c_{p}(p, T)$ and volume $c_{v}(p, T)$, also speed of sound $u(p, T)$ at high pressures and temperatures is required [11]. In this case, the constant pressure specific heat capacity $c_{p}\left(p_{0}, T\right)$ of the investigated ionic liquids is measured at $T=(283.15$ to 413.15) K using the Pyris 1 DSC Differential Scanning Calorimeter. The accuracy of evaluation of constant pressure specific heat capacity $c_{p}\left(p_{0}, T\right)$ is $\pm 0.1 \%$. The obtained experimental data were used for the calculation of specific heat capacities $c_{p}(p, T)$ and $c_{v}(p, T)$ at high pressures and temperatures, in which the densities of the investigated ionic liquids are experimentally investigated.

The speed of sound values $u\left(p_{0}, T\right)$ of investigated ionic liquids at ambient pressure and temperatures at $T=(283.15$ to 343.15$) \mathrm{K}$ are investigated using the Anton Paar DSA $5000 \mathrm{M}$ vibration tube densimeter and sound velocity meter with intervals of $\Delta T=(5-10)$ $\mathrm{K}$ and an uncertainty of $\Delta u= \pm 0.1 \mathrm{~m} \cdot \mathrm{s}^{-1}$. These high accuracy values are necessary to check the accuracy of calculated speed of sound values $u\left(p_{0}, T\right)$ at $p=0.101 \mathrm{MPa}$. 
$10^{\text {TH }}$ InTERnational CONFERENCE ON Sustainable ENERgy AND ENVIRONMENTAL Protection (June $27^{\mathrm{TH}}-30^{\mathrm{RD}}, 2017$, Bled, Slovenia), WATER AND Air Quality

K. Suleymanli, D. Uysal, R. Hamidova, A. Aliyev, J. Safarov, A. Shahverdiyev \& E. Hassel: Heat Capacity and Speed of Sound of 1-Butyl-3-Methylimidazolium Hexafluoro $\neg$ phosphate and 1-Butyl-3-Methylimidazolium Trifluoro-Methanesulfonate Over Wide Range of Temperature

Specific heat capacity values of investigated ionic liquids at ambient pressure $c_{p}\left(p_{0}, T\right)$ were fitted to the polynomial equation:

$c_{p}\left(p_{0}, T\right)=\sum_{i=0}^{2} a_{i} T^{i}$

where $a_{\mathrm{i}}$ are the coefficients of eqn. (1) and presented in Table 3.

Table 3. Coefficients $a_{i}$, of eqn. (1).

$[\mathrm{BMIM}]\left[\mathrm{PF}_{6}\right]$

\begin{tabular}{|c|c|}
\hline$a_{0} / \mathrm{J} \cdot \mathrm{kg}^{-1} \cdot \mathrm{K}^{-1}$ & 634.685289248021 \\
\hline$a_{1} / \mathrm{J} \cdot \mathrm{kg}^{-1} \cdot \mathrm{K}^{-2}$ & 3.19689261968619 \\
\hline$a_{2} / \mathrm{J} \cdot \mathrm{kg}^{-1} \cdot \mathrm{K}^{-3}$ & $-0.171804377292917 \cdot 10^{-2}$ \\
\hline
\end{tabular}

[BMIM][TFO]

\begin{tabular}{|c|c|}
\hline$a_{0} / \mathrm{J} \cdot \mathrm{kg}^{-1} \cdot \mathrm{K}^{-1}$ & 896.5314826 \\
\hline$a_{1} / \mathrm{J} \cdot \mathrm{kg}^{-1} \cdot \mathrm{K}^{-2}$ & 2.1577936223 \\
\hline$a_{2} / \mathrm{J} \cdot \mathrm{kg}^{-1} \cdot \mathrm{K}^{-3}$ & $-0.45613543147 \cdot 10^{-3}$ \\
\hline
\end{tabular}

The eqn. (1) describe the obtained specific heat capacity values at ambient pressure within max. in $\Delta c_{p}\left(p_{0}, T\right) / c_{p}\left(p_{0}, T\right)= \pm 0.02 \%$ average percent deviation.

Figures 1 and 2 presents the plot of deviation of literature heat capacities $c_{p}\left(p_{0}, T\right)$ values of investigated IL's at constant ambient pressure from our measured values versus temperature. 
Protection (June $27^{\mathrm{TH}}-30^{\mathrm{RD}}, 2017$, Bled, SLOVEniA), WATER AND Air Quality

K. Suleymanli, D. Uysal, R. Hamidova, A. Aliyev, J. Safarov, A. Shahverdiyev \& E. Hassel: Heat Capacity and Speed of Sound of 1-Butyl-3-Methylimidazolium Hexafluoro $\neg$ phosphate and 1-Butyl-3-Methylimidazolium Trifluoro-Methanesulfonate

Over Wide Range of Temperature

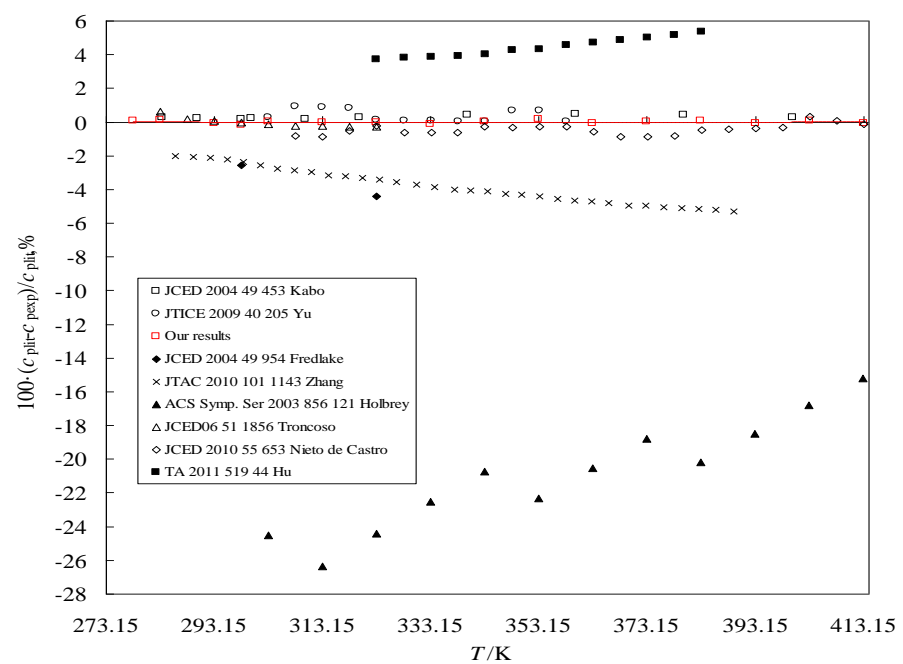

Figure 1. Plot of deviation of literature heat capacities $c_{p}\left(p_{0}, T\right)$ values of [BMIM] $\left.\mathrm{PF}_{6}\right]$ at constant ambient pressure from our measured values versus temperature.

The literature heat capacities $c_{p}$ values of $[\mathrm{BMIM}]\left[\mathrm{PF}_{6}\right]$ have good agreement with our results except the values Holbrey et al. [12].

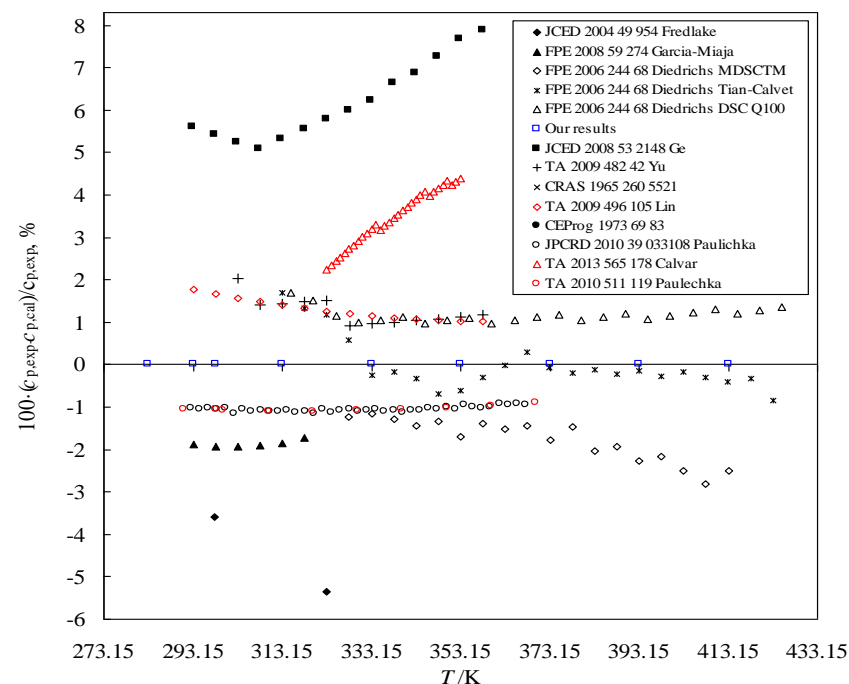

Figure 2. Plot of deviation of experimental $c_{p \text {,exp. }}\left(p_{0}, T\right)$ and literature $c_{\mathrm{p}, \text { lit. }}\left(p_{0}, T\right)$ heat capacities of [BMIM][TFO] at $p=0.101 \mathrm{MPa}$ versus temperature. 
$10^{\text {TH }}$ International Conference on Sustainable Energy and Environmental Protection (June $27^{\mathrm{TH}}-30^{\mathrm{RD}}, 2017$, Bled, Slovenia), WATER AND Air Quality

K. Suleymanli, D. Uysal, R. Hamidova, A. Aliyev, J. Safarov, A. Shahverdiyev \& E. Hassel: Heat Capacity and Speed of Sound of 1-Butyl-3-Methylimidazolium Hexafluoro $\neg$ phosphate and 1-Butyl-3-Methylimidazolium Trifluoro-Methanesulfonate Over Wide Range of Temperature

The literature heat capacities $c_{p}$ values of [BMIM][TFO] have good agreement with our results.

Speed of sound values of investigated IL's at ambient pressure $u_{\text {lit. }}\left(p_{0}, T\right)$ were fitted to the polynomial equation:

$u\left(p_{0}, T\right)=\sum_{i=0}^{2} b_{i} T^{i}$

where $b_{\mathrm{i}}$ are the coefficients of eqn. (2) and presented in Table 4.

Table 4. Coefficients $a_{i}$, of eqn. (2).

$[\mathrm{BMIM}]\left[\mathrm{PF}_{6}\right]$

\begin{tabular}{|c|c|}
\hline$b_{0} / \mathrm{m} \cdot \mathrm{s}^{-1}$ & 2413.34314835316 \\
\hline$b_{1} / \mathrm{m} \cdot \mathrm{s}^{-1} \cdot \mathrm{K}^{-1}$ & -4.11638421961098 \\
\hline$b_{2} / \mathrm{m} \cdot \mathrm{s}^{-1} \cdot \mathrm{K}^{-2}$ & $0.288736429969561 \cdot 10^{-2}$ \\
\hline
\end{tabular}

[BMIM][TFO]

\begin{tabular}{|c|c|}
\hline$b_{0} / \mathrm{m} \cdot \mathrm{s}^{-1}$ & 2270.23018863204 \\
\hline$b_{1} / \mathrm{m} \cdot \mathrm{s}^{-1} \cdot \mathrm{K}^{-1}$ & -3.62707403572968 \\
\hline$b_{2} / \mathrm{m} \cdot \mathrm{s}^{-1} \cdot \mathrm{K}^{-2}$ & $0.227904272860968 \cdot 10^{-2}$ \\
\hline
\end{tabular}

The eqn. (2) describe the obtained speed of sound values at ambient pressure in $\Delta u / u=$ $\pm 0.033 \%$ average percent deviation for $[\mathrm{BMIM}]\left[\mathrm{PF}_{6}\right]$ and $\Delta u / u= \pm 0.010 \%$ for [BMIM][TFO]. 
Figure 3 and 4 presents the plot of deviation of literature speed of sound $u\left(p_{0}, T\right)$ values of investigated IL's at constant ambient pressure from our measured values versus temperature.

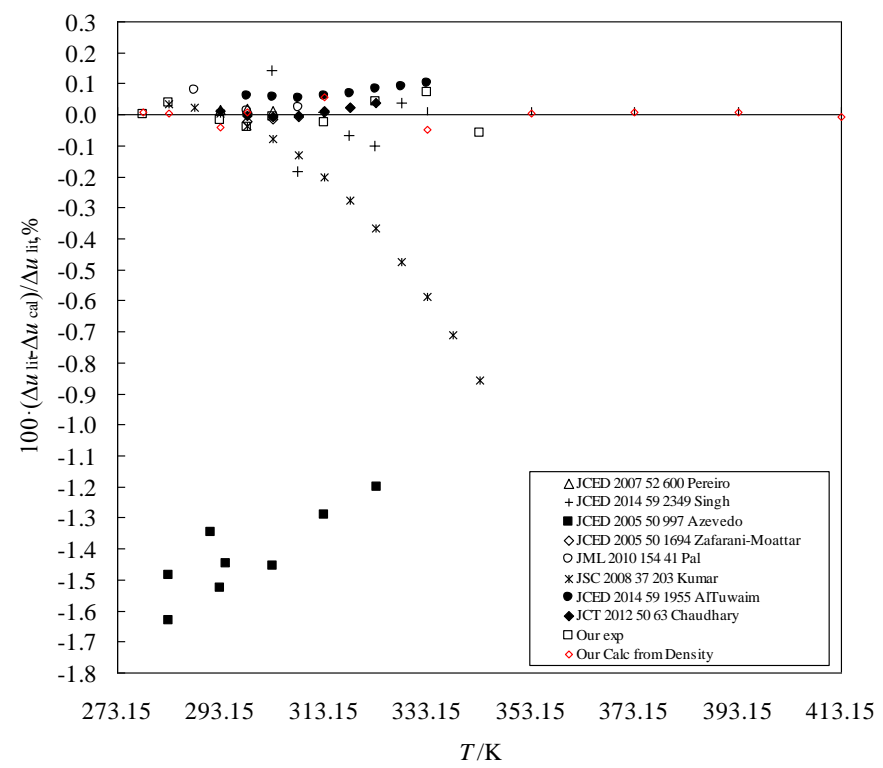

Figure 3. Plot of deviation of literature speed of sound $u_{\text {lit. }}\left(p_{0}, T\right)$ values of $[\mathrm{BMIM}]\left[\mathrm{PF}_{6}\right]$ at ambient pressure from our measured $u_{\text {exp. }}$ and calculated $u_{\text {cal. }}$ values versus temperature.

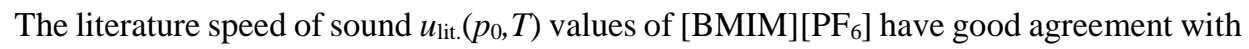
our results. Only the values of Azevado et al. have some deviation from other values. 
$10^{\text {TH }}$ International Conference on Sustainable Energy and Environmental Protection (June $27^{\mathrm{TH}}-30^{\mathrm{RD}}, 2017$, Bled, Slovenia), WATER AND Air Quality

K. Suleymanli, D. Uysal, R. Hamidova, A. Aliyev, J. Safarov, A. Shahverdiyev \& E. Hassel: Heat Capacity and Speed of Sound of 1-Butyl-3-Methylimidazolium Hexafluoro $\neg$ phosphate and 1-Butyl-3-Methylimidazolium Trifluoro-Methanesulfonate Over Wide Range of Temperature

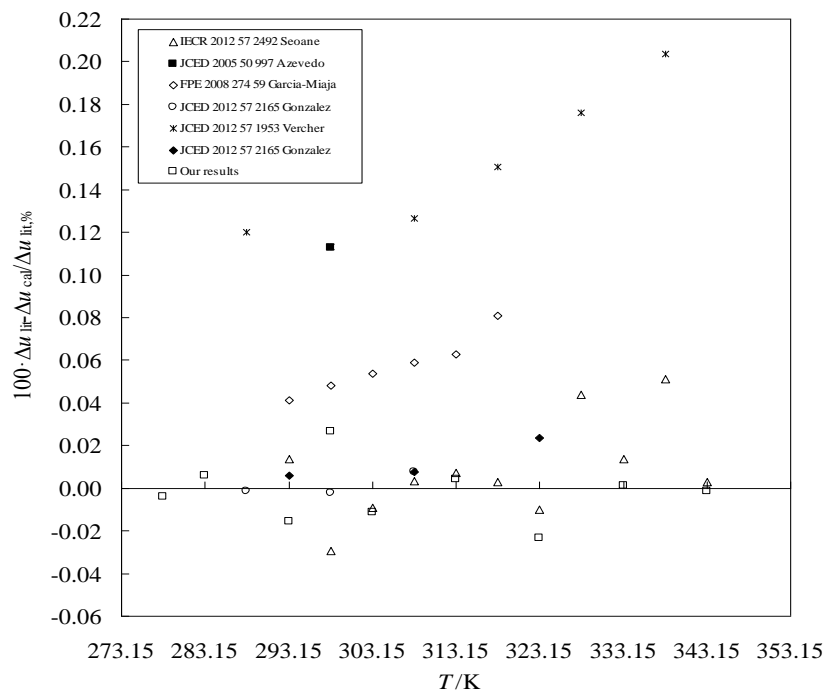

Figure 4. Plot of deviation of literature speed of sound $u_{\text {lit. }}\left(p_{0}, T\right)$ values of $[\mathrm{BMIM}][\mathrm{TFO}]$ at ambient pressure from our measured $u_{\text {exp. }}\left(p_{0}, T\right)$ and calculated $u_{\text {cal. }}\left(p_{0}, T\right)$ values versus temperature.

\section{Acknowledgements}

The Azerbaijan Technical University, University of Rostock and Gazi University thanks for the supporting of these research investigations.

\section{References}

[1] D.R. MacFarlane, K.R. Seddon, "Ionic liquids-progress on the fundamental issues", Austrian Journal of Chemistry, 60, 3-5, 2007.

[2] M. Deetlefs, K.R. Seddon, "Ionic liquids: fact and fiction”, Chim. Oggi, 24, 16-18, 2006.

[3] R.D. Rogers, K.R. Seddon, (eds.). Ionic Liquids as Green Solvents: Progress and Prospects, ACS Symposium Series. ACS, Washington, 2003.

[4] P. Wasserscheid, T. Welton (eds.). Ionic Liquids in Synthesis, Wiley-VCH, Weinheim, 2003.

[5] R.D. Rogers, K.R. Seddon, “Ionic liquids-solvents of the future?”, Science, 302, 792-793, 2003.

[6] F. Endres, S. Zein Al Abedin, "Air and water stable ionic liquids in physical chemistry", Physical Chemistry Chemical Physics, 8, 2101-2116, 2006.

[7] J. Dupont, R.F. de Souza, P.A.Z. Suarez, "Ionic liquid (molten salt) phase organometallic catalysis", Chemical Reviews, 102, 3667-3691, 2002.

[8] P. Wang, B. Wenger, R. Humphry-Baker, J.-E. Moster, J. Teuscher, W. Kantlehner, J. Mezger, E.V. Stoyanov, S.M. Zakeeruddin, M. Graetzel, "Charge separation and efficient 
K. Suleymanli, D. Uysal, R. Hamidova, A. Aliyev, J. Safarov, A. Shahverdiyev \& E. Hassel: Heat Capacity and Speed of Sound of 1-Butyl-3-Methylimidazolium Hexafluoro $\neg$ phosphate and 1-Butyl-3-Methylimidazolium Trifluoro-Methanesulfonate

light energy conversion in sensitized mesoscopic solar cells based on binary ionic liquids", Journal of American Chemical Society, 127, 6850-6856, 2005.

[9] P. Wang, S.M. Zakeeruddin, R. Humphry-Baker, M. Graetzel, "A binary ionic liquid electrolyte to achieve $\geq 7 \%$ power conversion efficiencies in dye-sensitized solar cells", Chemistry of Materials, 16, 2694-2696, 2004.

[10] M.E.V. Van Valkenburg, R.L. Vaughn, M. Williams, J.S. Wilkes, "Thermochemistry of ionic liquid heat-transfer fluids" Thermochimica Acta, 425, 181-188, 2005.

[11] J. Safarov, R. Hamidova, S. Zepik, H. Schmidt, I. Kul, A. Shahverdiyev, E. Hassel, "Thermophysical Properties of 1-hexyl-3-methylimidazolium bis(trifluoromethylsulfonyl) imide at high temperatures and pressures", J. Mol. Liq., 187, 137-156, 2013.

[12] J.D. Holbrey, W.M. Reichert, R.G. Reddy, R.D. Rogers, Heat Capacities of Ionic Liquids and Their Applications as Thermal Fluids, Ionic Liquids as Green Solvents: Progress and Prospects, ACS Symposium Series 856, 11, 121-133, American Chemical Society: Washington D. C., 2003. 
$26 \quad 10^{\mathrm{TH}}$ International CONFERENCE on Sustainable ENERgy AND ENVIRONMENTAL Protection (June 27 $7^{\mathrm{TH}}-30^{\mathrm{RD}}, 2017$, Bled, Slovenia), WATER AND Air Quality 
$10^{\mathrm{TH}}$ InTERnational CONFERENCE ON Sustainable ENERgy AND ENVIRONMENTAL PRotection (June $27^{\mathrm{TH}}-30^{\mathrm{RD}}$, 2017, BLed, SLOVENIA), WATER AND AIR QUALITY

J. Krope, A.Ghani Olabi, D. Goričanec \& S. Božičnik

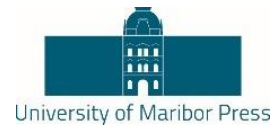

\title{
Permeable and Hygroscopic Building Envelopes: Hygrothermal Simulations of "Det Naturlige Hus"
}

\author{
DiANE BASTIEN \& MARTIN WINTHER-GAASVIG
}

\begin{abstract}
Unlike most conventional building materials currently used nowadays, natural building materials tend to be hygroscopic and permeable to water vapour. These two characteristics have the potential to improve the longevity and indoor air quality of buildings. For instance, the use of hygroscopic materials such as clay plasters can significantly reduce indoor humidity fluctuations, which yields many other indirect health benefits. However, with many countries that commonly use vapour retarders, there is lack of knowledge and general design guidelines on how to design safe permeable and hygroscopic building assemblies. This paper presents hygrothermal simulations of "det Naturlige Hus", a single-family house in Denmark mainly made of wood and clay. Simulation results indicate high levels of moisture on the exterior building layers, especially in the coldest months, mainly caused by driving rain and water vapour diffusion. The mold index calculated at the exterior surface of the exterior wood fibreboard according to ASHRAE 160 grew over the two years simulated period to reach a maximum of 2,7 and would likely reach higher values with a longer simulation period. When removing the exposure to driving rain, the maximum mold index reached a value of 0,2 . With a recommended threshold of 3 , it seems that the wall design investigated here could perform satisfactorily provided that great care is taken to minimize the wall exposure to driving rain.
\end{abstract}

Keywords: - Water vapour • hygroscopicity • water management techniques $\bullet$ diffusion $\bullet$ permeability $\bullet$

CoRRESPONDENCE AdDRESS: Diane Bastien, Postdoctoral Researcher, University of Southern Denmark, Faculty of Technology and Innovation, Campusvej 55, 5230 Odense M, Denmark, email: dib@iti.sdu.dk. Martin Winther-Gaasvig, University of Southern Denmark, Faculty of Technology and Innovation, Campusvej 55, 5230 Odense M, Denmark, e-mail: mwg@iti.sdu.dk.

https://doi.org/10.18690/978-961-286-064-6.4 ISBN 978-961-286-064-6

(C) 2017 University of Maribor Press

Available at: http://press.um.si. 
$10^{\mathrm{TH}}$ International Conference on Sustainable EnERgy AND Environmental Protection (June $27^{\mathrm{TH}}-30^{\mathrm{RD}}, 2017$, Bled, Slovenia), WATER AND Air Quality

D. Bastien \& M. Winther-Gaasvig: Permeable and Hygroscopic Building Envelopes: Hygrothermal Simulations of "Det Naturlige Hus"

\section{$1 \quad$ Introduction}

Water is estimated to be responsible for $75 \%$ of building failures [1]. Water management in buildings is therefore one of the biggest driver of building longevity. It is also closely related to the indoor air quality and the health of building occupants. Keeping the indoor relative humidity level between $40 \%$ and $60 \%$ can reduce asthmatic reactions, mites, fungi and the survival rate of infectious bacteria and viruses [2].

As such, water management strategies should be an important part of building design and should rely on more than one strategy to insure satisfactorily performance over time.

Different moisture management strategies can be effective, depending on the building usage and climate. The use of impervious or inorganic materials is often touted as a safe practice, but these could actually pose additional risks. For instance, manufacturers of petroleum-based insulation products claim that they are safer than natural products because of the absence of organic material available for mold growth. However, natural materials tend to be more hygroscopic (able to retain and release moisture), which reduces the risk for mold growth by having a more uniform moisture distribution [3]. As for impermeable walls, they are much more prone to transient episodes of condensation caused by cooking and washing than pervious surfaces [4].

\subsection{Moisture transfer mechanisms}

The four predominant moisture transfer mechanisms in buildings are: 1) liquid flow; 2) capillary suction; 3) air movement 4) vapour diffusion [5].

\section{Liquid flow}

Liquid flow as rain and groundwater is the most important source of water that buildings are exposed to. Appropriate strategies to control liquid flow include overhangs, gutters, site grading and drainage pipes at the footings.

Capillary suction

Capillary transport occurs through the absorption/desorption of water as liquid in porous materials. It becomes important when materials have a relative humidity above $95 \%$, when water vapour starts to condensate in the smaller pores. The best way to control undesirable capillary transport in building envelopes is by proving a capillary break, such as installing a rain screen cladding and waterproofing below grade elements.

\section{Air movement}

Unintended air movement through the building fabric as infiltration or exfiltration can carry a high amount of moisture, which can potentially condensate if a surface colder than the air dew point is met. Energy efficiency concerns are driving the quest for air 
$10^{\mathrm{TH}}$ INTERNATIONAL CONFERENCE ON SUSTAINABLE ENERGY AND ENVIRONMENTAL Protection (June $27^{\mathrm{TH}}-30^{\mathrm{RD}}, 2017$, Bled, SLOVenia), WATER AND Air Quality

D. Bastien \& M. Winther-Gaasvig: Permeable and Hygroscopic Building Envelopes: Hygrothermal Simulations of "Det Naturlige Hus"

tightness in buildings, which also contributes to reduce condensation risks and premature deterioration. Therefore, having airtight buildings is highly desirable from both the energy performance and building durability point of views. Fresh air should be provided year round through dedicated systems, either naturally or mechanically.

Vapour diffusion

In winter, the atmospheric water vapour pressure is lower than the indoor vapour pressure. This vapour pressure gradient can generate a vapour flow from the interior to the exterior of a wall. Water vapour carried out by diffusion through the building envelope typically involves smaller amount of water compared to the three other transport mechanisms. Therefore, water vapour diffusion is less likely to cause severe damage to buildings. It is thus surprising to have building codes in many countries (e.g. Canada, United-States...) that require a water vapour barrier while not having strict requirements to protect buildings from water damage that can occur by the three other transfer mechanisms.

The International Residential Code classified vapour retarders in three classes [6]:

- A class 1 vapour retarder, also called vapour barrier, has a permeability of less than 0.1 perm $\left(\mathrm{s}_{\mathrm{d}}=35 \mathrm{~m}\right.$ - equivalent air layer thickness), such as a polyethylene sheet.

- A class 2 vapour retarder has a permeability higher than 0.1 perm but less than 1 perm $\left(\mathrm{s}_{\mathrm{d}}=3,5 \mathrm{~m}\right)$, such as a plywood and bitumen coated kraft paper.

- A class 3 vapour retarder has a permeability higher than 1 perm but less than 10 perm $\left(\mathrm{s}_{\mathrm{d}}=0,35 \mathrm{~m}\right)$, such as latex paint.

Different classes are established in Europe by the CSTC [7], where a vapour barrier (class E4) is defined for materials with $\mathrm{s}_{\mathrm{d}}>200 \mathrm{~m}$ and materials are considered weak vapour retarders (class E1) with $2 \mathrm{~m}<\mathrm{s}_{\mathrm{d}}<5 \mathrm{~m}$.

Installing a vapour barrier on the interior in cold climates is indeed effective at stopping water vapour flow induced by vapour pressure gradient. However, it also impedes the drying potential of a building enclosure. Vapour barriers or retarders may cause significant damage when the building materials installed during the construction process have elevated moisture levels and during minor accidental moisture intrusion [8].

Rose (2003) notes that the numerical threshold values in the prescriptive requirements for vapour retarders by the Federal Housing Authority is lacking scientific support, although they remain the basis for US practice nowadays. He also describes the marketing strategy for convincing the public to adopt vapour retarders, for instance with a 1951 pamphlet titled "War Against Water" describing "the menace of moisture". The socalled diffusion paradigm that emerged at this period is based on four elements: 1) vapour pressure gradient as the principal moisture load; 2) diffusion as the principal transport mechanism; 3) the steady-state profile as the main analysis tool; 4) recommendations of 
$10^{\mathrm{TH}}$ INTERNATIONAL CONFERENCE ON Sustainable ENERGy AND ENVIRONMENTAL Protection (June $27^{\mathrm{TH}}-30^{\mathrm{RD}}, 2017$, Bled, Slovenia), WATER AND Air Quality

D. Bastien \& M. Winther-Gaasvig: Permeable and Hygroscopic Building Envelopes: Hygrothermal Simulations of "Det Naturlige Hus"

vapour barriers and attic ventilation. However, as mentioned by McDermott, condensation is maybe not the most appropriate term for describing the phase change from vapour to adsorbed/absorbed moisture in materials.

In the diffusion paradigm, the hygroscopicity of building materials is completely ignored. But it plays a major role on the durability of the building envelope.

\subsection{Benefits of permeable, hygroscopic building assemblies}

Although uncommon in developed countries, hygroscopic and permeable walls may provide many benefits.

Building walls that have the capability to buffer moisture can provide more stable indoor humidity levels year round. In cases where dehumidification is required, such walls allow selecting a dehumidifier with a lower capacity and thus contribute to save energy. A building envelope made of permeable and hygroscopic materials provides a safety net and is more likely to forgive construction errors and future failures in other systems or parts of the fabric, which unavoidably arise throughout the entire lifetime of a building. Natural materials such as timber, clay, straw and natural fibres are both permeable and hygroscopic, therefore they are the best from not only an environmental point of view, but also from a performance point of view [4].

As pointed out by Rode [10], if a hygroscopic material is covered by a non-hygroscopic material and is not directly exposed to the indoor air, its contribution in buffering indoor moisture levels becomes nearly null.

Simonson et al. (2004a) found that a permeable, hygroscopic building envelope primarily made of wood can affect the concentration of $\mathrm{CO}_{2}, \mathrm{SF}_{6}$ and water vapour. Such a building envelope can reduce significantly the $\mathrm{CO}_{2}$ concentration in low ventilation conditions, and still moderately when mechanical ventilation is provided. This building envelope reduced significantly the moisture fluctuations in a room in both well-ventilated and poorly ventilated conditions.

Simulations of hygroscopic building materials also showed that they are effective in reducing peak humidity levels and to increase the minimum humidity level in winter. [11]. This study concluded that additional research was needed to determine appropriate hygroscopic and permeable materials for different climates and buildings.

\subsection{Selected field and laboratory study}

A Canadian study on straw bale houses found that there is no doubt that strawbale houses can successfully function in a cold climate without having an interior vapour barrier. Three case study houses out of the nine that were monitored had borderline or unacceptable moisture readings. Designs which produced these moisture readings had two or more of the following conditions: 1) Insufficient overhangs 2) No capillary break 
$10^{\text {TH }}$ INTERNATIONAL CONFERENCE ON SUSTAINABLE ENERGY AND ENVIRONMENTAL

3) Extreme interior wetting 4) Below grade bales 5) Inadequate backsplash protection 6) Northern exposures. All of these conditions can be addressed by design, except for northern walls, which were found to have sustained humidity levels that resulted only from high atmospheric humidity levels [12].

Laboratory experiments performed by Geving et al. investigated, among other configurations, the conditions of a $50 \mathrm{~mm}$ wood fiber board acting as exterior wind barrier with wood fiber batt insulation and an interior gypsum board. The measurements have been recorded in Norway in 2014 over more than six months during the winter period. Even with this configuration without a vapour retarder and a hygroscopic material as inner layer, the relative humidity in the exterior wood fibre board exhibited a satisfactory performance and never exceeded $90 \%$.

\section{$1.4 \quad$ Scope of this study}

With a few studies performed in the last 30 years questioning the need for vapour retarders, there is still a lack of design guidelines for the construction of permeable building assemblies. Is it possible to build a durable building envelope without any vapour retarders? If so, then how? Experience from existing buildings shows that the answer to the first question is yes. The second answer can be partly answered by reviewing the different permeable assemblies that were proven successful over time, but because of the lack of general design guidelines, introducing any changes in the building envelope or locating a building in a different climate would require detailed simulations to ensure safe water management.

This contribution presents hygrothermal simulation results of a permeable building, "det Naturlige Hus" (dNH). This house, currently under construction in Denmark, is mainly made of wood and clay. It was designed by the owner with the intent to provide the highest indoor environment quality as possible to his family. The relative humidity and temperature levels of the different layers of the building envelop are examined in order to assess the risk of elevated moisture level and potential mold growth.

This house will be closely monitored. The objectives of the monitoring will be to gather field data for assessing the performance and safety of the building envelope under real conditions and contribute to acquiring knowledge on the dynamic of permeable and hygroscopic building envelopes. The case study presented in this paper is a first step towards the objective to develop guidelines for designing permeable building envelopes that are safe and resilient under various conditions.

\section{$2 \quad$ Hygrothermal Simulation}

\subsection{Det Naturlige Hus}

"Det Naturlige Hus" is a one-storey $187 \mathrm{~m}^{2}$ single family wood frame house located in Holbæk, near Copenhagen, in Denmark. The walls of dNH are made of lime plaster, wood 
D. Bastien \& M. Winther-Gaasvig: Permeable and Hygroscopic Building Envelopes: Hygrothermal Simulations of "Det Naturlige Hus"

fibreboard, cellulose, clay board and clay plaster, whose hygrothermal properties are provided in Table 1. The ceiling is made of $500 \mathrm{~mm}$ of cellulose over a clay board and clay plaster. The wooden floor structure that sits over the concrete footings is slightly above ground level, over a ventilated crawl space. It is made of $300 \mathrm{~mm}$ of cellulose insulation sandwiched between a wood fibreboard and oak flooring. The nominal Uvalues of the exterior walls, ceiling and floor are $0,09 \mathrm{~W} /\left(\mathrm{m}^{2} \mathrm{~K}\right), 0,07 \mathrm{~W} /\left(\mathrm{m}^{2} \mathrm{~K}\right)$ and $0,11 \mathrm{~W} /\left(\mathrm{m}^{2} \mathrm{~K}\right)$ respectively. The windows have a double glazed insulated glass unit (IGU) and an additional single pane on the inside, with a glass g-value of 0,55 and an overall Uvalue of $0,77 \mathrm{~W} /\left(\mathrm{m}^{2} \mathrm{~K}\right)$. These windows have the possibility to provide preheated fresh air by allowing air through openings in the window sill to flow between the single pane and the IGU and enter the room through an opening at the window head jamb.

Table 1. Wall Layers Material Properties

\begin{tabular}{|l|c|c|c|c|c|}
\hline $\begin{array}{c}\text { Material/Layer } \\
\text { (from outside to } \\
\text { incide) }\end{array}$ & $\begin{array}{c}\square \\
{\left[\mathrm{kg} / \mathrm{m}^{3}\right]}\end{array}$ & $\begin{array}{c}\mathrm{c} \\
{[\mathrm{J} / \mathrm{kgK}]}\end{array}$ & $\begin{array}{c}\square \\
{[\mathrm{W} / \mathrm{mK}} \\
]\end{array}$ & $\begin{array}{c}\text { Thick. } \\
{[\mathrm{m}]}\end{array}$ & $\begin{array}{c}\mathrm{S}_{\mathrm{d}} \\
{[\mathrm{m}]}\end{array}$ \\
\hline Lime Plaster & 1600 & 850 & 0,7 & 0,005 & 0,35 \\
\hline Ext wood fibreboard & 140 & 2100 & 0,04 & 0,06 & 0,18 \\
\hline Cellulose & 43 & 2500 & 0,037 & 0,34 & 0,68 \\
\hline Clay board & 615 & 2000 & 0,128 & 0,016 & 0,12 \\
\hline Basecoat clay plaster & 1844 & 850 & 0,1 & 0,003 & 0,04 \\
\hline Topcoat clay plaster & 1844 & 850 & 0,1 & 0,002 & 0,03 \\
\hline
\end{tabular}

For the exterior wall assembly, the layer with the highest equivalent air layer thickness is the cellulose with $\mathrm{s}_{\mathrm{d}}=0,68 \mathrm{~m}$. 


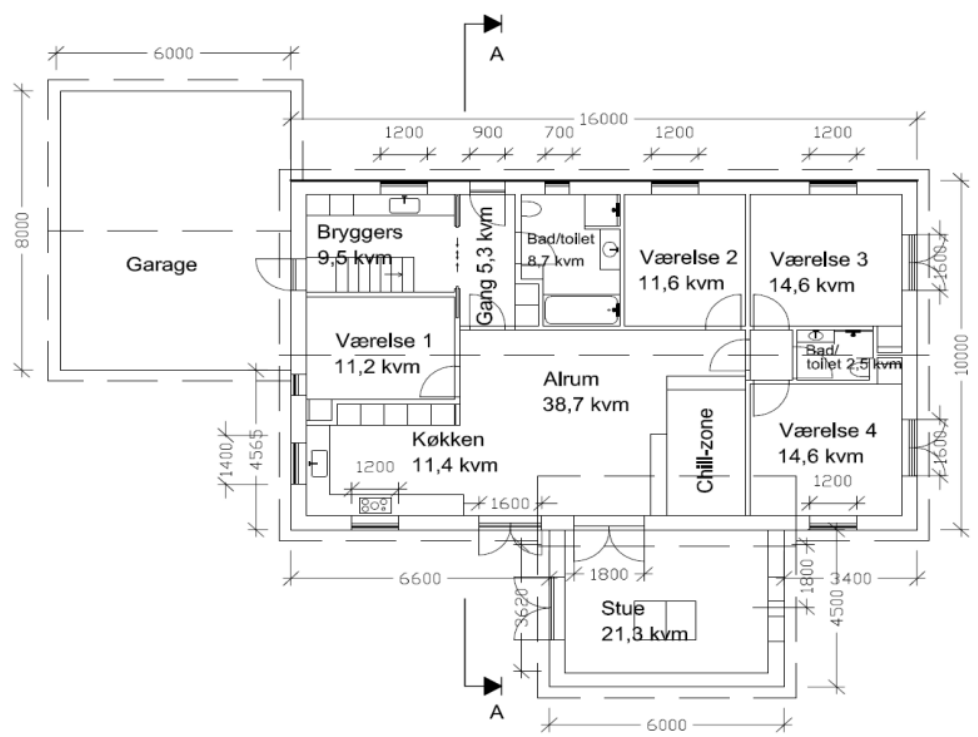

Figure 1. Floor plan of dNH

\subsection{Simulation parameters and model limitations}

Thermal and hygroscopic conditions inside the building assemblies are simulated with WUFI ${ }^{\circledR}$ Plus, a software that allows the calculation of transient heat and moisture flows. This tool has been validated through many studies [8]. Simulations are performed with the weather data from the WUFI database for the city of Lund, Sweden, which is $120 \mathrm{~km}$ East from Holbæk at the same latitude. Simulations are executed during two years, in order to see the initial drying immediately after construction and to allow enough time to get a stable annual dynamic. There are two adults and two children occupying the building constantly except during weekdays (8:00-16:00). The air tightness of $\mathrm{dNH}$ being unknown at the time being, the infiltration rate was set constant at $0,1 \mathrm{ACH}$. The special ventilation windows are considered unvented in the simulation model, but mechanical ventilation at $0,5 \mathrm{ACH}$ with a heat recovery of $60 \%$ is included to approximate the ventilation effect that can be obtained with the ventilated windows. Additional natural ventilation at $0,5 \mathrm{ACH}$ is provided from May $15^{\text {th }}$ until September $15^{\text {th }}$ to represent the window opening behaviour of occupants.

At this stage, only one-dimensional simulations are performed. Thus, thermal and hygric transfers through the structural lumber elements are neglected.

The model is divided as six zones. The house and the living room (stue) have a constant heating setpoint of $20^{\circ} \mathrm{C}$ and no mechanical cooling. The attics and crawl spaces of the house and the living room are continuously ventilated at $3 \mathrm{ACH}$. There is interzone ventilation between the house and the living room at $30 \mathrm{~m}^{3} / \mathrm{h}$. The indoor moisture 
$10^{\mathrm{TH}}$ INTERNATIONAL CONFERENCE ON Sustainable ENERGY AND ENVIRONMENTAL Protection (June $27^{\mathrm{TH}}-30^{\mathrm{RD}}, 2017$, Bled, Slovenia), WATER AND Air Quality

D. Bastien \& M. Winther-Gaasvig: Permeable and Hygroscopic Building Envelopes: Hygrothermal Simulations of "Det Naturlige Hus"

generation profiles were defined from the occupancy schedule for the family. In the main zone, the moisture generation is equal to $4610 \mathrm{~g} /$ day during the week and $8384 \mathrm{~g} /$ day during the weekend. The indoor relative humidity level is between $30 \%$ and $45 \%$ in winter and $35 \%$ and $55 \%$ in summer. In the living room, the moisture load is set at 432 $\mathrm{g} /$ day and the relative humidity level is similar to the main zone.

The two skylights, the attached garage and the mechanical room in the basement leading to the garage have not been not included in the model.

\section{$3 \quad$ Simulation Results and Discussion}

The highest water levels are found in the southwest wall assembly because of a higher exposure to driving rain due to the predominant winds $\left(305 \mathrm{~L} / \mathrm{m}^{2}\right.$ annually for this orientation); thus, only results for this orientation are presented here. The mean relative humidity within the different material layers is presented in Figure 1.

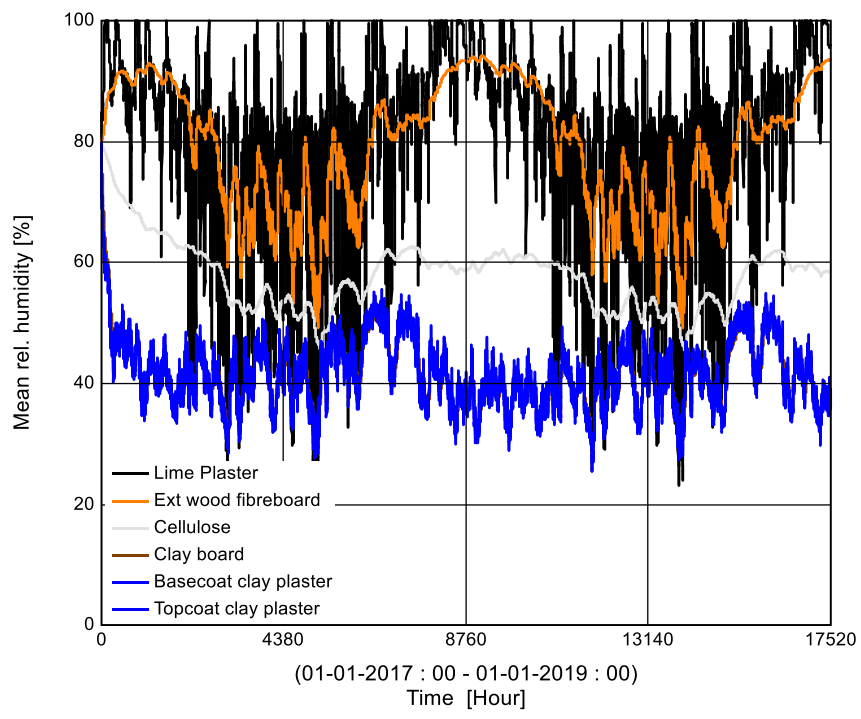

Figure 2. Mean layer relative humidity, SW

The most critical component is the exterior wood fibreboard, especially from December to February $20^{\text {th }}$ (around $8000-10000$ hours) when the relative humidity is above $90 \%$. During the second simulated year, the maximum relative humidity is $94 \%$ and is reached in early January. 


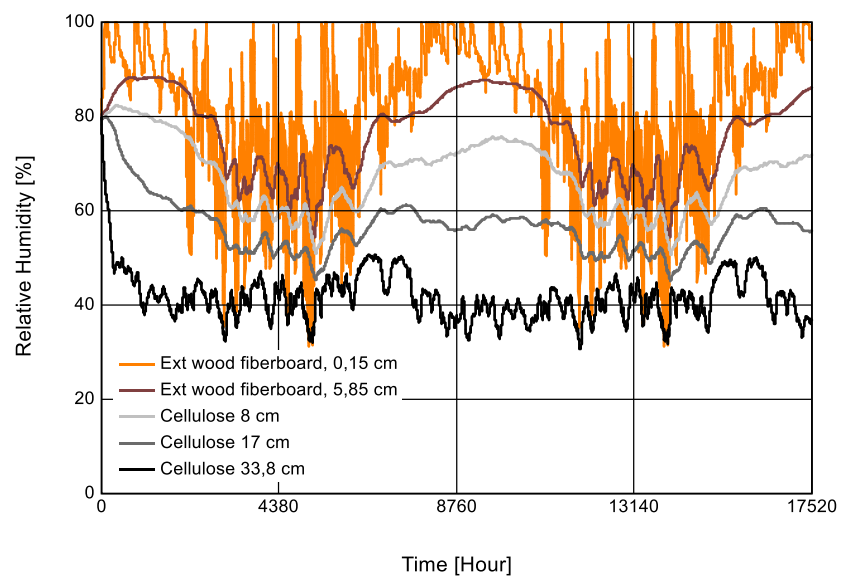

Figure 3. Relative humidity at different depths, SW

The relative humidity at different depths in the SW wall assembly is presented above. At $0.15 \mathrm{~cm}$ from the exterior surface of the wood fibreboard, saturation and rapid drying occur frequently because of driving rain and evaporation from solar radiation. The relative humidity level is more stable at $5.85 \mathrm{~cm}$ (brown curve), which stays over $80 \%$ during 160 days in the cold season.

At $1 / 4^{\text {th }}$ deep from the exterior side of the cellulose layer, the relative humidity level is always below $74 \%(8 \mathrm{~cm})$ while it remains below $60 \%$ in the middle of the cellulose layer $(17 \mathrm{~cm})$.

Observation of Figures 2 indicates a potential risk of mold development, with the exterior wood fibreboard having a mean relative humidity over $80 \%$ during approximately 180 days. However, when the humidity of the wood board is high, temperatures are relatively low, as shown in the Figure 4 below. While the mean moisture content is often above $20 \%$, the mean temperature is generally between 5 and 10 when this occurs. 
$10^{\mathrm{TH}}$ INTERNATIONAL CONFERENCE ON Sustainable ENERGY AND ENVIRONMENTAL Protection (June $27^{\mathrm{TH}}-30^{\mathrm{RD}}, 2017$, Bled, Slovenia), WATER AND Air Quality

D. Bastien \& M. Winther-Gaasvig: Permeable and Hygroscopic Building Envelopes: Hygrothermal Simulations of "Det Naturlige Hus"

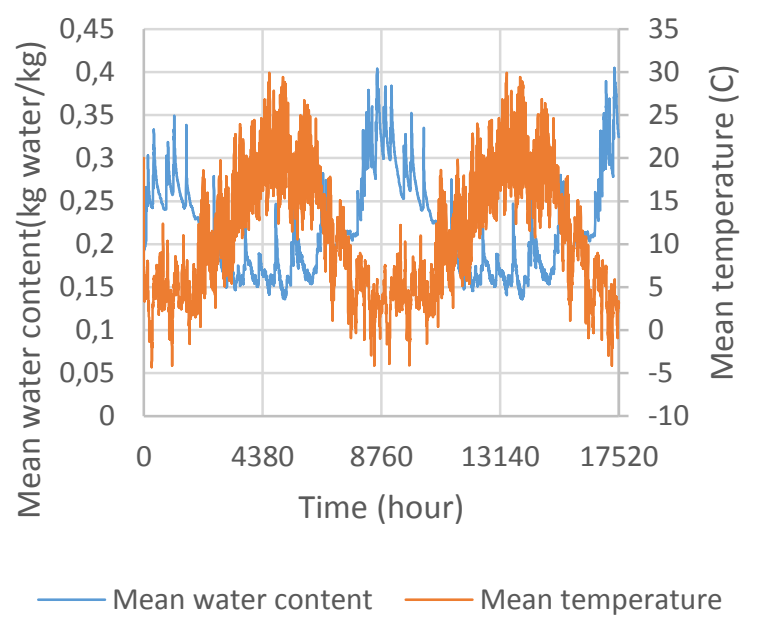

Figure 4. Mean water content and temperature of the wood board, SW

\subsection{Mold index}

The mold index has been calculated following the procedure described in ASHRAE Standard 160 [13] and addenda for the exterior wood fibreboard. This material was classified as a sensitive material for which a mold index decline coefficient of 0.1 was selected. Computation of the mold index over the two simulated years for the mean temperature and relative humidity of the board yield a maximum mold index of 0,7 , which is well below 3, the threshold indicated in the Standard 160. However, the mold index at $0.15 \mathrm{~cm}$ from the exterior surface reaches a maximum value of 2.7 and is likely to increase further over a longer simulation period.

When removing exposure to driving rain, the maximum mold index at $0.15 \mathrm{~cm}$ from the exterior surface of the wood fibreboard is only 0.2 . This indicates that this wall assembly could safely handle moisture flows if adequate protection from rain exposure is provided.

\subsection{Discussion}

From the results presented above, it becomes apparent that driving rain may compromise the performance of the wall assembly. Measures for minimizing driving rain such as overhangs are required for the durability of the wall assembly investigated here.

In future simulations, the model will be modified and consider the structural wood members, which should not exceed a moisture level of 16\%-19\%. Effects of varying the permeability of the inner layers on the moisture content of the outer layers will be investigated. 
$10^{\text {TH }}$ INTERNATIONAL CONFERENCE ON SUSTAINABLE ENERGY AND ENVIRONMENTAL Protection (June $27^{\mathrm{TH}}-30^{\mathrm{RD}}, 2017$, Bled, SLovenia), WATER AND Air Quality

D. Bastien \& M. Winther-Gaasvig: Permeable and Hygroscopic Building Envelopes: Hygrothermal Simulations of "Det Naturlige Hus"

\section{Conclusion}

Natural buildings materials have lower embodied energy and life cycle impacts than petroleum-based products. They are also highly hygroscopic and can therefore absorb high amounts of moisture, which can contribute to increase the longevity of buildings assemblies.

This paper presented hygrothermal simulation results of "det Naturlige Hus", a singlefamily wood frame house is Denmark. This house was specifically designed to be permeable to vapour diffusion and to buffer indoor moisture levels. The exterior walls are made of an exterior wood fibreboard, cellulose, clay board and clay plaster.

Results indicate that the southwest wall have the highest moisture content because of driving rain. When exposed to driving rain, the mold index near the exterior surface of the wood fibreboard reached a maximum of 2.7 over a two year simulation period. However, when removing the moisture contribution from driving rain, the maximum mold index reached 0,2 , indicating that the wall assembly may provide satisfactorily performance if adequate protection from rain exposure is provided.

This work is a first step towards the development of design guidelines for durable, permeable and hygroscopic wall assemblies for facilitating the use of natural building materials and reducing the environmental impacts of buildings.

\section{Acknowledgements}

The first author is grateful to the Natural Science and Engineering Research Council of Canada for a Postdoctoral Fellowship and to Professor Hua Ge for proving insightful comments on this work.

\section{References}

[1] N. May, "Breathability: The Key to Building Performance," 2005.

[2] A. V Arundel, E. M. Sterling, J. H. Biggin, and T. D. Sterling, "Indirect health effects of relative humidity in indoor environments," Env. Heal. Perspect., vol. 65, no. 3, pp. 351361, 1986.

[3] C. J. Simonson, M. Salaonvaara, and T. Ojanen, "Heat and Mass Transfer between Indoor Air and a Permeable and Hygroscopic Building Envelope: Part I - Field Measurments," J. Build. Phys., vol. 28, no. 2, pp. 161-185, 2004.

[4] T. Padfield, "The role of absorbent building materials in moderating changes of relative humidity," Technical University of Denmark, 1998.

[5] J. Lstiburek and J. Carmody, Moisture control handbook. Dames and Moore, Trow Inc., 1991.

[6] ASHRAE, "ASHRAE Handbook - Fundamentals," Am. Soc. Heating, Refrig. AirConditioning Eng., 2009.

[7] Centre Scientifique et Technique de la Construction, "La toiture plate: composition materiaux - realisation - entretien," NIT 215, 2000.

[8] H. M. Kunzel, "Adapted vapour control for durable building enclosures," in 10th DBMC 
$10^{\mathrm{TH}}$ InTERnATIONAL CONFERENCE ON Sustainable EnERgy AND ENVIRONMENTAL Protection (June $27^{\mathrm{TH}}-30^{\mathrm{RD}}, 2017$, Bled, Slovenia), WATER AND Air Quality

D. Bastien \& M. Winther-Gaasvig: Permeable and Hygroscopic Building Envelopes: Hygrothermal Simulations of "Det Naturlige Hus"

International Conference on Durability of Building Materials and Components, 2005, p. 8.

[9] W. B. Rose, The rise of the diffusion paradigm in the US. Research in Building Physics (J. Carmeliet, H. Hens, G. Vermeir Ed.). A.A. Balkema Publishers, 2003.

[10] C. Rode, "Organic Insulation Materials : Effect on Indoor Humidity and Necessity of a Vapor Barrier," in Thermal performance of the exterior envelopes of buildings, 1998, pp. 109-121.

[11] C. J. Simonson, M. Salaonvaara, and T. Ojanen, "Heat and Mass Transfer between Indoor Air and a Permeable and Hygroscopic Building Envelope: Part II - Verification and Numerical Studies," J. Build. Phys., vol. 28, no. 2, pp. 161-185, 2004.

[12] R. Jolly, "Strawbale moisture monitoring report CMHC," 2000.

[13] ANSI/ASHRAE Standard 160-2009, "Criteria for moisture-control design analysis in buildings," 2009. 
$10^{\mathrm{TH}}$ InTERnational CONFERENCE ON Sustainable ENERgy AND ENVIRONMENTAL PRotection (June $27^{\mathrm{TH}}-30^{\mathrm{RD}}$, 2017, BLed, SLOVENIA), WATER AND AIR QUALITY

J. Krope, A.Ghani Olabi, D. Goričanec \& S. Božičnik

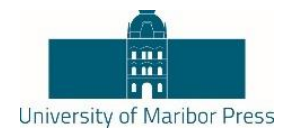

\title{
Water Quality Monitoring Using a Wireless Sensor Network - A Brief Review
}

\author{
Rubens Z. Sakiyama, Paulo Henrique SoAres, Linnyer B.R. AYlon \& Cid \\ MARCOS GONCQLUES ANDRADE
}

\begin{abstract}
The increase of discarded waste in riverbeds in large urban centers makes it essential to water quality monitoring in these environments. Until the year 2000 this monitoring was done manually, through sample collection and analysis of these samples in laboratories. From the year 2000 new technologies were introduced with the use of electronic devices that provide measurements at time. In recent years, several researchers have proposed the use of wireless sensor networks to automatically measures and analyzes water quality parameters. This work presents a review of researches and designs for the water quality monitoring using wireless sensor networks. The review considers the measured water quality parameters, the sensors used, the architecture and services offered by the wireless sensor network, the structure for the processing, storaging and presenting all the information collected, the autonomy of battery-powered systems and provision of energy from available renewable sources. Great progress in the use of wireless sensor networks for the water quality monitoring has been made, but there is still a need for research on some features to be implemented in these systems such as wireless sensor network data security, data aggregation and management algorithms, and power provisioning for devices installed in remote areas.
\end{abstract}

Keywords: • environment • water quality monitoring • wireless sensor network $\bullet$ hygrothermal $\bullet$ permeable $\bullet$

CoRrespondence AdDress: Rubens Z. Sakiyama, State University of Maringá, Av. Colombo, 5790 - Zona 7, Maringá - PR, 87020-900, Brazil, email: rubens.uem@ gmail.com. Paulo Henrique Soares, Federal University of Technology - Paraná, Av. Sete de Setembro, 3165 - Rebouças CEP 80230-901 - Curitiba - PR - Brazil, email: phsoaresdba@gmail.com. Linnyer B.R. Aylon, State University of Maringá, Av. Colombo, 5790 - Zona 7, Maringá - PR, 87020-900, Brazil, email: linnyer@gmail.com. Cid Marcos Goncqlues Andrade, State University of Maringá, Av. Colombo, 5790 - Zona 7, Maringá - PR, 87020-900, Brazil, email: cidmga@ yahoo.com.br.

https://doi.org/10.18690/978-961-286-064-6.5 ISBN 978-961-286-064-6

(C) 2017 University of Maribor Press

Available at: http://press.um.si. 
$10^{\mathrm{TH}}$ InTERNATIONAL CONFERENCE ON SuSTAINABLE ENERGY AND ENVIRONMENTAL Protection (June $27^{\mathrm{TH}}-30^{\mathrm{RD}}, 2017$, Bled, Slovenia), WATER AND Air Quality R.Z. Sakiyama, P.H. Soares, L.B.R.Aylon \& C.M.G. Andrade: Water Quality Monitoring Using a Wireless Sensor Network - A Brief Review

The increase in the waste quantity (whether industrial or residential) discarded in riverbeds, as well as in the air, of large urban centres, makes it essential to monitor the environment by measuring the level of water quality in the waters of river beds, as well as by measuring the level of $\mathrm{CO}_{2}$ in the air. Poor water quality could be a risk for human, aquatic life and ecosystem health [1]. Research indicates that water pollution causes many and diseases around the world. The records show that more than 14,000 people die daily worldwide [2]. Water is considered the most important factor for all live organisms and it's very important the monitoring of water resources available in nature [2]. The traditional water inspection method, called offline inspection, sometimes takes a few days to get result, because the sample needs to be collected on the spot and transported to the laboratory to analyse. This method has several drawbacks compared to online method that use sensors installed at the points of interest and sending the water parameters at the real time [3]. Wireless sensor network technology is used for the construction of these systems.

\section{System Application}

The use of wireless sensor networks for monitoring water quality has been increasingly frequent in recent years due to the reduced cost of components such as sensors, microcontrollers and radio transceivers. Water quality monitoring can be done for a variety of purposes, such as water used for irrigation in agriculture [4] and control of mining waste disposal [5]. For application in aquaculture, we have the examples used in farms for shrimp farming [6], fish [7] and crabs [8]. The monitoring of water quality in lakes is done by [9], [10] and [11]. The great majority of the works deal with water monitoring without mentioning a specific application but with the concern of the preservation of aquatic life and the quality of water for human consumption. [1], [2], [3], [12], [13], [14] and [15].

\section{$3 \quad$ Measured Parameters}

Several parameters are measured for water quality analysis depending on the purpose of the use of water, whether for human consumption, protection of aquatic life or control of dumping of waste. Among the parameters measured for water quality analysis, we highlight the $\mathrm{pH}$, electrical conductivity (EC), turbidity and dissolved oxygen (DO) for all the works, as shown in table 1 . The only work that differed from the others in relation to the measured parameters is [5], which besides $\mathrm{pH}$ measured parameters such as TDS, total hardness, chloride, nitrate, fluoride, $\mathrm{Fe}$, calcium and magnesium due to their specific application in a minning district. 
Table 1. Measured parameters

\begin{tabular}{|c|c|c|c|c|c|}
\hline $\mathrm{pH}$ & Temp. & Turb. & EC & DO & Work \\
\hline$\bullet$ & $\bullet$ & & $\bullet$ & $\bullet$ & {$[9],[10],[11]$} \\
\hline$\bullet$ & $\bullet$ & $\bullet$ & & & {$[4],[3]$} \\
\hline$\bullet$ & & $\bullet$ & $\bullet$ & & {$[2],[14]$} \\
\hline$\bullet$ & $\bullet$ & & & $\bullet$ & {$[6],[8]$} \\
\hline$\bullet$ & & $\bullet$ & & $\bullet$ & {$[12]$} \\
\hline$\bullet$ & & $\bullet$ & & & {$[13],[15]$} \\
\hline$\bullet$ & $\bullet$ & & & & {$[1]$} \\
\hline & $\bullet$ & & & $\bullet$ & {$[7]$} \\
\hline
\end{tabular}

The parameter $\mathrm{pH}$ is present in the great majority of cases.

\section{$4 \quad$ System Architecture}

The most used architecture in a wireless sensor network is composed of one or more sensor nodes and one gateway node (also named sink node). The water parameters are read by the sensors connected to the sensor node that transmits via radio to the gateway node. The gateway node receives and processes this data that can be viewed on-site or is transmitted to a remote station or to a web server. The gateway sensor may in some cases also operate as a web server depending on its processing capacity and internet connectivity in place. We will detail below the characteristics of the sensor nodes and the gateway node used in the analyzed works.

\section{5}

\section{Sensor Node}

The sensor node consists of sensors to measure water parameters, a radio transceiver for the wireless network communication, a microcontroller to control the circuit functions and interface the devices and a power supply.

\subsection{Sensors}

Sensors manufactured by Atlas Scientific [16] were used in [9], [1] and [10]. [9] and [1] used sensors to measure $\mathrm{pH}$ [17], EC [18] and DO [19] while [10] used only the $\mathrm{pH}$ sensor. For temperature measurement, the DS18B20 sensor, manufactured by Maxim [16] was used in [9], [1] and [7]. The other works did not detail the sensors used.

\subsection{Microcontroller}

In the research carried out, a great variety of microcontrollers were used in the construction of sensor node, as shown in Table 2. [12], [2] and [10] used Microchip PIC family microcontrollers. [4] used Cirronet's ZMN2405HP system-on-a-chip (SoC) [20] which is composed of an 8051 microcontroller from Intel together with the CC2430 transceiver from Texas Instruments. [9], [1] and [5] made use of the Arduino open 
$10^{\mathrm{TH}}$ International Conference on Sustainable EnERgy AND Environmental Protection (June $27^{\mathrm{TH}}-30^{\mathrm{RD}}, 2017$, Bled, Slovenia), WATER AND Air Quality R.Z. Sakiyama, P.H. Soares, L.B.R.Aylon \& C.M.G. Andrade: Water Quality Monitoring Using a Wireless Sensor Network - A Brief Review

platform, [1] and [5] used the UNO model and [9] used the MEGA model. [3] used an Marvell 88MZ100 SoC. [6] used a Texas EZ430-RF2500 SoC [21], based on the MSP430 microcontroller. [15] used an ATMega 328 microcontroller, the same one used in the Arduino platform. [14] used the Libelium Waspmote module. The other works did not mention the microcontroller models used.

Table 2. Sensor node microcontroller

\begin{tabular}{|c|c|}
\hline Microcontroller & Work \\
\hline Microchip PIC & {$[12],[2],[10]$} \\
\hline Arduino platform & {$[9],[1],[5]$} \\
\hline ATMega & {$[15]$} \\
\hline SoC & {$[4],[3],[6]$} \\
\hline
\end{tabular}

\section{$5.3 \quad$ System power supply}

Power supply is considered a great challenge for these systems, since it should operate in environments where there is no electricity available. The uses of batteries, or rechargeable batteries, together with solar panels are the solutions proposed and showed in Table 3. The use of $9 \mathrm{~V}$ batteries is proposed by [4], [1] and [5]. Rechargeable lithium polymer (Li-Po) batteries (3.7V - 6Ah) are used by [10] and [9], the latter also use a $10 \mathrm{~W}$ solar panel for recharging the batteries. [15] uses of a $12 \mathrm{~V}$ battery and a solar panel. The module used by [14] has an internal battery with 1 to 5 years autonomy. [12] and [11] use batteries, without further details. Other work does not inform the type of power supply used, as in [3], [6], [2], [7] and [8]. As these devices are installed where electrical power is not accessible, the autonomy of the system becomes critical. This concern is considered by [11] who proposed energy rules to increase the autonomy of the sensor nodes. [4] reports the autonomy of 12 hours of the sensor node powered by a $9 \mathrm{~V}$ battery

Table 3. Types of power supply

\begin{tabular}{|c|c|}
\hline Power supply & Work \\
\hline Non-rechargeable battery & {$[4],[1],[5],[14]$} \\
\hline Rechargeable Li-Po batteries & {$[9],[10],[15]$} \\
\hline Solar Panel & {$[9],[14]$} \\
\hline
\end{tabular}

6 Wireless Network Devices

Most of the work analyzed used the Zigbee network to transmit the collected data. Differences from this standard are the works of [2] using transceivers operating in the $433 \mathrm{MHz}$ band, [13] using radio modules without specifying them and [6] that although the transceivers operate at $2.4 \mathrm{GHz}$, they do not follow the Zigbee standard. The architecture of the wireless sensor network used in the reviewed works is the cluster tree, where we have several sensor nodes sending information to only one gateway node, although only [4] inform this configuration. The data security of the wireless sensor network is of extreme importance in order to avoid that values measured by the sensor 
nodes are correctly reported to the gateway node. The Zigbee protocol, developed by Zigbee Alliance, used by most of the reviewed works, has the ability to encrypt the transmitted messages, allowing a high level of security of the data of the network, according to its developers.

\section{$7 \quad$ Gateway Node}

The gateway node or sink node consists of a radio transceiver for the wireless network, a computer system capable of processing the data received from the sensor nodes and a power supply. In some cases, the data is showed on a display installed on gateway node or transmitted to another station or web server, via wifi, GSM, GPRS or another way of long-range radio communication. The gateway node using only a Zigbee transceiver connected a personal computer is used by [4], [12], [1] e [15]. [9] and [5] use Arduino Uno, [10] used PIC16F877A, [7] used Raspberry Pi, [2] used LPC2148 ARM processor and [6] used Texas EZ430-RF2500 SoC. Table 4 gives a view of the gateway node processor.

Table 4. Gateway node hardware

\begin{tabular}{|c|c|}
\hline Hardware & Work \\
\hline Personal Computer & {$[4],[12],[1],[15]$} \\
\hline Arduino platform & {$[9],[5]$} \\
\hline PIC microcontroller & {$[10]$} \\
\hline Raspberry Pi & {$[7]$} \\
\hline ARM processor & {$[2]$} \\
\hline SoC & {$[6]$} \\
\hline
\end{tabular}

The use of a GPRS/GSM module in the gateway node is done by [9], [6], [10] and [11]. [5] uses a wifi module on the gateway node to transmit data to devices connected to wifi network. [2] and [13] designate the gateway node as a local station and use an Xbee module to transmit its data to a remote station. Table 5 gives a view of the gateway node resources.

Table 5. Gateway node resources

\begin{tabular}{|c|c|}
\hline Resource & Work \\
\hline GPRS/GSM module & {$[9],[6],[10],[11]$} \\
\hline Wifi module & {$[5]$} \\
\hline Xbee & {$[2],[13]$} \\
\hline
\end{tabular}

\section{$8 \quad$ Data Management}

The management of the data obtained by the sensor nodes, that is, the way these data are processed, presented and stored are of great importance to the system. This represents the type of service offered by the system to the responsible agencies for maintaining water quality, as well as for the general public. Depending on the configuration of the gateway 
$10^{\mathrm{TH}}$ InTERNATIONAL CONFERENCE ON SuSTAINABLE ENERGY AND ENVIRONMENTAL Protection (June $27^{\mathrm{TH}}-30^{\mathrm{RD}}, 2017$, Bled, Slovenia), WATER AND Air Quality R.Z. Sakiyama, P.H. Soares, L.B.R.Aylon \& C.M.G. Andrade: Water Quality Monitoring Using a Wireless Sensor Network - A Brief Review

node, it can assume that task, as in [4], [12], [1] and [15] that used a PC. [4] used the Borland $\mathrm{C}++$ builder programming environment where in the initial screen, the network is visualized. By clicking a sensor node of the network, the parameters measured by this node is shown in real time, matching with the parameter quality indicator (LQI). [12] used Matlab to view the data and the MS Excel database for storage. [1] used the Phyton language for this processing and [15] did not detail the language or the programming environment used. In the case of gateways that are built with microcontrollers with high processing capacity, they can also perform these tasks, as in the case of [6] that used Visual Basic and [2] that used Matlab. [9] presents the data graphically using MySQL, PHP HTML and Java. [5] also used MySQL and a webpage with graphical API to display the data.

\section{$9 \quad$ Particularities of Each Work}

In this section we describe the characteristics of systems found in individual works. In [4] the autonomy of the battery of $9 \mathrm{~V}$ for sensor node power had autonomy of 12 hours and the communication range of the sensor node with the gate node was 10 to $50 \mathrm{~m}$. The lower cost of the proposed solution in relation to the cost of a commercial solution was highlighted in [9]. The emphasis of the project in [3] was the use of algorithms to detect abrupt variations of measurements using KPCA (Kernel Principal Component Analyzes) and DLM (Deep learn Machime). The system proposed by [6], [2] and [8] emits an alert via SMS if the readings performed are outside pre-established patterns. In [5] there is the availability of data on the Internet for public consultation. [7] obtains the DO parameter indirectly, that is, we use equations for $\mathrm{DO}$ determination from the temperature reading. [15] emphasizes that the measurements obtained by the system showed little difference in relation to the measurements obtained by conventional procedures.

\section{Conclusion}

In this article, we provide a brief review on water quality monitoring systems using wireless sensor network. The services offered constitute a fundamental part of the system by providing real-time information and issuing alerts when water quality is out of tolerance allowed. This is done by [2], [5], [6] and [8]. Although only three works [4], [3] and [6] use SoC devices, there is a very great tendency in the use of these devices, as it makes the design more compact and tends to have lower consumption, increasing the autonomy. The use of wireless sensor networks for monitoring water quality has increased in recent years. Projects with different configurations using different components for different purposes may be idealized, but some characteristics common to all of them should be taken into account, such as system autonomy, security in the transmission of collected data and the services offered by the system. 
$10^{\text {TH }}$ INTERNATIONAL CONFERENCE ON SUSTAINABLE ENERGY AND ENVIRONMENTAL 45 Protection (June 27 $7^{\mathrm{TH}}-30^{\mathrm{RD}}, 2017$, Bled, SLovenia), WATER AND Air QuAlity R.Z. Sakiyama, P.H. Soares, L.B.R.Aylon \& C.M.G. Andrade: Water Quality Monitoring Using a Wireless Sensor Network - A Brief Review

\section{References}

[1] C. E. H. Curiel, V. H. B. Baltazar, and J. H. P. Ramirez, "Wireless Sensor Networks for Water Quality Monitoring: Prototype Design", International Journal of environmental, Chemical, Ecological, Geological and Geophysical Engineering, vol. 10, no. 2, pp. 158163, 2016.

[2] M. Barabde and S. Danve, "Real Time Water Quality Monitoring System", International Journal of Innovative Research in Computer and Communication Engineering, vol. 3, Issue 6, pp. 5064-5069, Jun. 2015.

[3] P. Tidke and S. Mozarkar, "Environmental Water Pollution Based Abrupt Event Monitoring - A Survey", International Journal of Computer Science and Network, vol. 3, pp. 48-54, Feb. 2014.

[4] Z. Rasin, M. R. Abdullah, and M. H. C. Hasan, "Application and Evaluation of High Power Zigbee Based Wireless Sensor Network in Water Quality Monitoring System", presented at the $2^{\text {nd }}$ International Conference on engineering and ICT, Melaka, Malaysia, 2010, pp. 570-574.

[5] B. K. Rao, A. S. N. Chakravarthy, M. J. Rao, and G. R. Rao, "Design of WSN based Water Quality Monitoring System in a Mining District", International Journal of Science and Research, vol. 5, Issue 6, pp. 1183-1188, Jun. 2016.

[6] N. S. Haron, M. K. Mahamad, I. A. Aziz, and M. Mehat, "Remote Water Quality Monitoring Systema using Wireless Sensor", proceedings of the $8^{\text {th }}$ WSEAS Int. Conf. on Electronics, Hardware, Wireless and Optical Communications, Cambridge, UK, pp.148154.

[7] N. M. Parmar and R. S. Goradia, "IEEE 802.15.4 Based Water Quality Monitoring System", International Journal of Advance Research and Innovative Ideas in Education, vol. , Issue 2, pp. 110-116, 2015.

[8] M. Zhang, D. Li, L. Wang, D. Ma, and Q. Ding, "Design and Development of Water Quality Monitoring System Based on Wireless Sensor Network in Aquaculture", International Conference on Computer and Computing Technologies in Agriculture, CCTA 2010: Computer and Computing Technologies in Agriculture IV, Nanchang, China, 2010, pp 629-641.

[9] A. Faustine and A. N.Mvuma, "Ubiquitous Mobile Sensing for Water Quality Monitoring and Reporting within Lake Victorua Basin", Wireless Sensor Network, vol. 6, pp.257-264, Dec. 2014.

[10] K. Karuppasamy, B. Abinaya, R. Sudha, and J. P. ArunPrasath, "Water Quality Monitoring and Control Using Wireless Sensor Networks", International Journal of Engineering and Technology, vol. 3, Issue 3, pp. 1202-1206, Mar. 2016.

[11] X. Huang, J. Yi, S. Chen, and X. Zhu, "A Wireless Sensor Network-Based Approach with Decision Support for Monitoring Lake Water Quality", Sensors, 15, pp. 29273-29276, Nov. 2015.

[12] B. John and S. Muruganand, "Wireless Sensor Technology for Water Quality Monitoring", International Journal of Advanced Research in Biology Ecology Science and Technology, vol. I, Special Issue IV, pp. 7-10, Dec. 2015.

[13] M. A. Ambekar and K. S. Ingle, "Remote Area Water Quality Observation Using Aigbee and Solar Power", International Journal of Innovative Research in Computer and Communication Engineering, vol. 4, Issue 10, pp.18827-18831, Oct. 2016.

[14] M. Pule, A. Yahya, abd J. Chuma, "A Wireless Sensor Network Solution for Monitoring Water Quality in Botswana", presented at $3^{\text {rd }}$ National Foundation for Science and Technology Development Conference on Information and Computer Science, Danang City, Vietnam, 2016, pp. 12-16. 
$10^{\text {Th }}$ International Conference on Sustainable Energy and Environmental Protection (June $27^{\mathrm{TH}}-30^{\mathrm{RD}}, 2017$, Bled, Slovenia), WATER AND Air Quality

R.Z. Sakiyama, P.H. Soares, L.B.R.Aylon \& C.M.G. Andrade: Water Quality Monitoring Using a Wireless Sensor Network - A Brief Review

[15] S. M. Gaulkar, G. R. Gidveer, "Zigbee Based Water Quality Monitoring System Using Solpar Power", International Journal of Research in Engineering and Technology, vol. 5, Issue 03, pp. 194-196, Mar. 2016.

[16] Maxim Semiconductor. DS18B20 Datasheet. Available at: https://datasheets.maximintegrated.com/en/ds/DS18B20.pdf (Accessed April 2017).

[17] Atlas Scientific. pH sensor kit. Available at: https://www.atlasscientific.com/product_pages/kits/ph-kit.html (Accessed April 2017).

[18] Atlas Scientifc. Conductivity sensor kit. Available at: https://www.atlasscientific.com/product_pages/kits/ec_k1_0_kit.html (Accessed April 2017).

[19] Atlas Scientific. Dissolved oxygen kit. Available at: https://www.atlasscientific.com/product_pages/kits/do_kit.html (Accessed April 2017).

[20] Cirronet. ZMN2405HP Datasheet. Available at: http://pdf.datasheet.live/d4372336/rfm.com/ZMN2405HP-E.pdf (Accessed April 2017).

[21] Texas Instruments. EZ430-RF2500 Module. Available at: http://www.ti.com/tool/EZ430RF2500?keyMatch=EZ430-RF2500\&tisearch=Search-EN-Everything (Accessed April 2017). 
$10^{\mathrm{TH}}$ InTERnational CONFEREnCE ON Sustainable ENERgy AND ENVIRONMENTAL PRotection (June $27^{\mathrm{TH}}-30^{\mathrm{RD}}$, 2017, BLed, SLOVENIA), WATER AND AIR QuALITY

J. Krope, A.Ghani Olabi, D. Goričanec \& S. Božičnik

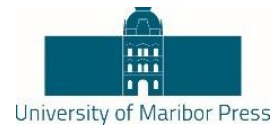

\title{
Effects of Climate Change on the Health of Citizens Modelling Urban Weather and Air Pollution
}

\author{
Roberto SAn José, JuAn L. PÉRez, Libia PÉReZ \& Rosa MARIa GonZalez Barras
}

\begin{abstract}
A dynamical downscaling tool has been implemented to know the impacts of the global climate on citizen health. The tool produces very high spatial (50 meters) and temporal (1 hour) resolution air quality and meteorological data to estimate the short term health impacts, using exposure-response functions extracted from epidemiological studies. Also, the corresponding economic cost based on the value of a statistical life and the cost of illness concepts is shown. The most popular possible IPCC global climate scenarios (RCP 4.5 low emissions and RCP 8.5 high emissions) have been considered for years 2030, 2050 and 2100. Future years are compared to 2011 conditions, keeping constant the anthropogenic emissions and the urban landscape to isolate the effects of the global climate. The effect of weather on health becomes more potent than exposure to concentrations of contaminants. Maps show how the effects depend of the city geometry.
\end{abstract}

Keywords: • health $\bullet$ climate $\bullet$ downscaling $\bullet$ impact $\bullet$ urban $\bullet$

CorRespondence AdDress: Roberto San José, Ph D., Professor, Technical University of Madrid (UPM), Environmental Software and Modelling Group, Computer Science School, Madrid, Spain, e-mail: roberto@fi.upm.es. Juan L. Pérez, Ph D., Professor, Technical University of Madrid (UPM), Environmental Software and Modelling Group, Computer Science School, Madrid, Spain, e-mail: jlperez@fi.upm.es. Libia Pérez, Ph D., Professor, Technical University of Madrid (UPM), Environmental Software and Modelling Group, Computer Science School, Madrid, Spain, e-mail: lperez@fi.upm.es. Maria Gonzalez Barras, Ph D., Professor, Technical University of Madrid (UPM), 2Department of Physics and Meteorology, Faculty of Physics, Complutense, Ciudad Universitaria, 28040 Madrid, Spain, e-mail: rgbarras@gmail.com.

https://doi.org/10.18690/978-961-286-064-6.6 ISBN 978-961-286-064-6

(C) 2017 University of Maribor Press

Available at: http://press.um.si. 
$10^{\mathrm{TH}}$ INTERNATIONAL CONFERENCE ON Sustainable ENERGy AND ENVIRONMENTAL Protection (June $27^{\mathrm{TH}}-30^{\mathrm{RD}}, 2017$, Bled, Slovenia), WATER AND Air Quality

R. San José, J. L. Pérez, L. Pérez \& R. Maria Gonzalez Barras: Effects of Climate Change on the Health of Citizens Modelling Urban Weather and Air Pollution

Air pollution and extreme temperatures can affect to the human health by modifying the rates of mortality and morbidity [1]. Resilience strategies to avoid the effects of climate change on health locally in a great challenge that should help the scientific community [2]. Cities are the areas where the expected response to global change is more important [3], recent studies have suggested that global climate change will have a significant impact on both the local climate and urban air quality [4]. Urban weather patterns and air pollution are heavily influenced by topography, land use, buildings, etc. so the studies of urban areas need information with very high spatial resolution to capture the spatial and temporal variability of meteorological conditions and air pollution in a city [5]. In previous studies on climate change and human health, they have been used projections of global climate models or regional climate models (RCMs) [6], [7] and [8], but few studies have used the results of a dynamic downscaling, using very high spatial resolution data to analyse local health impacts of climate change for cities. Recent scientific advances in computer science and the atmosphere, particularly in the use of dynamic scaling techniques, as well as the availability of computational resources, have opened up new opportunities for research climate-air pollution-related health consequences at city levels [9].

\section{$2 \quad$ Dynamical Downscaling}

Atmospheric flows and therefore the microclimate of cities are influenced by theirs urban characteristics, which further increase the atmospheric turbulence, thereby modifying the transport, dispersion and deposition of atmospheric pollutants [10]. In order to take all these phenomena into account in the most realistic way possible, we have chosen a dynamic downscaling process using numerical models of climate and air quality at the regional and urban levels that constitute the state of the art in computational modeling (WRF/Chem [11]). In addition, we have included a computational model of fluid dynamics (CFD) to take into account the effects of buildings, ventilation and shading effects that are so important in an urban environment. Future simulations were carried out with current emissions to isolate the effects of climate change. Emissions are generated with a mixed top-down and bottom-up approach using specific local city data (population, traffic and landuses) that are included in the EMIMO emissions model [12]. The description and evaluation of the dynamical downscaling method was published already, for detailed information; refer to publication [13].

\section{$3 \quad$ Health Impact Assessment}

Future projections of $\mathrm{O} 3$ and $\mathrm{PM}$ have been chosen because of their importance to public health from the air quality point of view and heat waves and apparent temperature from the meteorological point of view [14]. The equation (1) [15] is the formula applied in this study: 
$10^{\text {TH }}$ INTERNATIONAL CONFERENCE ON SUSTAINABLE ENERGY AND ENVIRONMENTAL Protection (June 27 $7^{\mathrm{TH}}-30^{\mathrm{RD}}, 2017$, Bled, SLovenia), WATER AND Air Quality

R. San José, J. L. Pérez, L. Pérez \& R. Maria Gonzalez Barras: Effects of Climate Change on the Health of Citizens Modelling Urban Weather and Air Pollution

$\Delta M=K^{*}\left(e^{\beta \Delta c}-1\right) * P$

Where $\Delta \mathrm{M}$ is the change in the health outcome because changes in an environmental factor (temperature, number of heat waves or air concentrations), $\mathrm{K}$ is the baseline mortality or morbidity rate, $\beta$ is the log relative risk associated with a change in the exposure to the environmental factor which can be calculated in epidemiological studies, $\Delta \mathrm{C}$ is the estimated change in the environmental factor (future-present) and $\mathrm{P}$ is the exposed population in the present (2011). Also $\mathrm{K}$ and $\beta$ are fixed to the 2011 values to isolate only the climate impacts, so in our study uses a constant population and mortality rate over time like other studies [16].

Several health effects or outcomes are calculated for mortality and morbidity: All causes mortality, cardiovascular mortality, respiratory mortality, respiratory hospital admissions and cardiovascular hospital admissions. These outcomes are for all ages, except in case of the heat waves where mortality +65 years old are calculated. The short-term health effects of the heat are analyzed based on two exposure variables: Apparent Temperature (AT) and Heat waves (HW). Only summer months (June-August) are considered to study the health effects of the heat waves days. For PM10 the exposure indicator is the daily mean and for ozone we used the daily maximum 8-hour average. Mortality and morbidity rates ( $\mathrm{K}$ in the equation 1 ) has been extracted from European mortality database of the WHO and the European Hospital Morbidity Database of the WHO by countries.

\subsection{Economic model}

Estimates of the economic costs can be used in cost-benefit analysis for the comparison of adaptation strategies [17]. Monetary estimates of changes in premature mortality risk are often expressed in terms of the Value of a Statistical Life (VSL). We have available data from the meta-analysis of VSL studies. In the case of estimating the cost of morbidity, the total value to society of an individual's avoidance of a hospital admission has a principal component: the cost of illness (COI) The Cost of Illness metric summarizes the expenses that an individual must bear for hospital admissions. The Unit values available for Hospital admissions are: Cardiovascular: \$26,123 and Respiratory: $\$ 19,612$. Unit values are based on ICD-code-specific estimated hospital charges and the opportunity cost of time spent in the hospital (based on the average length of a hospital stay for the illness). The opportunity cost of a day spent in the hospital is estimated as the value of the lost daily wage, regardless of whether or not the individual is in the workforce. These values are used in the BENMAP software and they are based on discharge statistics provided by the Agency for Healthcare Research and Quality's Healthcare Utilization Project National Inpatient Sample (NIS) database (2007).

\section{$4 \quad$ Case Study}

We have applied the described tool to assess the potential future changes of mortality and morbidity and theirs respective economic costs over the area of Kensington and Chelsea 
$10^{\mathrm{TH}}$ INTERNATIONAL CONFERENCE ON SUSTAINABLE ENERGy AND ENVIRONMENTAL Protection (June $27^{\mathrm{TH}}-30^{\mathrm{RD}}, 2017$, Bled, Slovenia), WATER AND Air Quality R. San José, J. L. Pérez, L. Pérez \& R. Maria Gonzalez Barras: Effects of Climate Change on the Health of Citizens Modelling Urban Weather and Air Pollution

(K\&C), London. We use result with 50 meters of spatial resolution and one hour of temporal resolution for years 2011, 2030, 2050 and 2100 from the explained dynamical downscaling process. In this specific exercise, the impacts of the future three years 2100 , 2050 and 2030 will be studied against the base situation 2011. In order to describe the health effect of exposure variables on mortality and morbidity, the Table 1 gives the relative risk and mortality/morbidity rates used in the health impact assessment. For the economic calculations the estimated value VSL (2010) in US\$ is 3.55 million in UK.

Table 1. London, relative risks values for each exposure variables and reference

\begin{tabular}{|c|c|c|c|}
\hline Exposure Variable & Health Outcome & RR & $\begin{array}{c}\text { Mortality/ } \\
\text { Morbidity } \\
\text { rates }\end{array}$ \\
\hline PM10 daily average & All causes mortality & 1,00694 & 423.6 \\
\hline PM10 daily average & Cardiovascular mortality & 1,00551 & 125.77 \\
\hline PM10 daily average & Respiratory mortality & 1,00286 & 51.77 \\
\hline PM10 daily average & Respiratory hospital admisions & 1,00860 & 946.13 \\
\hline PM10 daily average & Cardiovascular hospital admisions & 1,00600 & 1103.97 \\
\hline $\mathrm{O} 3$ max mean $8 \mathrm{~h}$ & All causes mortality & 1,00310 & 423.6 \\
\hline $\mathrm{O} 3 \mathrm{max}$ mean $8 \mathrm{~h}$ & Cardiovascular mortality & 1,00672 & 125.77 \\
\hline $\mathrm{O} 3 \mathrm{max}$ mean $8 \mathrm{~h}$ & Respiratory mortality & 1,01250 & 51.77 \\
\hline $\mathrm{O} 3$ max mean $8 \mathrm{~h}$ & Respiratory hospital admisions & 1,00300 & 946.13 \\
\hline Apparent temperature $\max >23.9^{\circ} \mathrm{C}$ & All causes mortality & 1,01540 & 423.6 \\
\hline Apparent temperature $\max >23.9^{\circ} \mathrm{C}$ & Cardiovascular mortality & 1,02440 & 125.77 \\
\hline Apparent temperature $\max >23.9^{\circ} \mathrm{C}$ & Respiratory mortality & 1,06100 & 51.77 \\
\hline Apparent temperature $\mathrm{P} 90>24.6^{\circ} \mathrm{C}$ & Respiratory hospital admisions & 1,01700 & 946.13 \\
\hline Days of heat waves* & All causes mortality +65 & 1,10400 & 2774.73 \\
\hline Days of heat waves waves * & Cardiovascular mortality +65 & 1,09300 & 922.49 \\
\hline Days of heat waves waves * & Respiratory mortality +65 & 1,18000 & 403.04 \\
\hline
\end{tabular}

$*(\operatorname{Tmin}>16,8$ or Atmax $>27,1$ 


\subsection{Climate scenarios}

In the simulations we have used boundary conditions from two Representative Concentration Pathways (RCPs), RCP 4.5 [18] and RCP 8.5 [19] defined by the IPCC (Intergovernmental Panel on Climate Change) institution in the Fifth Assessment Report (AR5). The IPCC report [20] identifies up to four climate scenarios. Of the four possible climatic scenarios available, we have selected the two scenarios most used by the scientific community. They represent the two extremes in terms of greenhouse gas emissions. On one hand we have the worst scenario (RCP 8.5) and on the other the best realistic scenario (RCP 4.5). The selection of the two extremes was motivated with the only objective of showing extreme changes that can be predicted at city level.

\section{$5 \quad$ Results}

In table 2, we present the economic cost associated to the climate impact for a 50 meters mean grid cell for years 2030, 2050 and 2100 for a mean grid cell of 50 meters by 50 meters located on Kensington and Chelsea.

The major impacts will occur at 2100. For this year, the emission reduction strategies (scenario RCP 4.5) will reduce the health cost, but if the future is close to the RCP 8.5 scenario, the citizens will suffer important health problems. The increment of the annual cost for hospital admission for year 2100 respect to the 2011 could be up to $11669 \$$ in the RCP 8.5 climate scenario and $1362 \$$ in the RCP 4.5 for an average grid cell of the domain. For the mortality costs could be increments of $963.9 \mathrm{~K} \$$ in RCP 8.5 and decrements of 73.8 for RCP 4.5. Heat is the environmental factor which causes these increments in the RCP 8.5 whilst in the RCP 4.5 the health effects for $\mathrm{O} 3$ exposure and number of heat waves will be decreased. The total annual cost of the climate change could be up to $1 \mathrm{~K} \$ / \mathrm{m} 2$ with the climate scenario RCP 8.5 and we can save up to 0.22 $\mathrm{K} \$ / \mathrm{m} 2$ if the global climate scenario RCP 4.5 is present in the year 2100 . 
$52 \quad 10^{\mathrm{TH}}$ INTERNATIONAL CONFERENCE ON Sustainable ENERGy AND ENVIRONMENTAL Protection (June $27^{\mathrm{TH}}-30^{\mathrm{RD}}, 2017$, Bled, Slovenia), WATER AND Air Quality

R. San José, J. L. Pérez, L. Pérez \& R. Maria Gonzalez Barras: Effects of Climate Change on the Health of Citizens Modelling Urban Weather and Air Pollution

Table 2. Monetary estimates of the 2100 annual health costs due to climate change's effects on $\mathrm{K} \& \mathrm{C}$ for 50 meters

\begin{tabular}{|c|c|c|c|c|c|c|c|c|}
\hline \multirow{2}{*}{\multicolumn{3}{|c|}{ Mean $50 \mathrm{~m}$. grid cell }} & \multicolumn{6}{|c|}{ Kensington and Chelsea } \\
\hline & & & \multicolumn{2}{|c|}{2030} & \multicolumn{2}{|c|}{2050} & \multicolumn{2}{|c|}{2100} \\
\hline \multirow{2}{*}{ Outcome } & \multirow{2}{*}{ Cause } & \multirow{2}{*}{ Factor } & $\mathrm{RCP}$ & $\mathrm{RCP}$ & RCP & $\mathrm{RCP}$ & $\mathrm{RCP}$ & $\mathrm{RCP}$ \\
\hline & & & 4.5 & 8.5 & 4.5 & 8.5 & 4.5 & 8.5 \\
\hline \multirow{4}{*}{$\begin{array}{c}\text { Hopspital } \\
\text { Cost } \\
(2000 \$)\end{array}$} & Resp. & ATP90 & 2620,1 & $-4525,1$ & 971,5 & 1458,8 & 1362,5 & 11669,8 \\
\hline & Resp. & PM10 & $-1448,5$ & $-196,3$ & $-409,3$ & $-1705,9$ & 5153,9 & $-777,8$ \\
\hline & Resp. & $\mathrm{O} 3$ & $-856,1$ & $-723,9$ & $-899,9$ & 423,6 & $-4417,7$ & $-594,9$ \\
\hline & Cardio & PM10 & -1627 & $-263,2$ & $-502,4$ & -1898 & 5530,1 & $-887,5$ \\
\hline \multirow{12}{*}{$\begin{array}{c}\text { Mortality } \\
\text { Cost } \\
(2000 \mathrm{~K} \$)\end{array}$} & All +65 & H. Waves & 298,5 & $-957,7$ & 125,8 & -418 & -245 & 411,4 \\
\hline & Cardio & H. Waves & 88,6 & $-284,4$ & 37,6 & $-124,1$ & $-72,9$ & 122,8 \\
\hline & Resp. & H. Waves & 75,7 & $-242,5$ & 30,6 & $-106,4$ & $-61,4$ & 100,7 \\
\hline & All & ATMAX & 211,7 & $-468,9$ & 111,1 & 139,7 & 79,8 & 963,9 \\
\hline & Cardio & ATMX & 102 & $-223,4$ & 53,5 & 68,7 & 39,7 & 473 \\
\hline & Resp. & ATMAX & 115,9 & $-242,2$ & 60,6 & 84,8 & 51,1 & 581 \\
\hline & All & PM10 & $-96,9$ & $-14,8$ & -29 & $-113,4$ & 334,8 & $-52,6$ \\
\hline & Cardio & PM10 & $-23,3$ & $-3,9$ & $-7,3$ & $-27,1$ & 78,5 & $-12,7$ \\
\hline & Resp. & PM10 & $-5,2$ & -1 & $-1,7$ & $-5,9$ & 16,6 & $-2,9$ \\
\hline & All & $\mathrm{O} 3$ & $-71,6$ & $-60,6$ & $-75,3$ & 35,5 & $-369,9$ & $-49,8$ \\
\hline & Cardio & $\mathrm{O} 3$ & $-44,7$ & $-37,7$ & $-47,2$ & 24,1 & $-235,9$ & $-30,6$ \\
\hline & Resp. & O3 & $-32,6$ & $-27,4$ & $-34,6$ & 19,9 & $-178,1$ & $-21,7$ \\
\hline
\end{tabular}

The next figures show the spatial distribution of annual total costs due to premature mortality by changes in the daily maximum apparent temperature for year 2100 under two possible climate scenarios RCP 4.5 (Figure 1) and RCP 8.5 (Figure 2) over $2 \mathrm{~km}$ by $2 \mathrm{~km}$ area of Kensington and Chelsea. The economic cost is close to ten times greater in the RCP 8.5 than in the RCP 4.5. The purple areas (parks and water bodies) are zones where there are not people living, so nobody is exposed to the environmental factors Areas with a high density of buildings and population are the most affected by climate change. The figures identify also several hot spots where the cost of the climate change could be up to $0.88 \mathrm{~K} \$ / \mathrm{m} 2$ and zones very close to the hot spots where cost is only 0.28 
$\mathrm{K} \$ / \mathrm{m} 2,30 \%$ less, this situation is observed along the for example the same street. These results shown that it is very important to get health impacts with very high spatial resolution over urban areas.

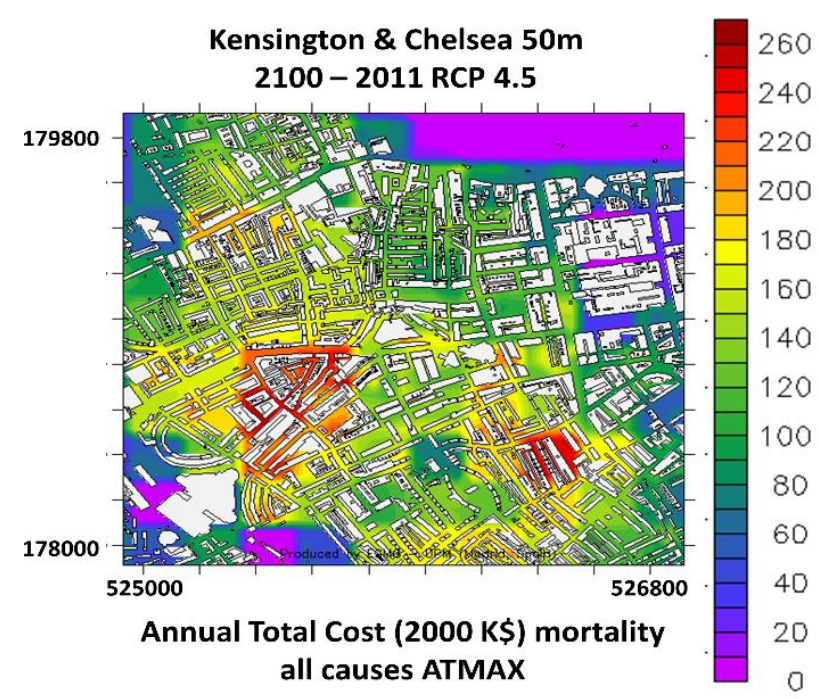

Figure 1.: Spatial distribution of the differences in annual total cost (2000 K\$) mortality for 2100 respect to 2011 following RCP 4.5 scenarios with $50 \mathrm{~m}$. of spatial resolution over Kensington and Chelsea.

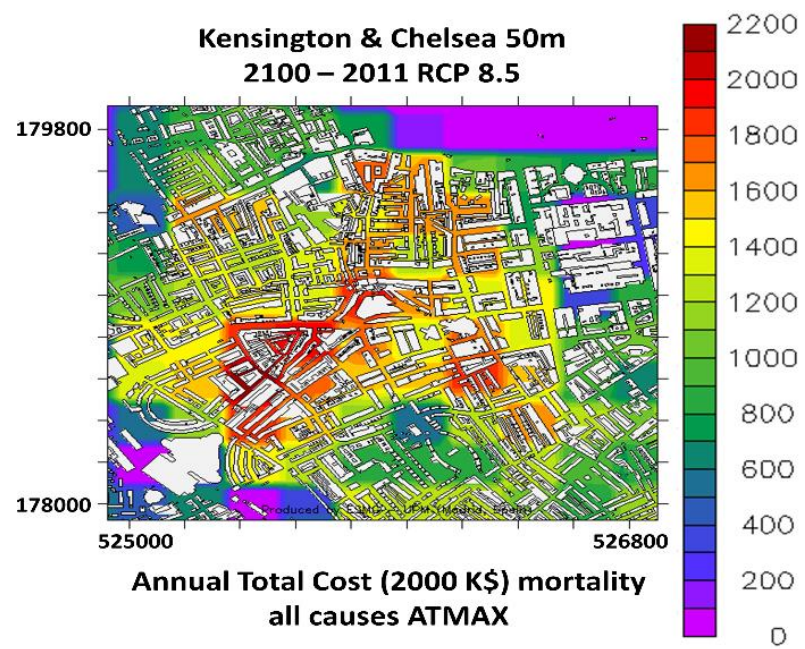

Figure 2. Spatial distribution of the differences in annual total cost (2000 K\$) mortality for 2100 respect to 2011 following RCP 8.5 scenarios with $50 \mathrm{~m}$. of spatial resolution over Kensington and Chelsea. 
$10^{\mathrm{TH}}$ InTERnAtional CONFERENCE ON Sustainable ENERgy AND ENVIRONMENTAL Protection (June $27^{\mathrm{TH}}-30^{\mathrm{RD}}, 2017$, Bled, Slovenia), WATER AND Air Quality

R. San José, J. L. Pérez, L. Pérez \& R. Maria Gonzalez Barras: Effects of Climate

Change on the Health of Citizens Modelling Urban Weather and Air Pollution

\section{Conclusions}

This paper presents a tool to estimate the cost of the impact of global climate change on human mortality and morbidity by changes of high temperatures and air pollution concentrations. The tool is an integrated modeling framework for assessing potential public health impacts of climate changes at the urban scale. The integrated framework facilitates projections of climate and related health impacts at temporal and spatial scales relevant to urban planning. It was applied over Kensington and Chelsea, London using very high spatial resolution information, 50 meters. We have considered two climate projections, which were based on two IPCC climate scenarios: RCP 8.5 and RCP 4.5. Inputs to the health impact assessment have been produced applying a dynamical downscaling process which includes a regional and CFD numerical models with high demand exercise for computational resources. The procedure and scheme described and applied in this work is totally portable to other cities. You would only need to adjust the model parameters and use the input data of the city to simulate. The larger increase of costs of mortality and morbidity was noted in the increasing scenario (RCP8.5) than the stabilization scenario (RCP4.5), because RCP 8.5 is known by temperature increments. With these simulations of high spatial resolution, we have been able to observe that the influence of buildings is very important in order to detect hot spots or sensitive areas to be affected by global climate change. It is important to recognize that there are many uncertainties in any effort to quantify the human health and economic impacts of climate change over the cities because there are model uncertainties in both economic and atmospheric simulations that are difficult to quantify. The results from this study could be usable by local authorities and stakeholders for assisting in developing better polices on health protections and balancing policy decisions. This study may enhance current understanding of climate change problems related to human health in the cities.

\section{Acknowledgements}

The UPM authors acknowledge the computer resources and technical assistance provided by the Centro de Supercomputación y Visualización de Madrid (CeSViMa). The UPM authors thankfully acknowledge the computer resources, technical expertise and assistance provided by the Red Española de Supercomputación.). We acknowledge the DECUMANUS EU project from EU Space Call FP7-SPACE-2013-1 at SPA.20131.1-06. Ordnance Survey data for London: (C) Crown copyright and database rights 2015 OS 100021668.

\section{References}

[1] M. Medina-Ramón and J. Schwartz , "Temperature, temperature extremes, and mortality: a study of acclimatisation and effect modification in 50 US cities," Occup Environ Med 64:827-833, 2007.

[2] S. Hajat and T. Kosatsky , "Heat-related mortality: a review and exploration of heterogeneity," J Epidemiol Community Health 64(9):753-760, 2010.

[3] K.W. Oleson,, A Monaghan, O. Wilhelmi , M. Barlage , N. Brunsell , J. Feddema , L. Hu , and D. F. Steinhoff, "Interactions between urbanization, heat stress, and climate change," Climatic Change, 129, 525-541, 2010. 
[4] L.J. Mickley, D.J. Jacob, B.D. Field and D. Rind, "Effects of future climate change on regional air pollution episodes in the United States”, Geophys. Res. Let.; 31, L24103, 2004.

[5] M. Valari and L. Menut, "Does an increase in air quality models' resolution bring surface ozone concentrations closer to reality?," J. Atmos. Ocean. Tech.; 25, 1955-1968, 2008.

[6] HH Shin, DM Stieb, B. Jessiman , MS. Goldberg, O. Brion, J. Brook, T. Ramsay and RT Burnett, "A temporal, multicity model to estimate the effects of short-term exposure to ambient air pollution on health," Environ Health Perspect 116:1147-1153, 2008.

[7] R. Basu and BD Ostro, "A multicounty analysis identifying the populations vulnerable to mortality associated with high ambient temperature in California," Am J Epidemiol 168:632-637, 2008.

[8] W. Hu, K. Mengersen, A. McMichael and S. Tong, "Temperature, air pollution and total mortality during summers in Sydney, 1994-2004,” Int J Biometeorol 52:689-696, 2008

[9] C. Rosenzweig, W Solecki, SA. Hammer and S. Mehrotra, "Cities lead the way in climatechange action," Nature 467: 909-911, 2010.

[10] M. Piringer, E. Petz, I. Groehn, and G. Schauberger , "A sensitivity study of separation distances calculated with the Austrian Odour Dispersion Model (AODM)," Atmospheric Environment, pp.41, 725-1735, 2007.

[11] Grell GA, SE Peckham, R Schmitz, and SA McKeen, G Frost, WC Skamarock, and B Eder. Fully coupled 'online' chemistry in the WRF model. Atmos. Environ., 39, 2005, 6957-6976

[12] San Jose R, Juan L. Perez, Jose L. Morant, Rosa M. Gonzalez, European operational air quality forecasting system by using MM5-CMAQ-EMIMO tool, Simulation Modelling Practice and Theory, Volume 16, Issue 10, 2007

[13] R. José, J. Pérez, L. Pérez, R. González, J. Pecci, A. Garzón and M. Palacios, “Impacts on the Urban Air Quality and Health of Global Climate Scenarios Using Different Dynamical Downscaling Approaches," Journal of Geoscience and Environment Protection, 4, 168174, 2016.

[14] KL. Ebi and G. McGregor, "Climate change, tropospheric ozone and particulate matter, and health impacts," Environ Health Perspect. 2008;116:1449-1455.

[20] D.P. Vuuren and Coauthors, "The representative concentration pathways: an overview," Clim. Change, 109, 5-31, 2011.

[15] HH. Chang, J. Zhou and M. Fuentes, "Impact of climate change on ambient ozone level and mortality in Southeastern United States," Int J Environ Res Public Health. 2010;7:2866-2880

[16] PE Sheffield, K. Knowlton, JL. Carr, PL. Kinne, “ Modeling of regional climate change effects on ground-level ozone and childhood asthma," Am J Prev Med. 2011;41(3):251257.

[17] G. Hutton, "The economics of health and climate change: key evidence for decision making," Global Health 7:18, 2011.

[18] IPCC. Climate Change, "The Physical Science Basis," Cambridge University Press: Cambridge, UK; New York, NY, USA, 2013

[19] A.M. Thomson and Coauthors, "RCP4.5: a pathway for stabilization of radiative forcing by 2100, , Clim. Change, 109, 77-94, 2011.

[20] K. Riahi and Coauthors, " RCP 8.5-A scenario of comparatively high greenhouse gas emissions," Clim. Change, 109, 33-57, 2011. 
$56 \quad 10^{\mathrm{TH}}$ International CONFERENCE on Sustainable ENERgy AND ENVIRONMENTAL Protection (June 27 $7^{\mathrm{TH}}-30^{\mathrm{RD}}, 2017$, Bled, Slovenia), WATER AND Air Quality 
$10^{\mathrm{TH}}$ InTERnational CONFERENCE ON Sustainable ENERgy AND ENVIRONMENTAL PRotection (June $27^{\mathrm{TH}}-30^{\mathrm{RD}}$, 2017, BLed, SLOVENIA), WATER AND AIR QuALITY

J. Krope, A.Ghani Olabi, D. Goričanec \& S. Božičnik

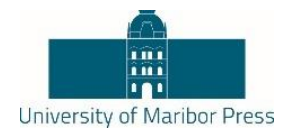

\title{
A Platform for Air Quality Monitoring Using Wireless Sensor Network - A Brief Review
}

\author{
Paulo Henrique SoAres, Rubens Z. SAKiyama \& Cid Marcos Goncalves \\ ANDRADE
}

\begin{abstract}
Due to the numerous problems caused by the emission of excess pollutant gases into the atmosphere, it has become essential that more effective monitoring of air quality is carried out, especially in public places and with a large circulation of people. In recent years, there have been numerous articles proposing air quality monitoring platforms, mainly formed by a wireless sensor networks, capable of operating at several points simultaneously for a certain period of time. However, when analyzing these works, it is observed that each of them has its main focus directed to a certain characteristic, such as sensor precision, autonomy, communication capacity, among others. In this context, this article will present a review of several air quality monitoring mechanisms based on wireless sensor networks, analyzing its architecture, with the objective of proposing a new and more efficient platform, merging the main characteristics raised.
\end{abstract}

Keywords: • greenhouse gases • air quality • wireless sensor network • monitoring platforms $\mathrm{CO} 2 \cdot$ platform $\bullet$

CORRESPONDENCE AdDRESS: Paulo Henrique Soares, master, adjunct teacher, Federal University Technological of Paraná, Computer Departament, Laura Pacheco Bastos street, 800 Guarapuava, Brazil, e-mail: paulosoares@utfpr.edu.br. Rubens Z. Sakiyama, master, teacher, State University of Maringá, Faculty of Chemical Engineering, Colombo Avenue, 5790 Maringá, Brazil, e-mail: rubens.uem@gmail.com. Cid Marcos Goncalves Andrade, Ph.D., Associate teacher, State University of Maringá, Faculty of Chemical Engineering, Colombo Avenue, 5790 Maringá, Brazil, e-mail: cidmga@yahoo.com.br. 
$10^{\mathrm{TH}}$ InTERnAtional CONFERENCE ON Sustainable ENERGy AND ENVIRONMENTAL Protection (June $27^{\mathrm{TH}}-30^{\mathrm{RD}}, 2017$, Bled, Slovenia), WATER AND Air Quality P.H. Soares, R.Z. Sakiyama \& C.M.G. Andrade: A Platform for Air Quality Monitoring Using Wireless Sensor Network - A Brief Review Introduction

According to data from the NOAA laboratory, located in the United States at more than 3,500 meters of altitude and considered one of the most reliable in the world, the concentration of carbon dioxide in the atmosphere reached for the first time in 2015, since measurements began to be made, the value of $400 \mathrm{ppm}$. This same laboratory indicates that the CO2 concentration was less than 320ppm in 1960 [1]. This significant increase was generated by a number of factors, but the burning of fossil fuels made by industry and automotive vehicles is considered one of the main causes of this worrisome number pointed out by the laboratory.

Considering that the emission of $\mathrm{CO} 2$ and several other toxic gases in the atmosphere are increasing annually, causing people to have a greater exposure to this type of pollution, it has become fundamental that a more effective monitoring of air quality is carried out periodically, especially in large cities, where the number of vehicles and industries are usually higher.

Following this trend, in recent years several research groups have emerged around the world with the central objective of developing an efficient way to monitor air pollution, especially by measuring carbon dioxide, which is a good indicator of air quality . Within this context, it is possible to find works that propose different monitoring platforms and technologies, which are differentiated by the number of resources, cost of construction, degree of precision of the results, among others. This article will analyze the main characteristics of these mechanisms, finally proposing the resources that a monitoring platform must have so that a more efficient air quality analysis can be performed.

\section{Monitoring Platforms}

Of the several research groups that are developing mechanisms for monitoring air quality, one of the highlights in this scenario is the so-called CitySee, located in Wuxi City, China, where pollution rates are alarming in much of the country. Through resources provided by the Chinese government, the researchers implemented a wireless sensor network consisting of 1196 nodes, being able to monitor in real time the levels of carbon dioxide, humidity and temperature. Due to the large number of nodes, one of the group's main goals is to develop protocols and tools capable of managing communication and data traffic over the network. The technology used in the construction of the sensor network is proprietary, leaving the final cost of the project high [2].

In contrast to CitySee, a Mexican research group, based at the University of Monterrey, developed a low-cost carbon dioxide monitoring platform using only free technologies, such as Arduino, MySQL, among others. In this case, the main objective is to monitor in real time the concentration of $\mathrm{CO} 2$ especially in the vicinity of the production lines present in the region's industries. A graphical interface was developed so that the information collected by the sensors can be visualized [3]. 
$10^{\text {TH }}$ INTERNATIONAL CONFERENCE ON SUSTAINABLE ENERGY AND ENVIRONMENTAL Protection (June 27 $7^{\mathrm{TH}}-30^{\mathrm{RD}}, 2017$, Bled, SLOVEniA), WATER AND Air QuAlity 59

P.H. Soares, R.Z. Sakiyama \& C.M.G. Andrade: A Platform for Air Quality Monitoring Using Wireless Sensor Network - A Brief Review

Another example of a mechanism for monitoring carbon dioxide in urban centers was proposed by a Canadian research group. In this project, sensors were implanted in the antennas of a certain group of automobiles, that when circulating through the city ended up forming a mobile network structure, with capacity to measure and store the concentration of $\mathrm{CO} 2$ in several distinct points of the city. Several tests were carried out in Vancouver, Canada, where it was possible to determine the air quality present in the central and outlying regions of the city [4]. A project very similar to this was also developed in China, with the difference that, in addition to cars, bicycles were also used in the monitoring of carbon dioxide. These equipment were tested in some Chinese cities, and critical points of $\mathrm{CO} 2$ concentration were found, reaching values close to $800 \mathrm{ppm}$ [5].

Some Brazilian capitals, concerned about the increase in the emission of polluting gases, have also been trying to implement air quality monitoring systems. The city of Recife, in partnership with a local university, deployed a platform capable of measuring air quality at some points considered critical of the city. To do this, a series of sensors perform measurements of the concentration of some gases and send them to a central, where the data is made available to the community through a website. However, a number of proprietary technologies were used, making the cost to install only 4 collection points close to $\$ 100,000$ [6].

\section{Analysis of Monitoring Platforms}

By analyzing the air quality monitoring platforms presented, some important points can be observed. Firstly, all the projects are formed by a network of sensors with capacity to monitor the quality of the air in several points. This feature is fundamental, since different regions of the same city may have totally different levels of pollution. These wireless sensor networks are elaborated in different ways, and their nodes can be fixed or formed by cars and even bicycles, which during their displacement already take measurements of carbon dioxide. However, managing the communication of a structure like this, where it is necessary to treat adverse situations, such as interferences and bad weather conditions for example, is a very complex activity, being the main focus of all the works illustrated in the previous section.

Another important point to be analyzed is the cost of developing the project, which can vary considerably depending on the components used. As an example of this variation we have the CitySee, which used proprietary technology to form its modern wireless sensor network. Thus, despite the excellent infrastructure of data collection, the cost to implement the project was high. The same happened with the Recife's project, in Brazil, which although efficient, exceeded the $\$ 100,000$ range, making it impossible for smaller cities and with fewer resources to acquire such equipment.

In contrast, there are numerous projects that aim to monitor the quality of air through a wireless sensor network, but keeping the cost of construction reduced. For this, only free and low cost components and technologies are used. This was the case of the project 
$10^{\mathrm{TH}}$ InTERnAtional CONFERENCE ON Sustainable ENERgy AND ENVIRONMENTAL Protection (June $27^{\mathrm{TH}}-30^{\mathrm{RD}}, 2017$, Bled, Slovenia), WATER AND Air Quality P.H. Soares, R.Z. Sakiyama \& C.M.G. Andrade: A Platform for Air Quality Monitoring Using Wireless Sensor Network - A Brief Review

developed at the University of Monterrey, which built its entire platform making use of free tools, such as the MySQL database and the Arduino microcontroller for example.

Comparing the characteristics of the various air quality monitoring platforms, it is clear that all of them have a specific focus, be it the cost reduction or the different forms of communication and construction of the wireless sensor network, but none of them have The main objective is the implementation of a tool or software that allows a more indepth analysis of the collected data, helping researchers and environmental engineers to have a better understanding of local pollution levels.

\section{Proposal for a Monitoring Platform}

Considering the main characteristics of the presented mechanisms, our research group is proposing and developing a new air quality monitoring platform, made exclusively with free technologies and low cost components. The project has a wireless sensor network capable of measuring carbon dioxide levels at several points simultaneously. In addition, as a differential of the platform, several query and analysis resources of the information collected are being implemented, as well as data mining mechanisms, which, through algorithms based on artificial intelligence, will be able to determine the air quality profile at points Monitored.

The project will have a central database server responsible for storing the concentrations of carbon dioxide collected by the sensor nodes. This structure enables the development of data mining and query tools, so that the most diverse types of information can be provided to environmental engineers and researchers, assisting them in planning the pollution control policies they will adopt.

\section{Conclusion}

Considering the increase in greenhouse gas emissions in recent years, as well as the need for strict monitoring of pollution levels, the main objective of this work was to carry out a comparative study among several recently published air quality monitoring platforms, analyzing its main characteristics and pointing out the potentialities and the failures. At the end of the study, it was found that the projects, despite being made up of modern wireless sensor networks, did not present mechanisms of consultation and advanced analysis of data, so that it could provide information capable of assisting the work of engineers and environmentalists. Because of this, our research group is proposing and developing an air quality monitoring platform that will fill this gap, making use primarily of data mining tools.

\section{References}

[1] NOAA. "National Oceanic and Atmospheric Administration", http://www.esrl.noaa.gov/. (current Mar. 5, 2017). 
[2] Xufei, Mao. Xin, Miao. Yuan, He. Xiang-Yang, Li. Yunhao, Liu. "CitySee: Urban CO2 Monitoring with Sensors". IEEE INFOCOM, EUA, 2012.

[3] Escorza, Victor. Guedea, Federico. "A Wireless Sensors Network Development for Environmental Monitoring using OPC Unified Architecture in a Generic Manufacturing System". International Conference on Mechatronics and Control (ICMC), China, 2014.

[4] J. Lee, A. Christen, R. Ketler, Z. Nesic. "A mobile sensor network to map carbon dioxide emissions in urban environments", Atmos. Meas. Tech, vol. 10, Mar. 2017.

[5] S. Hu, Y. Wang, C. Huang, Y. Tseng. " Measuring air quality in city areas by vehicular wireless sensor networks", Journal of Systems and Software, vol. 84, Nov. 2011.

[6] Oliveira, Manuely. Lacerda, Marcela. Lira, Max. "MonitorARecife: Solução para monitoramento da qualidade do ar". Unibratec, Recife, 2011. 
$62 \mid 10^{\mathrm{TH}}$ International CONFERENCE on Sustainable EnERgy AND ENVIRONMENTAL Protection (June 27 $7^{\mathrm{TH}}-30^{\mathrm{RD}}, 2017$, Bled, Slovenia), WATER AND Air Quality 
$10^{\mathrm{TH}}$ InTERnational CONFERENCE ON Sustainable ENERgy AND ENVIRONMENTAL PRotection (June $27^{\mathrm{TH}}-30^{\mathrm{RD}}$, 2017, BLed, SLOVENIA), WATER AND AIR QuALITY

J. Krope, A.Ghani Olabi, D. Goričanec \& S. Božičnik

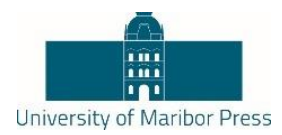

\title{
The Influence of Damaged Tubular Combustion Chamber on Smoke Particle Emissions at the Pellet Burners
}

\author{
ZdRAVko Praunseis, SEbastiJan SEME, BojAn ŠTuMbERGER \& MiraLEM \\ HADŽISELIMOVIĆ
}

\begin{abstract}
Wood-burning boilers are a popular source of heating in Slovenia. However in recent years there has been much debate about the potential negative health effects associated with wood smoke. Wood smoke is increasingly being seen as an important component of airborne particulate matter (PM), especially as the new sort time standard for fine particles in ambient air. During good combustion conditions with sufficient oxygen supply and high temperature, most of the organic substances will be burnt in the boilers. In this study, the influence of damaged tubular combustion chamber on smoke fine-particle emissions at the pellet burners is presented. The purpose is to reduce emissions of particulate matter at the small scale pellet boilers and contribute to cleaner air.
\end{abstract}

Keywords: • particulate matter $\bullet$ small scale pellet boilers $\bullet$ fine particle emission • pellet burner • air •

CORRESPONDENCE AdDREss: Zdravko Praunseis, Ph.D., Assistant Professor, University of Maribor, Faculty of Energy Technology, Hočevarjev trg 1, 8270 Krško, Slovenia, e-mail: zdravko.praunseis@um.si. Sebastijan Seme, Ph.D., Associate Professor, University of Maribor, Faculty of Energy Technology, Hočevarjev trg 1, 8270 Krško, Slovenia, e-mail: sebastijan.seme@um.si. Bojan Štumberger, Ph.D., Full Professor, University of Maribor, Faculty of Energy Technology, Hočevarjev trg 1, 8270 Krško, Slovenia, e-mail: bojan.stumberger@um.si. Miralem Hadžiselimović, Ph.D., Associate Professor, University of Maribor, Faculty of Energy Technology, Hočevarjev trg 1, 8270 Krško, Slovenia, e-mail: miralem.h@um.si.

https://doi.org/10.18690/978-961-286-064-6.8 ISBN 978-961-286-064-6

(C) 2017 University of Maribor Press

Available at: http://press.um.si. 
$10^{\mathrm{TH}}$ International Conference on Sustainable EnERgy AND Environmental Protection (June $27^{\mathrm{TH}}-30^{\mathrm{RD}}, 2017$, Bled, SLovenia), WATER AND Air Quality Z. Praunseis, S. Seme, B. Štumberger \& M. Hadžiselimović: The Influence of Damaged Tubular Combustion Chamber on Smoke Particle Emissions at The Pellet Burners

Residential wood combustion has been identified as one of the main sources of particulate matter (PM); fine particles are important because of their adverse effects on human health and the environment [1]. Particulate matter is defined as the total mass of suspended particles in the air. PM is typically divided into three subclasses, i.e., PM10, PM2.5 and PM0.1, which are defined as particle matter with an aerodynamic diameter smaller than $10 \mu \mathrm{m}, 2.5 \mu \mathrm{m}$ and $0.1 \mu \mathrm{m}$, respectively. PM2.5 particles are generally called "fine particles"; however, this term can also be applied to the number or surface area based on particle diameters less than $2.5 \mu \mathrm{m}$. In the atmosphere, particles can be solid or liquid; the mixture of particles and gases is called "aerosol" [2]. When particles from combustion sources are discussed, particles with aerodynamic diameters less than $1 \mu \mathrm{m}$ or $2.5 \mu \mathrm{m}$ (PM1 or PM2.5) are often used, whereas particles with sizes ranging from $2.5 \mu \mathrm{m}$ to 10 $\mu \mathrm{m}$ are called coarse particles. Examples of coarse particle sources include road wear and wind-blown dust [3]. Fine particles are known to have adverse effects on human health and to cause respiratory and cardiac symptoms and even premature death, especially among those with reduced health conditions, e.g., children, elderly and those with chronic diseases.

Wood is the most commonly used biomass fuel in Slovenia due to the large forest base, forest industry and relatively easy access to cheap wood for many individuals. The use of wood in heat and power production is increasing. Wood pellets are primarily used in continuously operated combustion appliances [4] as an example of renewable energy [5], [6].

In this study, the influence of damaged tubular combustion chamber on smoke fine particle emissions at the pellet burners is presented. The purpose is to reduce emissions of particulate matter at the small scale pellet boilers and contribute to cleaner air.

\section{Experimental Section}

Combustion experiments were performed in a laboratory environment with a small scale $25 \mathrm{~kW}$ pellet boiler suitable for household heat production. The pellet boiler operates with a overfed fuel input and includes a prefabricated burner (Figure 1). The burner can be operated continuously between the loads of 14 and $30 \mathrm{~kW}$. It is equipped with logiccontrolled fans for the supply of combustion air. The primary air was fed in through holes before the grille at the bottom of the cylindrical furnace - tubular combustion chamber with $3 \mathrm{~mm}$ steel wall thickness. The width of the grille was approximately $100 \mathrm{~mm}$, and the diameter of each hole was approximately $6 \mathrm{~mm}$. Commercial wood pellets originating from Slovenia were used in the study. The primary pellet raw material was pinewood. 

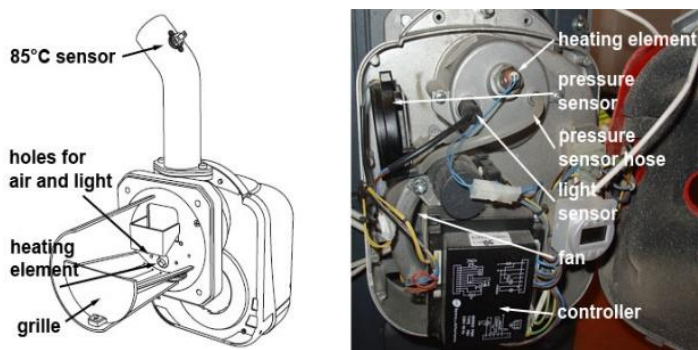

Figure 1. Sketch of the pellet burner used in this study

The tubular combustion chamber should be made by high temperature resistance steel which contains prescribed amount of $\mathrm{Cr}$ and Mo due to the high flame temperature which can exceed $800{ }^{\circ} \mathrm{C}$. The flame temperatures were measured by infrared camera as is shown in Figure 2.

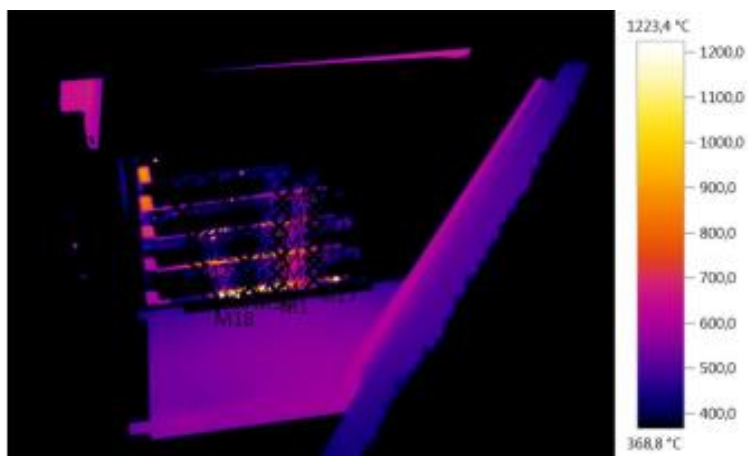

Figure 2. Flame temperatures measurement at the tubular combustion chamber of pellet burner

The shape of the pellet burner's flame can be seen at the Figure 3.

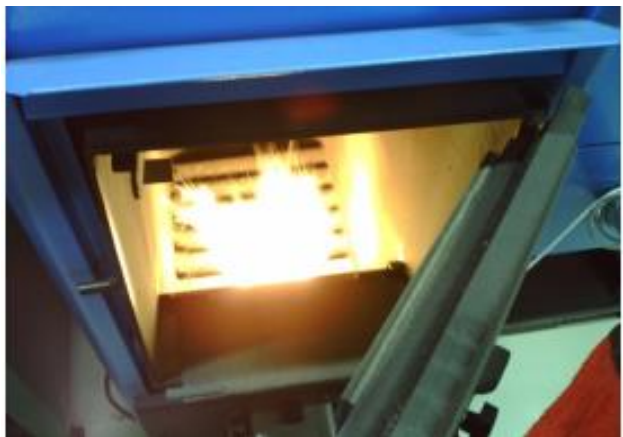

Figure 2. The shape of the flame in the pellet burner 

Protection (June $27^{\mathrm{TH}}-30^{\mathrm{RD}}, 2017$, Bled, SLOVEniA), WATER AND Air Quality

Z. Praunseis, S. Seme, B. Štumberger \& M. Hadžiselimović: The Influence of Damaged Tubular Combustion Chamber on Smoke Particle Emissions at The Pellet Burners

The damages of the steel tube (tubular combustion chamber) and the grille were occured after one year of the burner operation time as is shown in Figure 4 and Figure 5.

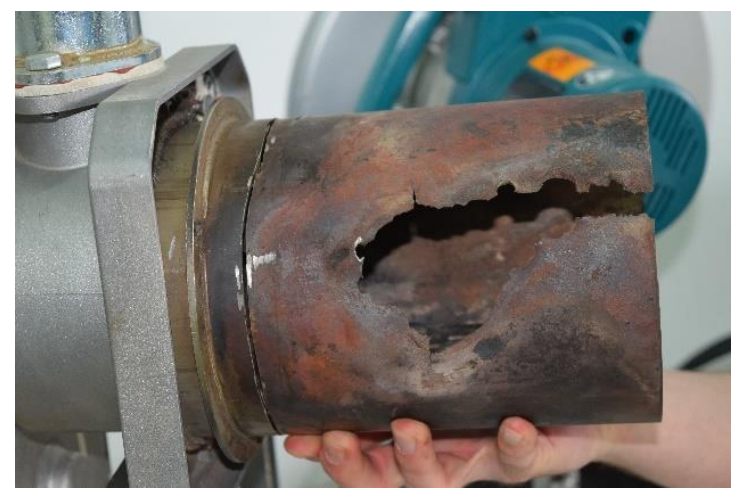

Figure 4. Hole as a damage of the steel tube (tubular combustion chamber)

Chemical analyses of steel tube (tubular combustion chamber) was performed with Xray fluorescence spectrometry (XRF) using an X-ray fluorescence spectrometer (Thermo Scientific Niton XL3t GOLD+) and is given in Table 1.

Two different measurement procedures were used in the present research.

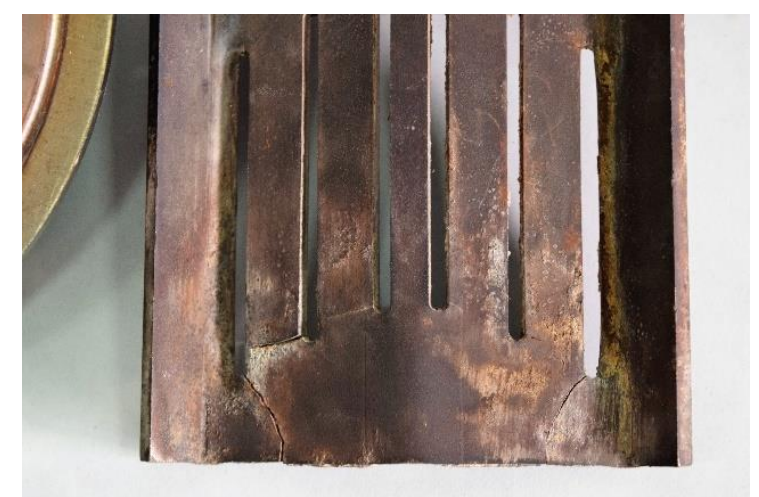

Figure 5. Hot cracks as a damage of the steel grille

Measurements were carried out manually and with the use of the support panel. Each measurement was repeated three times, and later the average value calculated. Each measurement was done for one minute. 
$10^{\text {TH }}$ INTERNATIONAL CONFERENCE ON SUSTAINABLE ENERGY AND ENVIRONMENTAL Protection (June $27^{\mathrm{TH}}-30^{\mathrm{RD}}, 2017$, Bled, Slovenia), WATER AND Air Quality

Z. Praunseis, S. Seme, B. Štumberger \& M. Hadžiselimović: The Influence of Damaged Tubular Combustion Chamber on Smoke Particle Emissions at The Pellet

Burners

Table 1. Chemical analyses of steel tube (tubular combustion chamber)

\begin{tabular}{|c|c|}
\hline $\begin{array}{c}\text { Composition } \\
(\%)\end{array}$ & Mild steel \\
\hline $\mathrm{C}$ & 0.28 \\
\hline $\mathrm{Si}$ & 0.52 \\
\hline $\mathrm{Mn}$ & 0.71 \\
\hline $\mathrm{P}$ & 0.011 \\
\hline $\mathrm{S}$ & 0.007 \\
\hline $\mathrm{Cr}$ & 0.05 \\
\hline $\mathrm{Ni}$ & 0.01 \\
\hline $\mathrm{Mo}$ & 0.013 \\
\hline $\mathrm{Cu}$ & 0.62 \\
\hline $\mathrm{Al}$ & 0.001 \\
\hline \multicolumn{2}{|c}{} \\
\hline
\end{tabular}

Fine particle measurements were made in the chimney tube at the distance $20 \mathrm{~cm}$ from the boiler by the fine particle analyzer (Figure 6) which carry out fine particles, $\mathrm{O}_{2}$ concentration and $\mathrm{CO}$ emissions in real time of 15 minutes.

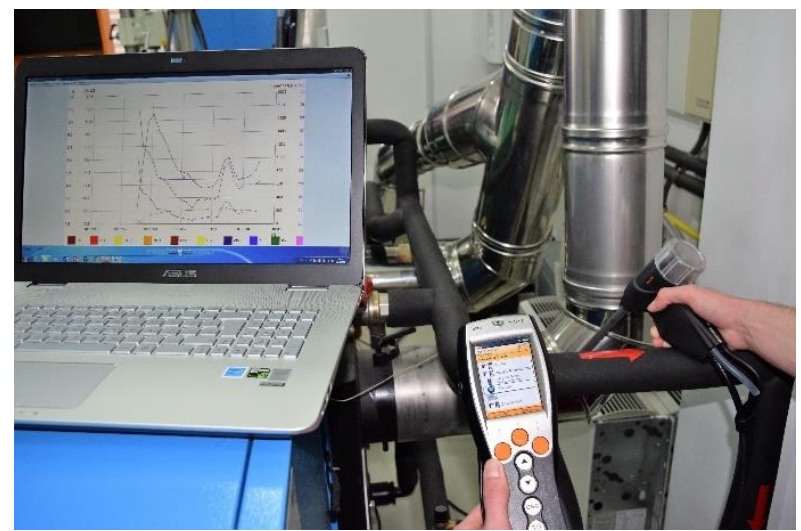

Figure 6. Fine particle measurement by the fine particle analyzer

\section{$3 \quad$ Results and Discussion}

From the results of chemical analyses (Table 1) of steel tube (tubular combustion chamber) is evident that the mild steel is used for construction of tubular combustion chamber. The mild steel is typically carbon steel, with a comparatively mild amount of carbon $(0.16 \%$ to $0.30 \%)$. It has ferromagnetic properties. The high amount of carbon, also makes mild steel vulnerable to rust. Mild steel is also used in construction as structural steel and is not useful for operation at high temperatures, higher than $100{ }^{\circ} \mathrm{C}$. Unproper selection of base material (mild steel) leads to the damages of steel tube due to the high operating temperatures during combustion of pellets (Figure 4). The highest 
$10^{\mathrm{TH}}$ International Conference on Sustainable EnERgy AND Environmental Protection (June $27^{\mathrm{TH}}-30^{\mathrm{RD}}, 2017$, Bled, Slovenia), WATER AND Air Quality

Z. Praunseis, S. Seme, B. Štumberger \& M. Hadžiselimović: The Influence of Damaged Tubular Combustion Chamber on Smoke Particle Emissions at The Pellet Burners

flame temperature of $793{ }^{\circ} \mathrm{C}$ were measured at the surface of steel tube by infrared camera as is shown in Figure 2.

Thus, the tubular combustion chamber must be made by high temperature resistance steel which contains prescribed amount of $\mathrm{Cr}$ and Mo due to the high flame temperature which can exceed $800^{\circ} \mathrm{C}$.

The damages were appeared at the burner tube as a holes as can be seen from Figure 4 . The total amount of damaged tube surface was $22,75 \mathrm{~cm}^{2}$. In this research, the influence of damaged tubular combustion chamber on smoke fine-particle emissions at the pellet burners is study.

Because of this, holes with diameter of $11 \mathrm{~mm}$ were drilled into the new steel tube made by high temperature resistance steel with the purpose to simulate the damages of the tube (tubular combustion chamber) during fine particle measurements by fine particle analyzer (Figure 6).

Combustion experiments were performed with optimal operational manipulation (loads, primary combustion air supplies). Normal operation was assumed to obtain nominal load of $25 \mathrm{~kW}$, represented as an optimal baseline.

Each of the combustion experiments were performed in a preheated pellet boiler. The boiler was turned on one hour before the start of the experiment, and the warming was performed on full load.

The influence of damaged tubular combustion chamber on smoke fine-particle emissions (FPE), $\mathrm{O}_{2}$ concentration and $\mathrm{CO}$ emissions at the pellet burner is presented in Table 2 and Figure 7. Table 2 is presented total values of smoke fine-particle emissions (FPE), $\mathrm{O}_{2}$ concentration and $\mathrm{CO}$ emissions after 15 minutes measurements by fine particle analyzer.

By reviewing the results (Table 2 and Figure 7) of measurements of smoke fine-particle emissions (FPE), $\mathrm{O}_{2}$ concentration and $\mathrm{CO}$ emissions it is clear that the highest values were reached at the largest damaged tube surface $22,75 \mathrm{~cm}^{2}$ (24 holes). FPE value is approximately $77 \%$ higher than the optimal value at the zero damage surface. Damaged pellet burner chamber also influence on lower $\mathrm{O}_{2}$ concentration for about $48 \%$ and approximately $50 \%$ higher $\mathrm{CO}$ emissions in comparison with optimal values at the zero damage tube surface. 
$10^{\text {TH }}$ INTERNATIONAL CONFERENCE ON SUSTAINABLE ENERGY AND ENVIRONMENTAL Protection (June 27 $7^{\mathrm{TH}}-30^{\mathrm{RD}}$, 2017, Bled, SLOVEnia), WATER AND Air Quality Z. Praunseis, S. Seme, B. Štumberger \& M. Hadžiselimović: The Influence of Damaged Tubular Combustion Chamber on Smoke Particle Emissions at The Pellet

Burners

Table 2. The results of measurements of smoke fine-particle emissions (FPE), $\mathrm{O}_{2}$ concentration and $\mathrm{CO}$ emissions at the damaged pellet burner chamber

\begin{tabular}{|l|l|l|l|}
\hline $\begin{array}{l}\text { Damage surface } \\
\left(\mathrm{cm}^{2}\right)\end{array}$ & $\begin{array}{l}\mathrm{FPE} \\
\left(\mathrm{mg} / \mathrm{Nm}^{3}\right)\end{array}$ & $\begin{array}{l}\mathrm{O}_{2} \\
(\%)\end{array}$ & $\begin{array}{l}\mathrm{CO} \\
\left(\mathrm{mg} / \mathrm{Nm}^{3}\right)\end{array}$ \\
\hline 0,00 & 16,7 & 6,2 & 68 \\
\hline $0,95(1$ hole $)$ & 16,9 & 6,1 & 69 \\
\hline $1,90(2$ holes $)$ & 17,1 & 5,8 & 72 \\
\hline $3,80(4$ holes $)$ & 17,9 & 5,1 & 75 \\
\hline $5,70(6$ holes $)$ & 18,1 & 4,9 & 79 \\
\hline $22,75(24$ holes $)$ & 29,6 & 3,2 & 101 \\
\hline
\end{tabular}

The damage effect of tubular combustion chamber on smoke fine-particle emissions (FPE), $\mathrm{O}_{2}$ concentration and $\mathrm{CO}$ emissions is insignificant at damage surfaces $0,00 \mathrm{~cm}^{2}$, $0,95 \mathrm{~cm}^{2}, 1,90 \mathrm{~cm}^{2}$ and $3,80 \mathrm{~cm}^{2}$ (4 holes) where measured values not exceed $7 \%$ of optimal values.

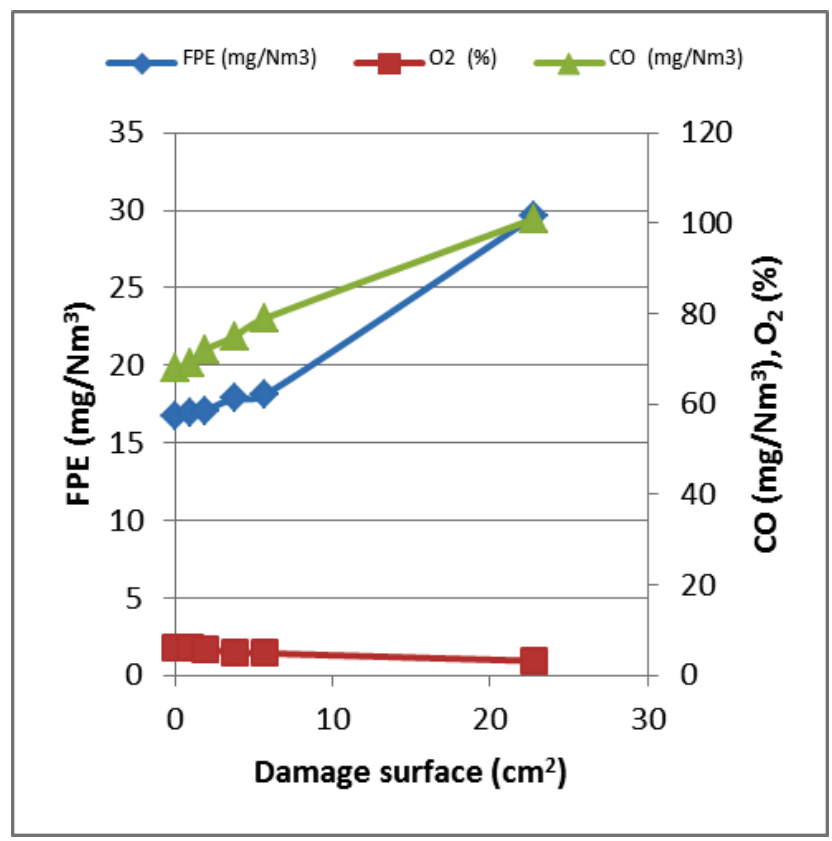

Figure 7. The influence of damaged tubular combustion chamber on smoke fine-particle emissions (FPE), $\mathrm{O}_{2}$ concentration and $\mathrm{CO}$ emissions at the pellet burner

The next higher values were reached at the damaged tube surface of $5,70 \mathrm{~cm}^{2}$ ( 6 holes). FPE value is approximately $10 \%$ higher than the optimal value at the zero damage surface. Damaged pellet burner chamber also influence on lower $\mathrm{O}_{2}$ concentration for 
$10^{\mathrm{TH}}$ InTERnAtional CONFERENCE ON Sustainable ENERgy AND ENVIRONMENTAL Protection (June $27^{\mathrm{TH}}-30^{\mathrm{RD}}, 2017$, Bled, SLOVEnia), WATER AND Air Quality

Z. Praunseis, S. Seme, B. Štumberger \& M. Hadžiselimović: The Influence of Damaged

Tubular Combustion Chamber on Smoke Particle Emissions at The Pellet Burners

about $20 \%$ and approximately $13 \%$ higher CO emissions in comparison with optimal values at the zero damage tube surface.

\section{$4 \quad$ Conclusions}

Wood is the most commonly used biomass fuel in Slovenia due to the large forest base, forest industry and relatively easy access to cheap wood for many individuals. The use of wood in heat and power production is increasing. Wood pellets are primarily used in continuously operated combustion appliances. In real applications, combustion conditions are never ideal. Moreover, fuel and combustion air contain several components that affect the combustion process and emission formation. The combustion of solid fuel in real-life applications always require more air than what is theoretically needed.

The tubular combustion chamber of pellet burner should be made by high temperature resistance steel which contains prescribed amount of $\mathrm{Cr}$ and $\mathrm{Mo}$ due to the high flame temperature which can exceed $800{ }^{\circ} \mathrm{C}$.

Unproper selection of base materials for construction of steel tubes leads to the damages due to the high operating temperatures during combustion of pellets.

The damages were appeared at the burner tube as a holes. Damaged tubular combustion chamber at the pellet burner has significant influrence on smoke fine-particle emissions (FPE), $\mathrm{O}_{2}$ concentration and $\mathrm{CO}$ emissions.

The highest values of smoke fine-particle emissions (FPE), $\mathrm{O}_{2}$ concentration and $\mathrm{CO}$ emissions were reached at the largest damaged tube surface $22,75 \mathrm{~cm}^{2}$ (24 holes). FPE value is approximately $77 \%$ higher than the optimal value at the zero damage surface. Damaged pellet burner chamber also influence on lower $\mathrm{O}_{2}$ concentration for about $48 \%$ and approximately $50 \%$ higher $\mathrm{CO}$ emissions in comparison with optimal values at the zero damage tube surface. The damage effect of tubular combustion chamber on smoke fine-particle emissions (FPE), $\mathrm{O}_{2}$ concentration and $\mathrm{CO}$ emissions is insignificant at damage surfaces $0,00 \mathrm{~cm}^{2}, 0,95 \mathrm{~cm}^{2}, 1,90 \mathrm{~cm}^{2}$ and $3,80 \mathrm{~cm}^{2}$ (4 holes) where measured values not exceed $7 \%$ of optimal values.

\section{Acknowledgements}

The authors thank to firm Žaga Cugmajster d.o.o. Loče for pellet material supply.

\section{References}

[1] Z. Praunseis and R. Strojko, Energy supply of buildings. Krško: University of Maribor, 2013.

[2] Z. Praunseis and R. Strojko,"Energy renovation of an older house.," Science journal of energy engineering," vol. 2, pp. 47-52, Aug. 2014. 
[3] H. Lamberg, "Physicochemical properties of fine particles from small-scale wood combustion ,"Atmospheric Environment, vol. 45, pp. 7635-7643, Feb. 2011.

[4] U. Fernandes and A. Costa, "Formation of fine particulate matter in a domestic pellet-fired boiler," Energy \& Fuels, vol 27, pp. 1081-1092, Jan. 2013.

[5] S. Seme, B. Stumberger and M. Hadžiselimović, "A novel prediction algorithm for solar angles using second derivative of the energy for photovoltaic sun tracking purposes," Solar energy, vol. 137, pp. 201-211, Nov. 2016.

[6] M. Hadžiselimović, B. Štumberger and S. Seme, "Energy efficiency and use of renewable solutions of small and medium enterprises," Przeglęad Elektrotechniczny, vol. 92, pp. 203216, Dec. 2016. 
\begin{tabular}{l|l}
72 & $10^{\mathrm{TH}}$ International CONFERENCE on Sustainable EnERgy AND ENVIRONMENTAL
\end{tabular} Protection (June 27 $7^{\mathrm{TH}}-30^{\mathrm{RD}}, 2017$, Bled, Slovenia), WATER AND Air Quality 
$10^{\mathrm{TH}}$ InTERnational CONFEREnCE ON Sustainable ENERgy AND Environmental Protection (June $27^{\mathrm{TH}}-30^{\mathrm{RD}}, 2017$, Bled, SLOVENIA), WATER AND AIR QuALITY

J. Krope, A.Ghani Olabi, D. Goričanec \& S. Božičnik

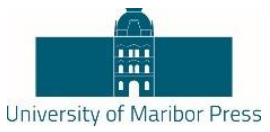

\title{
Pm from the Combustion of Heavy Fuel Oils
}

\author{
Abdulrahman Alkhateeb, Ayman M. Elbaz, Jianguo Du \& William. L. Roberts
}

\begin{abstract}
Experiments of single Heavy Fuel Oil droplets combustion were carried out to understand the effect of droplet initial burning temperature on cenosphere formation and differences between two types of cenosphere morphologies. Two different experiment techniques were used; falling droplet combustion inside a preheated furnace and suspended droplet combustion by the captive droplet technique. Particulate matters were collected to characterize cenosphere morphology by using SEM. Furthermore, high speed images and temperature profile of burning droplets were recorded. Results show that the morphology changes from skeleton-membrane to porous shell if critical ignition condition was met by the ambient air and the droplet vaporized component mixture. Relatively high initial burning temperature is required to meet the critical ignite condition and generate cenospheres with porous shell structure.
\end{abstract}

Keywords: • PM • HFO • SEM • cenosphere • morphology •

CoRresPOndence AdDRESS: Abdulrahman Alkhateeb, Ph.D., Student, King Abdullah University of Science and Technology, Clean Combustion Research Centre, Thuwal 23955-6900, Saudi Arabia, e-mail: abdulrahman.khateeb@kaust.edu.sa. Ayman M. Elbaz, Ph.D., Research Scientist, King Abdullah University of Science and Technology, Clean Combustion Research Centre, Thuwal 23955-6900, Saudi Arabia, e-mail: ayman.elhagrasy@kaust.edu.sa. Jianguo Du, Ph.D., Student, King Abdullah University of Science and Technology, Clean Combustion Research Centre, Thuwal 23955-6900, Saudi Arabia, e-mail: jianguo.du@kaust.edu.sa. William. L. Roberts, Ph.D., Professor, King Abdullah University of Science and Technology, Director of Clean Combustion Research Centre, Thuwal 23955-6900, Saudi Arabia, e-mail: william.roberts@kaust.edu.sa.

https://doi.org/10.18690/978-961-286-064-6.9 ISBN 978-961-286-064-6

(C) 2017 University of Maribor Press

Available at: http://press.um.si. 
$10^{\mathrm{TH}}$ InTERNATIONAL CONFERENCE ON SuSTAINABLE ENERGY AND ENVIRONMENTAL Protection (June $27^{\mathrm{TH}}-30^{\mathrm{RD}}, 2017$, Bled, Slovenia), WATER AND Air Quality

A. Alkhateeb, A. M. Elbaz, J. Du \& W. L. Roberts: Pm from the Combustion of Heavy Fuel Oils

\section{Introduction}

Recently, petroleum oil products constitute a significant share of the world energy supply. In Saudi Arabia, Heavy Fuel Oil (HFO) is commonly used rather than conventional light oils due to its lower production cost and wider availability ${ }^{[1]}$. However, the emission of Particulate Matters (PM) from the combustion of HFO still remains a major concern. These emissions contain unburned carbon particles. The cenosphere in particular, causes not only environmental problems, but also operational issues such as fouling and erosion of equipment ${ }^{[2]}$.

Two typical types of cenosphere morphologies could be found in earlier research. The traditional morphology, which is widely observed ${ }^{[3-10]}$, has a carbonaceous and porous

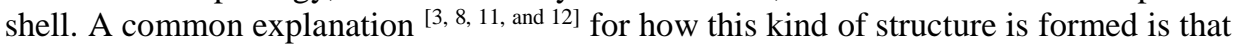
volatile components of HFO at the droplet surface evaporate and form a vapor layer surrounding the droplet. As a result, the more viscous components remaining at the surface begin to form a shell, which prevents the emission of vapor formed by the volatile inner components. With a diffusion flame formed outside the vapor layer, droplet temperature increases, accelerating vaporization and vapor accumulation inside the shell. Eventually, the inside vapor ejects out through the weak points of the shell, forming the porous structure. The other type of morphology is mentioned as globules, which can reach a diameter, much larger than that of traditional cenosphere ${ }^{[8]}$. The globules are hollow and contain many bubbles. Seen from outside, the cenosphere is a skeletal structure, attached by a membrane among those frames. This structure was also observed by Wornat ${ }^{[13]}$, from single droplet combustion of pine oil and by Gay ${ }^{[10]}$, during fluidized-bed combustion of bituminous coals.

However, few studies are found which explain this phenomenon, nor has any investigation of the factors that contribute to these different morphologies. In this paper, focuses are put on finding out those main factors and comparing between two different types of cenospheres. To reach this purpose, two single droplet experiments were performed. a falling droplet experiment in order to collect cenospheres from the combustion of a stream of uniform HFO single droplets, surrounded by a preheated air co-flow inside a controllable furnace. Scanning Electron Microscope (SEM) was also implemented to investigate the physical characteristics of cenospheres. The second experiment is a suspended droplet combustion by the captive technique to capture images of the droplet burning process along with the temperature history profile. 


\section{Experimental Setup}

\subsection{Falling droplet experiment}

Schematic map of experimental apparatus for the combustion of HFO falling droplet is shown in Figure 1.

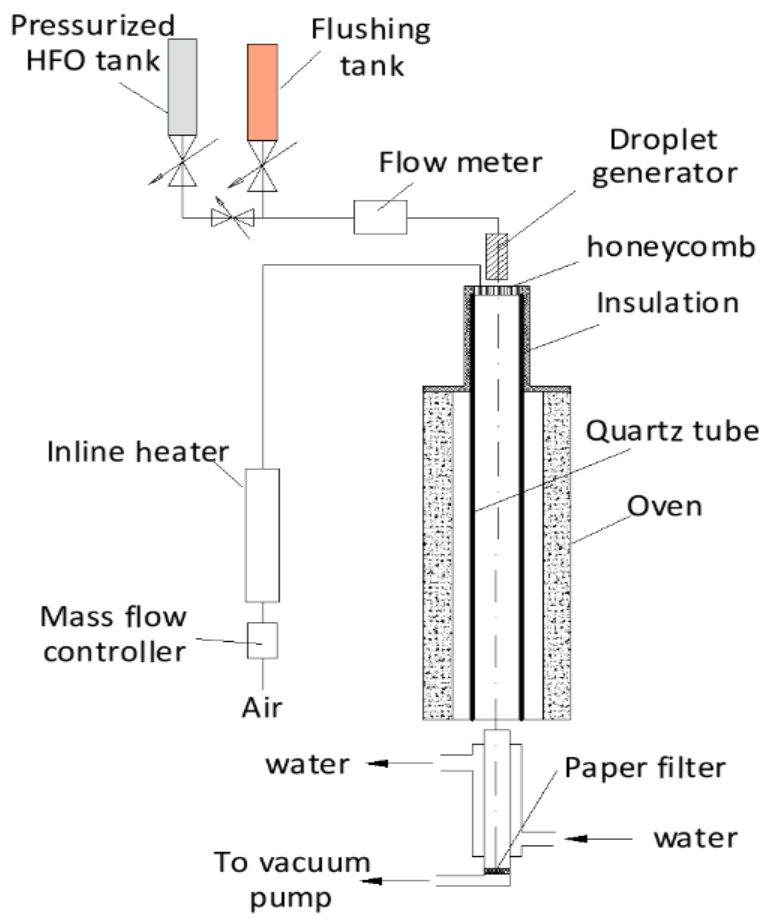

Figure 1: Falling Droplet Setup.

For easier piping and ignition, the feeding line of HFO from the pressurized HFO tank to the droplet generator was heated up to $150^{\circ} \mathrm{C}$. By using different orifices and $\mathrm{HFO}$ flow rates, the droplet generator (TSI MDG100 Monodisperse droplet generator) can generate three different droplet diameters $(422 \pm 23 \mu \mathrm{m}, 365 \pm 22 \mu \mathrm{m}, 291 \pm 15 \mu \mathrm{m})$.

Surrounding the central droplet entrance hole, four holes are uniformly distributed and connected to air, which is heated by an inline heater (Sylvania heater, F074719, 8000 Watt). Before flowing into the vertically positioned quartz tube $(134 \mathrm{~mm}$ inner diameter and $1500 \mathrm{~mm}$ length) inside a hinged tube furnace (Lindberg/blue, HTF55000 series), the co-flow air first goes through a ceramic honeycomb; after that, the flow proceeds to the furnace is assumed to be uniform as a result. The tube furnace includes three separate heating zones and individual temperature controllers. With this feature of the furnace, we 
$10^{\mathrm{TH}}$ INTERNATIONAL CONFERENCE ON SuSTAINABLE ENERGY AND ENVIRONMENTAL Protection (June $27^{\mathrm{TH}}-30^{\mathrm{RD}}, 2017$, Bled, Slovenia), WATER AND Air Quality

A. Alkhateeb, A. M. Elbaz, J. Du \& W. L. Roberts: Pm from the Combustion of Heavy Fuel Oils

can adjust the temperature profile inside the quartz tube. Cenospheres are collected from water cooled exhaust gas by paper filter (retention diameter 20 microns) placed on a wire mesh at the end of the exhaust tube and the exhaust gas is sucked away by a vacuum pump.

\subsection{Suspended droplet experiment}

Schematic map of the experimental setup is shown in Figure 2. The captive droplet technique was chosen here because it enables droplet behavior to be monitored over the whole period of heat treatment inside an enclosure ${ }^{[14]}$.

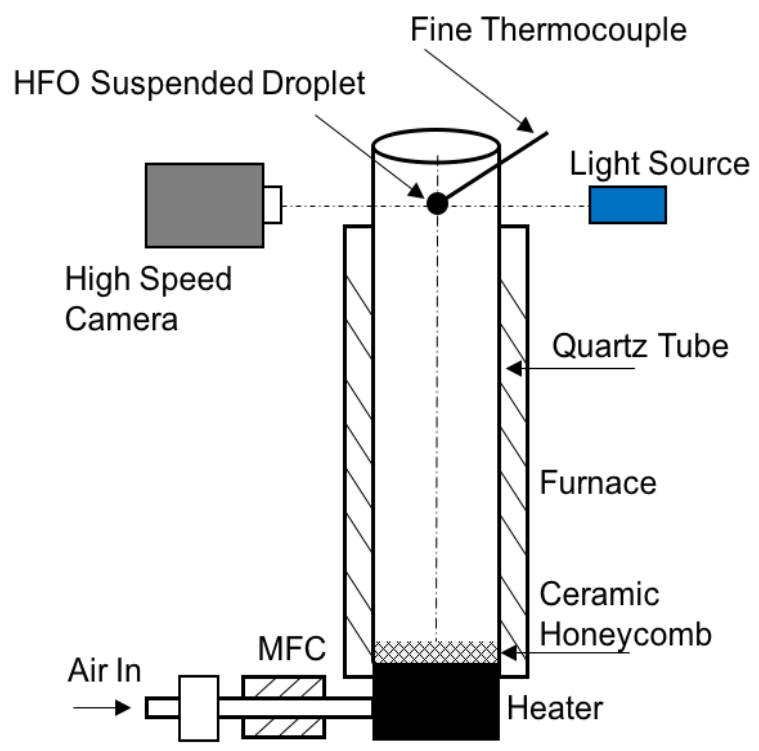

Figure 2: Suspended Droplet Setup.

Preheated air co-flow by an inline heater (Sylvania heater, F074719, 8000 Watt) goes upwards through a ceramic honeycomb from the bottom of a hinged tube furnace (Lindberg/blue, HTF55000 series) through quartz tube (134 mm inner diameter and 750 $\mathrm{mm}$ length). The co-flow air is assumed to be uniform after that and can be controlled with flow rate up to $130 \mathrm{l} / \mathrm{min}$. Once the temperature profile inside the electrical furnace reaches required values, HFO droplet is suspended on a thermocouple junction (Type S, $75 \mu \mathrm{m}$ diameter, Omega P10R-003). The thermocouple is inserted inside a two-hole ceramic tube and connected to a computer for data processing and temperature readings. The droplet is positioned into the preheated electrical furnace by a 3D mechanism through an air cooling channel. This channel will keep the droplet temperature low until reaching the burning point inside the furnace. High speed camera (LaVision, Imager HS) is used to record the whole HFO droplet combustion process and a data acquisition card will read the temperature history inside the droplet from the thermocouple simultaneously. 


\section{$3 \quad$ Results}

Heavy Fuel Oil was collected from Shoaiba Power Plant in Saudi Arabia to generate single droplet for falling and suspended experiments. The HFO in Saudi Arabia has asphaltene content ranges between $7 \%$ to $15 \%$ and has high sulfur content of $3 \mathrm{wt} \%$ to 4 wt ${ }^{[1]}$. Physical and chemical properties of the HFO used in our experiment are shown in Table $1^{[1]}$.

Table 1: HFO Properties.

\begin{tabular}{|l|l|}
\hline Properties & Results \\
\hline Density at $288 \mathrm{~K}\left(\mathrm{Kg} / \mathrm{m}^{3}\right)$ & 970.5 \\
\hline Kinematic viscosity at $40^{\circ} \mathrm{C}(\mathrm{cSt})$ & 617.740 \\
\hline Sulfur $(\mathrm{wt} \%)$ & 3.292 \\
\hline Asphaltenes $(\%)$ & 8.2 \\
\hline Vanadium $(\mathrm{mg} / \mathrm{Kg})$ & 18.0 \\
\hline Carbon $(\mathrm{wt} \%)$ & 85.0 \\
\hline Hydrogen $(\mathrm{wt} \%)$ & 10.89 \\
\hline Oxygen $(\mathrm{wt} \%)$ & 0.030 \\
\hline Nitrogen $(\mathrm{wt} \%)$ & 0.239 \\
\hline
\end{tabular}

\subsection{SEM analysis}

To better understand the differences in cenosphere morphology and its microstructure, SEM (Quanta 600F) was done on a series of cenosphere samples collected under various conditions. Two different types of large particles were observed, shown in Figure 3.

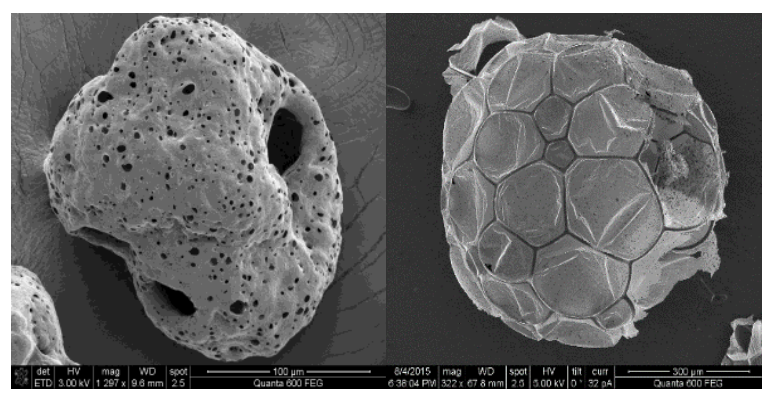

Figure 3: Two Typical Morphologies of Cenosphere.

The cenosphere morphology in Figure 3 (left) shows several small and large holes on the thick shell, called porous-shell structure. This kind of structure is widely observed in earlier researches. While totally different from the cenosphere in Figure 3 (right) which has a skeletal structure with membrane spreading and connecting between those frames, called skeleton-membrane structure. Some of this type of cenosphere has only one outside membrane layer and hollow inside, while some contain several layers formed by lots of 
$10^{\mathrm{TH}}$ InTERnATIONAL CONFERENCE ON Sustainable EnERgy AND ENVIRONMENTAL Protection (June $27^{\mathrm{TH}}-30^{\mathrm{RD}}, 2017$, Bled, Slovenia), WATER AND Air Quality

A. Alkhateeb, A. M. Elbaz, J. Du \& W. L. Roberts: Pm from the Combustion of Heavy Fuel Oils

cells, which are also enclosed by membrane and hollow inside. Cenospheres with traditional structure (50 200 micron) are always smaller than initial droplets, while those with skeleton-membrane structure (300 1100 micron) are much larger. Obviously, the mechanisms of forming these two cenosphere types are different. According to our experiment, the initial temperature of the droplet burning zone has a big effect on the cenosphere morphological differences. Thus, falling droplet experiment was conducted to collect cenospheres under variable temperature entrance zones. Three initial temperatures were selected to make high, moderate and low entrance zones as show in Figure 4. Initial droplet diameter was kept consistent at $291 \pm 15 \mu \mathrm{m}$ and air co-flow rate was kept at $130 \mathrm{lpm}$.

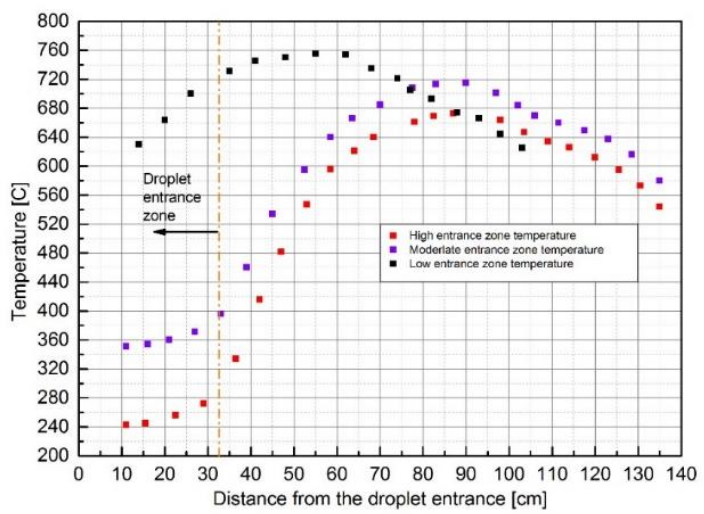

Figure 4: Furnace Temperature Profiles.

From SEM results Figure 5, it is found that with high entrance temperature, cenospheres collected are all with porous shell structure and have uniform size (smaller than initial droplets). While with moderate temperature profiles, there is transition particles coexist along with porous shell ones. In the case of low entrance zone temperature, skeletonmembrane structure coexists with porous shell cenosphere as well. Worth to mention is that porous shell cenosphere always appears with a lot of ash collected on paper filter. 


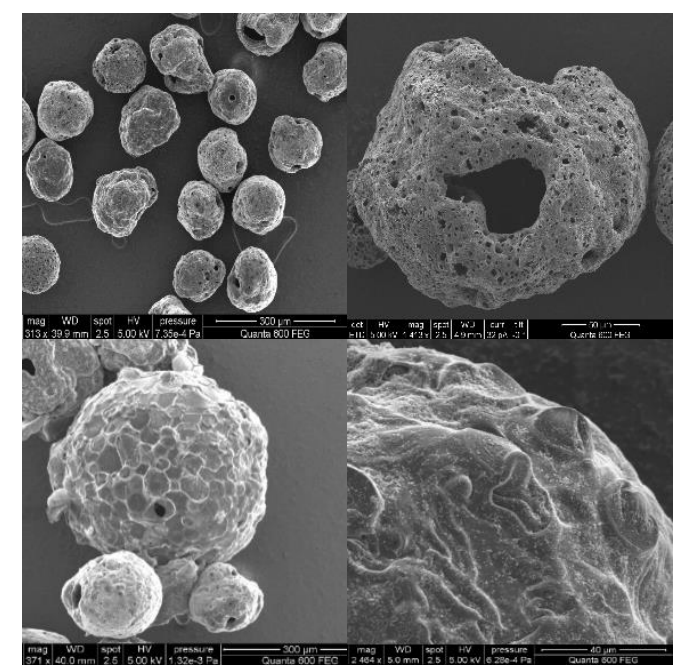

Figure 5: SEM Results for Cenospheres with Different Temperature Profiles.

\subsection{Suspended droplet}

It was discovered from the falling droplet experimental results that initial burning temperature of HFO droplet plays a critical role in cenosphere morphology. Therefore, a suspended droplet experiment was performed to further investigate on this approach. Figure 6 shows temperature history of HFO droplets exposed to different initial temperatures. The initial droplet diameter was kept at $320 \pm 15 \mu \mathrm{m}$ and air co-flow rate was kept at $30 \mathrm{lpm}$.

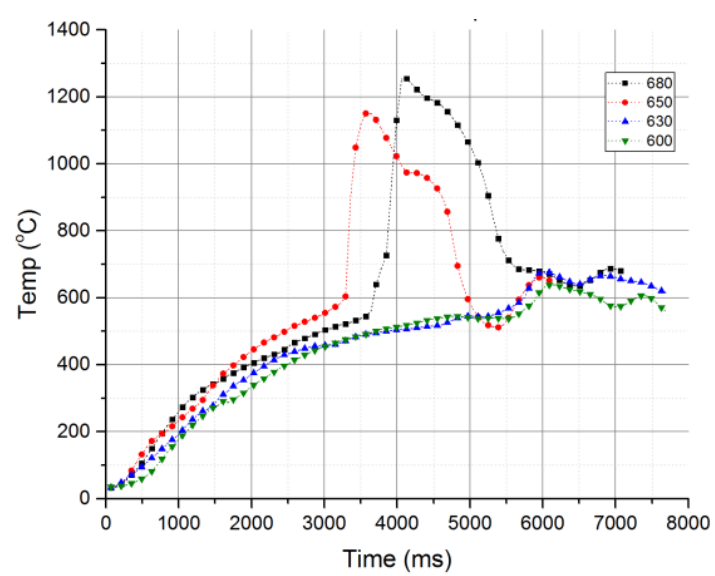

Figure 6: Temperature History Profile. 
$10^{\text {TH }}$ International CONFEREnce on Sustainable Energy and Environmental Protection (June $27^{\mathrm{TH}}-30^{\mathrm{RD}}, 2017$, Bled, Slovenia), WATER AND Air Quality

A. Alkhateeb, A. M. Elbaz, J. Du \& W. L. Roberts: Pm from the Combustion of Heavy Fuel Oils

At high temperatures (i.e. $680^{\circ} \mathrm{C}$ and $650^{\circ} \mathrm{C}$ ), the total burning time was around 7 seconds. The droplet started releasing volatile material once it was located inside the furnace. After 3.5 seconds the ambient air and vaporized components mixture reached the critical ignition condition which causes droplet ignition flame as shown in Figure 7. Ejection of viscous residue was splashing through the flame front due to the formation of vapor bubbles ${ }^{[15]}$. Cenosphere formation with porous shell structure was produced at the end of the droplet combustion.

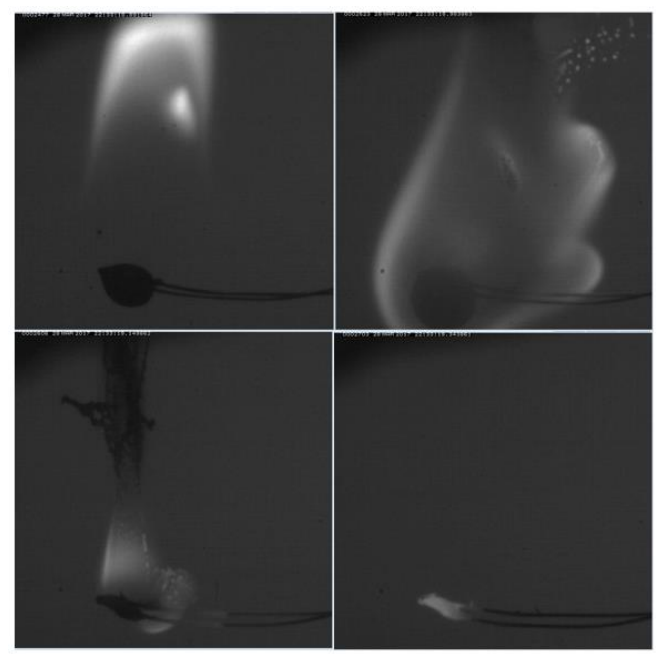

Figure 7: Droplet Ignition.

At low temperatures (i.e. $600^{\circ} \mathrm{C}$ and $630^{\circ} \mathrm{C}$ ), the critical ignition condition was not reached by the ambient air and the vaporized components and therefore, the droplet did not ignite as shown in Figure 8. However, the droplet size doubled due to the emission of vapor formed by the volatile inner components which could not escape due to high viscosity of the surface layer. But finally, the inside vapor ejects out through weak points of the shell leading to a cenosphere formation of skeleton-membrane structure. 


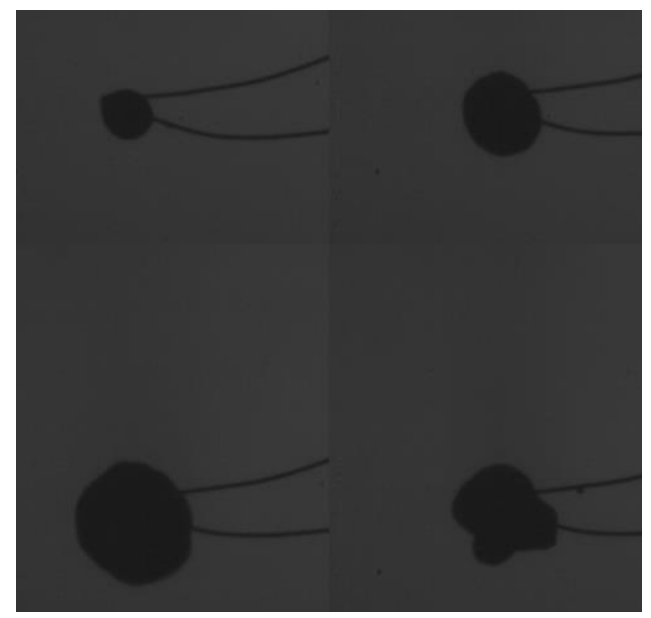

Figure 8: Droplet without Ignition.

The size history of suspended droplet with different initial temperature is plotted in Figure 9. Expansions and contractions alternates during the droplet burning time. At high initial temperature, the droplet size dropped by $40 \%$ while it was almost doubled at low initial temperature. Eventually, cenospheres with traditional structure are always smaller than initial droplets, while those with skeleton-membrane structure are much larger.

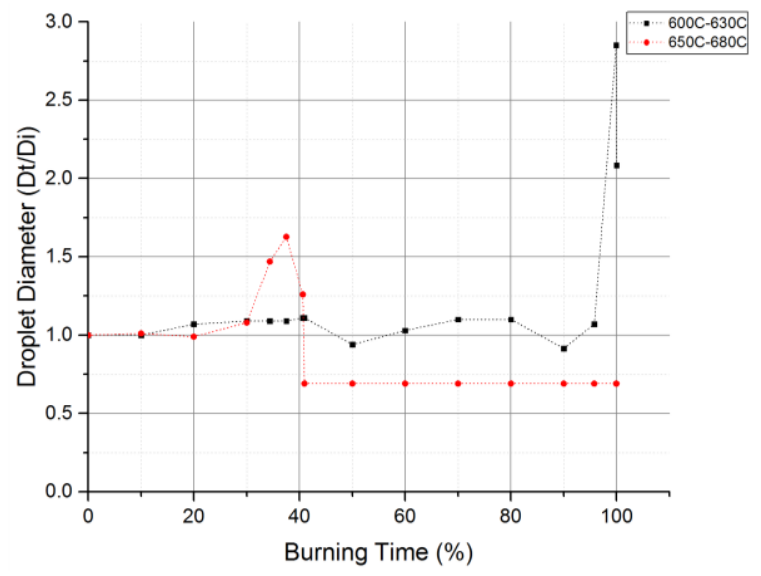

Figure 9: Droplet Diameter History.

\section{Discussion}

Based on the previously described experimental results, it is possible to determine that with the same source of HFO, the initial temperature profile are the main factor affecting cenosphere morphology. 
$10^{\mathrm{TH}}$ InTERnAtional CONFERENCE ON Sustainable ENERgy AND ENVIRONMENTAL Protection (June $27^{\mathrm{TH}}-30^{\mathrm{RD}}, 2017$, Bled, SLOVenia), WATER AND Air Quality

A. Alkhateeb, A. M. Elbaz, J. Du \& W. L. Roberts: Pm from the Combustion of Heavy Fuel Oils

When a droplet exposed to high temperature, it undergoes several stages before becoming a cenosphere, volatile component evaporation, droplet swelling, and vapor burning surrounding the droplet. Variations in these stages cause different morphology. When ambient air temperature is high and vaporized components from the droplet is sufficient, critical ignition condition is met. This helps to form a diffusion flame in the vapor layer surrounding the droplet. This, in turn, leads to formation of a shell, a sudden increase of temperature inside the droplet and acceleration of internal vaporization. Due to the high temperature caused by flame, viscosity decreases greatly and surface tension is insufficient to balance the suddenly increased internal pressure. When pressure inside the droplet reaches a critical value, internal vapor will eject out through weak points on the shell to form a porous-shell structure. The ejected vapor also enhances the surrounding flame.

On the other hand, if the ambient air temperature is low, the evaporation rate will be slow correspondingly. Therefore, critical ignition condition will not be met; which will allow sufficient time for volatile components to evaporate gradually and form many small bubbles inside. But the vapor does not eject out because of a relatively slow temperature increase caused by furnace radiation and convection, rather than a flame. As the droplet temperature increases gradually, the bubbles become larger and this process is seen as droplet swelling; and the resulting cenosphere is recognized as having a skeletonmembrane structure.

\section{Conclusion}

This study focused on two different cenosphere morphologies, skeleton-membrane structure and porous shell structure, observed in falling HFO droplet combustion and suspended droplet combustion experiments. By comparing the cenospheres collected under various conditions with SEM, initial droplet burning temperature are decided to be the main factor that affect cenosphere formation. For same air co-flow rate and initial droplet size, cenosphere morphology changes from porous shell to skeleton-membrane when ambient air temperature becomes lower. From these comparisons, it is shown that relatively high initial droplet temperature and is required to be fulfilled to meet the critical ignition condition which helps to generate porous shell cenosphere, otherwise it will be possible to find cenospheres with skeleton-membrane structure.

Future work will include experimental study on single HFO droplet combustion to better understand the effect of; initial droplet diameter; asphaltene content; different types of additives; and emulsions on droplet vaporization and combustion behavior.

\section{Acknowledgements}

This research is supported by Saudi Electrical Company (SEC) in collaboration with Clean Combustion Research Center of King Abdullah University of Science and Technology (KAUST). 


\section{References}

[1] Elbaz, A. Gani, N. Hourani, A. Emwas, S. Sarathy and W. Roberts, "TG/DTG, FT-ICR Mass Spectrometry, and NMR Spectroscopy Study of Heavy Fuel Oil", Energy \& Fuels, vol. 29, no. 12, pp. 7825-7835, 2015.

[2] N. Marrone, I. Kennedy and F. Dryer, "Coke Formation in the Combustion of Isolated Heavy Oil Droplets", Combustion Science and Technology, vol. 36, no. 3-4, pp. 149-170, 1984.

[3] R. Clayton and L. Back, "Physical and Chemical Characteristics of Cenospheres From the Combustion of Heavy Fuel Oil", Journal of Engineering for Gas Turbines and Power, vol. 111, no. 4, p. 679, 1989.

[4] P. Northrop, Y. Levendis and G. Gavalas, "Combustion characteristics of carbonaceous residues from heavy oil fired boilers", Energy \& Fuels, vol. 5, no. 4, pp. 587-594, 1991.

[5] D. Urban and F. Dryer, "New results on coke formation in the combustion of heavy-fuel droplets", Symposium (International) on Combustion, vol. 23, no. 1, pp. 1437-1443, 1991.

[6] D. Urban, S. Huey and F. Dryer, "Evaluation of the coke formation potential of residual fuel oils", Symposium (International) on Combustion, vol. 24, no. 1, pp. 1357-1364, 1992.

[7] K. Bartle, J. Jones, A. Lea-Langton, M. Pourkashanian, A. Ross, J. Thillaimuthu, P. Waller and A. Williams, "The combustion of droplets of high-asphaltene heavy oils", Fuel, vol. 103, pp. 835-842, 2013.

[8] E. Kwack, P. Shakkottai, P. Massier and L. Back, "Morphology of Globules and Cenospheres in Heavy Fuel Oil Burner Experiments", Journal of Engineering for Gas Turbines and Power, vol. 114, no. 2, p. 338, 1992.

[9] Bertran and C. Marques, "Study of the particulate matter emitted from residual oil combustion and natural gas reburning", Journal of the Brazilian Chemical Society, vol. 15, no. 4, pp. 548-555, 2004.

[10] Gay, R. Littlejohn and P. van Duin, "Formation of carbonaceous cenospheres during fluidized-bed combustion of bituminous coals", Fuel, vol. 62, no. 10, pp. 1224-1226, 1983.

[11] M. Ikegami, G. Xu, K. Ikeda, S. Honma, H. Nagaishi, D. Dietrich and Y. Takeshita, "Distinctive combustion stages of single heavy oil droplet under microgravity $\xi^{2}$ ", Fuel, vol. 82, no. 3, pp. 293-304, 2003.

[12] N. Feldman, "Control of residual fuel oil particulate emissions by additives", Symposium (International) on Combustion, vol. 19, no. 1, pp. 1387-1393, 1982.

[13] M. Wornat, B. Porter and N. Yang, "single Droplet Combustion of Biomass Pyrolysis Oils", Energy \& Fuels, vol. 8, no. 5, pp. 1131-1142, 1994.

[14] P. Lage, C. Hackenberg and R. Rangel, "Nonideal vaporization of dilating binary droplets with radiation absorption", Combustion and Flame, vol. 101, no. 1-2, pp. 36-44, 1995.

[15] R. Villasenor and F. Garcia, "An experimental study of the effects of asphaltenes on heavy fuel oil droplet combustion", Fuel, vol. 78, no. 8, pp. 933-944, 1999. 
$84 \quad 10^{\text {TH }}$ International CONFEREnce on Sustainable EnERgy AND ENVIRONMENTAL Protection (June 27 $7^{\mathrm{TH}}-30^{\mathrm{RD}}, 2017$, Bled, Slovenia), WATER AND Air Quality 
$10^{\mathrm{TH}}$ INTERNATIONAL CONFERENCE ON Sustainable ENERgy AND EnVironmental Protection (June $27^{\mathrm{TH}}-30^{\mathrm{RD}}, 2017$, BLED, SLOVENIA), WATER AND AIR QUALITY

J. Krope, A.Ghani Olabi, D. Goričanec \& S. Božičnik

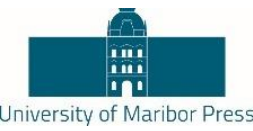

\title{
Removal of As3+ Ions from Water Solutions in Column by Adsorption on Activted Carbon
}

\author{
Milena Stojiljković, Sanja Petrović, SaŠa Savić, StaniŠa Stojiluković \& \\ BRATISLAV TODOROVIĆ
}

\begin{abstract}
Arsenic belongs to a group of highly toxic elements and its presence in ground water can easily affect on drinking water quality. Bearing in mind water scarcity and climate change, arsenic removing becomes a very sensitive issue, because it could be expected increasing demand on groundwater sources. To now, researches are developed a several different technologies for attenuating arsenic concentrations in groundwater, but adsorption and coagulation-flocculation procedures are the most commonly applied procedures for arsenic removal.

In this study the adsorption of arsenic from water solutions on activated carbon in column was investigated. Experiments were designed in two directions: first, arsenic adsorption was investigated on fixed bed of activated carbon in two columns (full and porpus) with the same diameter; and second, arsenic adsorption was investigated on polypropylene and polyester carriers impregnated by activated carbon. Carriers were cropped in circular shape and placed in a same column. Arsenic solution of $10 \mathrm{ppm}$ through a column was purged and at the bottom was collected. All colected samples were filtered and analyzed by ICP-OES (Inductively Coupled Plasma - Optical Emission Spectrometry) method.

Results from investigation of influence of column type on arsenic adsorption were shown that porous column was more efficiency in compared to the full column. Increasing of column height increases arsenic adsorption, and on the end of process it was $76.46 \%$. Based on investigation of influence of flow rate, it could be concluded that at lower flow rate $(1 \mathrm{ml} / \mathrm{min})$ percentage of adsorbed arsenic was higher. Investigations of arsenic adsorption on polypropylene and polyester carriers impregnated by activated carbon were shown that in both cases with increasing numbers of cycles arsenic removal also increases. In addition, increasing the layers number also increases the percentage of the removed arsenic from starting solutions, while comparing of influence of carriers on arsenic removal shows that polypropylene carrier was better.
\end{abstract}

Keywords: • activated carbon $\bullet$ adsorption $\bullet$ arsenic $\bullet$ clay $\bullet$ water solutions $\bullet$

CORRESPONDENCE ADDRESS: Milena Stojiljković, University of Nis, Faculty of Technology, Bulevar Oslobodjenja 124, Leskovac, Serbia, e-mail: milena0919@yahoo.com. Sanja Petrović, University of Nis, Faculty of Technology, Bulevar Oslobodjenja 124, Leskovac, Serbia, e-mail:, Saša Savić, University of Nis, Faculty of Technology, Bulevar Oslobodjenja 124, Leskovac, Serbia, e-mail:, Staniša Stojiljković, University of Nis, Faculty of Technology, Bulevar Oslobodjenja 124, Leskovac, Serbia, e-mail:, Bratislav Todorović, University of Nis, Faculty of Technology, Bulevar Oslobodjenja 124, Leskovac, Serbia, e-mail:.

https://doi.org/10.18690/978-961-286-064-6.10 ISBN 978-961-286-064-6

(C) 2017 University of Maribor Press

Available at: http://press.um.si. 
$10^{\mathrm{TH}}$ INTERNATIONAL CONFERENCE ON Sustainable ENERGy AND ENVIRONMENTAL Protection (June $27^{\mathrm{TH}}-30^{\mathrm{RD}}, 2017$, Bled, Slovenia), WATER AND Air Quality M. Stojiljković, S. Petrović, S. Savić, S. Stojiljković \& B. Todorović: Removal of As3+ Ions from Water Solutions in Column by Adsorption on Activted Carbon

\section{Introduction}

Environmental pollutants and their toxic effects represent a major problem worldwide. Water pollution represent one of the biggest environmental issue that causing serious problems to living systems [1]. Metallurgical engineering, mining, nuclear power operations, electroplating, printing, dyeing, battery, pigment, PVC stabilizers, semiconductor, cosmetics, and so on belong to industries that generate various types of pollutants in wastewater effluent $[1,2,3]$

Heavy metals represent a special serious environmental problem due to their toxicity and abundance. Due to its presence in sludge, fertilizers, pesticides, municipal waste, mines residues, and smelting industries they could contaminate a large area of land $[4,1]$. Their presence in aquatic environment could cause various health problems to live systems [5]. Previous studies were also shown that heavy metals possess carcinogenic properties and accumulative and non-degradable properties [6,7,8]. Arsenic is probably one of the most famous elements that belongs to the group of heavy elements. It is widespread in nature, there is in atmosphere, natural waters and organisms, but it is the most common in the earth's crust where its average concentration is $2-3 \mathrm{ppm}$. In organism arsenic usually reaches via contaminated water, air or food. It presence in water usually originates from groundwater that is a natural source of drinking water [9].

In order to reduce the presence of arsenic and other hazardous pollutants in wastewater, several new technologies have been developed and proposing globally. Techniques like electrochemical treatment, evaporation, solvent extraction, chemical precipitation, ion exchange, and membrane filtration technologies and others have been used for removing of hazardous pollutants. But, on the other hand these techniques have certain disadvantages because they are not suitable to use in the removal of low metal concentrations, and could cause damage on environment and life.

Due to significant advantages like low-cost, availability, profitability, ease of operation, efficiency, and effectiveness than other techniques, adsorption process always represented a suitable technique for pollutants removal from wastewater $[10,11,12,13,14,15]$. Although modern knowledge and practice familiar a wide range of natural materials (natural zeolites, natural minerals, aluminum, iron and manganese, shellfish, natural clays, bio sorbent) which can serve as a matrix for the treatment of water, activated carbon is still the most interesting. It could adsorbs a large number of organic and inorganic substances from the water, remove odor and taste, reduced turbidity, and water hardness associated micro-organisms and the products of their activities, as well as the scraps resulting upon their cleavage by other techniques. Adsorption capacity of activated carbon is reflected in his highly developed porosity, and chemical reactivity of their surfaces.

In this study we investigated arsenic adsorption on activated carbon in column. Two type of experiments were performed and compared. In the first set, arsenic adsorption was investigated in two type columns (full and porous) with fixed bed and the same diameter. 
In the second set, arsenic adsorption was investigated on polypropylene and polyester carriers impregnated by activated carbon. Carriers were cropped in circular shape and placed in column with same diameter as well as and in firts set of experimens. We belive that this results could be beneficial to develop new improved system for removing arsenic from water by adsorption.

\section{$2 \quad$ Materials and Methods}

\subsection{Materials}

Polypropylene and polyester as carriers for impregnation by activated carbon were used. Carriers were firstly impregnated by activated carbon, and after that they were cropped in circular shape with a diameter of one inch and placed in a column with the same diameter. Standard solution of arsenic $\left(1000 \mathrm{ppm}\right.$, TraceCERT $\left.{ }^{\circledR}\right)$ for all experiments was used. The final concentration of arsenic $(10 \mathrm{ppm})$ was adjusted by diluting of standard solution with distilled water, filtered by Fisher Chemical (HPLC grade).

\section{$2.2 \quad$ Experimental procedure}

In this study two set of experiments were performed. In first set of experiments standard solution of arsenic (10 ppm) was passed through a columns (full and porous) with fixed bed and at the bottom was collected at specified time interval. Optimization of adsorption proccess by changes of flow rate and height of adsorbent was done. The process was repeated two more times. All colected samples were filtered and analyzed by ICP-OES (Inductively Coupled Plasma - Optical Emission Spectrometry) method.

In the second experiment set arsenic adsorption on polypropylene and polyester carriers impregnated by activated carbon was investigated. Carriers were cropped in circular shape with a diameter of one inch and placed in a full column. Standard solution of arsenic $(10 \mathrm{ppm})$ was passed through a full column and at the bottom sample was collected. The process was repeated three times. Influence of carriers number on arsenic adsorption was also investigated. Colected samples were filtered and analyzed by ICPOES method.

\subsection{ICP-OES analysis of samples}

The quantitative analysis of all samples was performed on the ICP-OES (Inductively Coupled Plasma-Optical Emission Spectrometry, ARCOS FHE12, SPECTRO, Germany), according to the manufacturer's instructions. The instrument conditions and determined parameters are given in a Table 1. 
$10^{\mathrm{TH}}$ International Conference on Sustainable EnERgy AND Environmental Protection (June $27^{\mathrm{TH}}-30^{\mathrm{RD}}, 2017$, Bled, Slovenia), WATER AND Air Quality M. Stojiljković, S. Petrović, S. Savić, S. Stojiljković \& B. Todorović: Removal of As3+ Ions from Water Solutions in Column by Adsorption on Activted Carbon

Table 1. ICP-OES operating conditions

\begin{tabular}{|c|l|}
\hline Plasma Power (W) & 1400 \\
\hline Gas flow (L/min) & 13 \\
-Coolant & 0.80 \\
\hline -Auxiliary & Cross flow \\
\hline Nebulizer type & 0.95 \\
\hline Nebulizer flow rate (L/min) & 30 \\
\hline Pump speed & 0 \\
\hline $\begin{array}{c}\text { Number of probes for each } \\
\text { measuring }\end{array}$ & 3 \\
\hline Plasma observation & axial \\
\hline
\end{tabular}

The carrier gas was argon 5.0 (99.999\% purity). For calibration, standard solutions of arsenic was used, and preparation of standard solution was done by diluting the standard solution, so that the standard concentrations for the calibration chart were in the range of expected test element concentrations. Table 2 shows the detection wavelength, correlation coefficient $\left(\mathrm{R}^{2}\right)$, limit of detection (LOD), and the range of linearity for As.

Table 2. Calibration parameters for the determined elements: $\lambda, n m ; R^{2} ; \mathrm{LD}(\mu \mathrm{g} / \mathrm{L})$ and the extent of linearity $(\mu \mathrm{g} / \mathrm{L})$

\begin{tabular}{|c|c|c|c|c|}
\hline Element & $\begin{array}{c}\text { Detection } \\
\text { wavelength } \\
(\mathrm{nm})\end{array}$ & $\begin{array}{c}\text { Correlation } \\
\text { coefficient } \\
\left(R^{2}\right)\end{array}$ & $\begin{array}{c}\text { Limit of } \\
\text { detection } \\
(\mu \mathrm{g} / \mathrm{L})\end{array}$ & $\begin{array}{c}\text { Linearity } \\
\text { range } \\
(\mathrm{mg} / \mathrm{L})\end{array}$ \\
\hline \multirow{2}{*}{ As } & 189.042 & 0.99997 & 0.88 & $0.00088-12.00$ \\
& 197.262 & 0.99998 & 1.24 & $0.00124-12.00$ \\
\hline
\end{tabular}

\section{$3 \quad$ Results and Discussion}

\subsection{Arsenic removal in full and porous column with activated carbon}

Arsenic removal from water solution in full and porous column with fixed bed was investigated. These column were chosen ecause they are completely two different cases in terms of the flow character and stream dynamic conditions. In the full column at the periphery flow velocity is zero and at the center velocity is the highest. On the other side, in the porous column is reversed, the periphery flow velocity is the largest and in the center is the smallest. The flow rate in a full column is very small and for flow $1 \mathrm{ml} / \mathrm{min}$ is $0.13165 \mathrm{~mm} / \mathrm{s}$, and at flow $1.5 \mathrm{ml} / \mathrm{min}$ flow rate is $0.1974 \mathrm{~mm} / \mathrm{s}$. The time of passage for folow of $1 \mathrm{ml} / \mathrm{min}$ is about $607 \mathrm{~s}$, while for the flow of $1.5 \mathrm{ml} / \mathrm{min}$ time passage is $910.5 \mathrm{~s}$. At this rates it is logical to expect that in the full column a flow resistance on laminar flow rate was the highest in the center, and the smallest in the periphery. However, in the porous column flow resistance on the periphery is the the smallest and the largest in the center of column. Based on this it could be concluded that velocity profile in the cross section is homogeneous, and provides a larger surface contact as well 
as the adsorption, thereby increasing the efficiency of the column althought the rate is very low.

Table 3. Percentage of removed arsenic from water solution after adsorption on activated carbon in full and porous column $4 \mathrm{~cm}$ height

\begin{tabular}{|c|c|c|c|c|}
\hline \multirow{2}{*}{$\begin{array}{c}\text { Time } \\
{[\mathrm{min}]}\end{array}$} & \multicolumn{2}{|c|}{$1 \mathrm{mLmin}^{-1}[\%]$} & \multicolumn{2}{c|}{$1.5 \mathrm{mLmin}^{-1}[\%]$} \\
\cline { 2 - 5 } & Full & Porous & Full & Porous \\
\hline 5 & 14.23 & 18.52 & 12.67 & 17.9 \\
\hline 10 & 17.72 & 21.27 & 16.85 & 20.53 \\
\hline 15 & 18.85 & 23.64 & 18.4 & 23.31 \\
\hline 30 & 23.69 & 34.07 & 22.67 & 31.12 \\
\hline 45 & 26.58 & 37.72 & 25.9 & 37.2 \\
\hline 60 & 30.12 & 41.09 & 28.75 & 40.7 \\
\hline 90 & 33.1 & 47.04 & 31.7 & 45.85 \\
\hline 120 & 36.57 & 49.49 & 35.3 & 48.8 \\
\hline
\end{tabular}

Table 4. Percentage of removed arsenic from water solution after adsorption on activated carbon in full and porous column $6 \mathrm{~cm}$ height

\begin{tabular}{|c|c|c|c|c|}
\hline \multirow{2}{*}{$\begin{array}{c}\text { Time } \\
{[\mathrm{min}]}\end{array}$} & \multicolumn{2}{|c|}{$1 \mathrm{~mL} / \mathrm{min}[\%]$} & \multicolumn{2}{c|}{$1.5 \mathrm{~mL} / \mathrm{min}[\%]$} \\
\cline { 2 - 5 } & Full & Porous & Full & Porous \\
\hline 5 & 21.79 & 24.9 & 19.8 & 24.26 \\
\hline 10 & 31.52 & 32.72 & 24.6 & 29.22 \\
\hline 15 & 34.0 & 37.47 & 29.45 & 33.96 \\
\hline 30 & 41.24 & 45.75 & 35.24 & 37.29 \\
\hline 45 & 44.17 & 47.3 & 38.27 & 42.87 \\
\hline 60 & 44.34 & 49.56 & 40.32 & 43.97 \\
\hline 90 & 49.03 & 52.01 & 43.85 & 46.07 \\
\hline 120 & 50.61 & 52.17 & 45.87 & 49.38 \\
\hline
\end{tabular}


$10^{\mathrm{TH}}$ International CONFERENCE on Sustainable EnERgy and Environmental Protection (June $27^{\mathrm{TH}}-30^{\mathrm{RD}}, 2017$, Bled, Slovenia), WATER AND Air Quality M. Stojiljković, S. Petrović, S. Savić, S. Stojiljković \& B. Todorović: Removal of As3+ Ions from Water Solutions in Column by Adsorption on Activted Carbon

Table 5. Percentage of removed arsenic from water solution after adsorption on activated carbon in full and porous column $8 \mathrm{~cm}$ height

\begin{tabular}{|c|c|c|c|c|}
\hline \multirow{2}{*}{$\begin{array}{c}\text { Time } \\
{[\mathrm{min}]}\end{array}$} & \multicolumn{2}{|c|}{$1 \mathrm{~mL} / \mathrm{min}[\%]$} & \multicolumn{2}{c|}{$1.5 \mathrm{~mL} / \mathrm{min}[\%]$} \\
\cline { 2 - 5 } & Full & Porous & Full & Porous \\
\hline 5 & 30.4 & 34.72 & 29.77 & 31.92 \\
\hline 10 & 47.23 & 51.02 & 46.6 & 48.85 \\
\hline 15 & 49.71 & 59.7 & 54.03 & 55.5 \\
\hline 30 & 62.27 & 66.34 & 61.72 & 63.68 \\
\hline 45 & 62.5 & 68.52 & 63.97 & 65.27 \\
\hline 60 & 65.32 & 69.2 & 64.57 & 67.35 \\
\hline 90 & 69.38 & 74.01 & 68.73 & 71.91 \\
\hline 120 & 71.06 & 76.46 & 70.2 & 73.89 \\
\hline
\end{tabular}

As it can be seen from obtained results in column of $4 \mathrm{~cm}$ height (Table 3) indicates that percentage of arsenic removal increases during the time of passage. In both investigated case porous column were more effective compared to the full.

In the case when the investigated column with height $6 \mathrm{~cm}$ (table 4), in comapared to full column porous column was about $4 \%$ more efficient at flow of $1 \mathrm{ml} / \mathrm{min}$, while at the flow rate of $1.5 \mathrm{ml} / \mathrm{min}$ about $2 \%$. By comparing of results obtained at different flow rates it could be concluded that lower flow rate $(1.0 \mathrm{ml} / \mathrm{min})$ is effective from 3 to $5 \%$ depending on the type of the column.

Looking of table 5 it colud be conluded that porosity column with $8 \mathrm{~cm}$ height was effective compared to full at both flow rates. Comparing of flow rates, as in previuos two cases it could be concluded that at lower flow rates precentage of removed arsenic was higher.

Based on this it could be concluded that for industrial purposes using pre porous than a full column. In order to compare the efficiency of the column it is necessary to calculate for each the ratio of height and diameter $\mathrm{H} / \mathrm{d}$.

Table 6. Efficiency of the columns

\begin{tabular}{|c|c|}
\hline $\mathrm{H}, \mathrm{cm}$ & $\mathrm{H} / \mathrm{D}$ ratio \\
\hline 4 & 3.14 \\
\hline 6 & 4.72 \\
\hline 8 & 6.28 \\
\hline
\end{tabular}

As it can be seen from table there are two extremes values. Column with $4 \mathrm{~cm}$ height has a very small retention time, so that it is possible circulation and probably the most of the flow passes the flange without contacting of all carbon. Also, if we consider the small ratio of H/D it could be concluded that unbalanced flow in this section was possible. On 
the other side, porous column with a height of $8 \mathrm{~cm}$ has the highest efficiency for arsenic removing of about $70 \%$. Its $\mathrm{H} / \mathrm{D}$ ratio was 6.28 . At a flow rate at $1 \mathrm{ml} / \mathrm{min}$ column of 8 $\mathrm{cm}$ height for 120 minutes binding $0.1 \mathrm{mg}$ of arsenic per carbon gram.

This column can be used as a model for the development of an industrial plant. It would consists of a number of porous column placed in a cylinder and the upper side would be flush with waste water. The advantage of a porous column is in permanent contact with oxygen from the air that can accelerate and chemisorption.

\subsection{Arsenic removal in column with impregnated activated carbonon carriers}

In this set of experiments was investigated the arsenic removal on activated carbon that was impregnated on two carriers (polypropylene and polyester). Based on obtained results it could be concluded several facts: first, with increasing numbers of cycles arsenic removal increases. Second, increasing the layers number increases the percentage of the removed arsenic from starting solutions. On the other side, comparing of carrier influence on arsenic removal it could be concluded that polypropylene showed a better result.

Table 7. Percentage of removed arsenic from water solution

\begin{tabular}{|c|c|c|c|}
\hline & Cycles & Polyester & Polypropylene \\
\hline \multirow{3}{*}{ 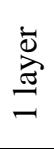 } & 1 & 23.23 & 23.51 \\
\hline & 2 & 23.74 & 24.27 \\
\hline & 3 & 26.4 & 25.12 \\
\hline \multirow{3}{*}{$\begin{array}{l}\frac{\infty}{\Delta} \\
\frac{\vec{d}}{2} \\
\text { N }\end{array}$} & 1 & 24.81 & 25.23 \\
\hline & 2 & 25.43 & 30.55 \\
\hline & 3 & 25.92 & 30.67 \\
\hline \multirow{3}{*}{$\frac{\stackrel{n}{0}}{\frac{\vec{d}}{m}}$} & 1 & 27.91 & 35.2 \\
\hline & 2 & 28.84 & 37.26 \\
\hline & 3 & 30.22 & 37.59 \\
\hline \multirow{3}{*}{$\begin{array}{l}\frac{n}{0} \\
\frac{\grave{\sigma}}{\sigma}\end{array}$} & 1 & 31.9 & 40.8 \\
\hline & 2 & 32.69 & 41.6 \\
\hline & 3 & 36.65 & 42.9 \\
\hline
\end{tabular}

These results were expected and logic, because with increasing number of layers amount of adsorbent is higher and chance for arsenic adsorption is higher. Also, with increasing of cycles number concentration of arsenic decreases because in every next cycle starting arsenic concentration is lower in compared to previous cycle and on the other side the adsorption capacity still exists, but it is not high as in first cycle [16]. Good result of 
$10^{\text {TH }}$ InTERnATIONAL CONFERENCE ON Sustainable ENERgy AND ENVIRONMENTAL Protection (June $27^{\mathrm{TH}}-30^{\mathrm{RD}}, 2017$, Bled, SLOVEnia), WATER AND Air Quality M. Stojiljković, S. Petrović, S. Savić, S. Stojiljković \& B. Todorović: Removal of As3+ Ions from Water Solutions in Column by Adsorption on Activted Carbon

activated carbon in arsenic removal was expected because activated carbon was has a good result and in previous studies, even up $42.9 \%$.

\section{Conclusion}

In summary, arsenic adsorption on activated carbon in column were investigated. Two sets of experiment were investigated. In the first set arsenic adsorption in two type of columns (full and porpus) with fixed bag and the same diameter, and in the second set arsenic adsorption on polypropylene and polyester carriers previously impregnated by activated carbon were investigated.

Results from investigation of column type influence on arsenic adsorption were shown that porous column was more efficiency in compared to the full column. Also with increasing of column height percentage of adsorbed arsenic increases, and at the end of process in $8 \mathrm{~cm}$ height column removed arsenic was $76.46 \%$. Comparing the influence of flow rate, it could be concluded that at lower flow rate $(1 \mathrm{ml} / \mathrm{min})$ percentage of adsorbed arsenic was higher, probably because the contact time was greater.

Investigations of arsenic adsorption on impregnated polypropylene and polyester by activated carbon were shown that with increasing numbers of cycles arsenic removal increases. Also, increasing the layers number increases the percentage of the removed arsenic from starting solutions, and finally comparing of carrier influence on arsenic removal it could be concluded that polypropylene was showed as better.

\section{Acknowledgements}

This work was supported by the Ministry of Education, Science and Technological Development of the Republic of Serbia under Project No.III 42006.

\section{References}

[1] M. K. Uddin, A review on the adsorption of heavy metals by clay minerals, with special focus on the past decade, Chemical Engineering Journal 308 (2017) 438-462

[2] I. Ali, V.K. Gupta, Advances in water treatment by adsorption technology, Nat. Protoc. 1 (2007) 2661-2667.

[3] V.K. Gupta, P.J.M. Carrott, M.M.L. Ribeiro Carrott, Suhas, Low-cost adsorbents: growing approach to wastewater treatment - a review, in: Crit. Rev. Environ. Sci. Technol. 39 (2009) 783-842.

[4] M. Halim, P. Conte, A. Piccolo, Potential availability of heavy metals to phytoextraction from contaminated soils induced by exogenous humic substances, Chemosphere 52 (2002) 26-75.

[5] M. Alkan, M. Dogan, Adsorption of copper(II) onto perlite, J. Colloid Interface Sci. 243 (2001) 280-291.

[6] R. Balasubramanian, S.V. Perumal, K. Vijayaraghavan, Equilibrium isotherm studies for the multicomponent adsorption of lead, zinc, and cadmium onto Indonesian peat, Ind. Eng. Chem. Res. 48 (2009) 2093-2099. 
[7] V.K. Gupta, I. Ali, Removal of lead and chromium from wastewater using bagasse fly ash - a sugar industry waste, J. Colloid Interface Sci. 271 (2004) 321-328.

[8] R.A.K. Rao, M. Kashifuddin, Kinetics and isotherm studies of Cd (II) adsorption from aqueous solution utilizing seeds of bottlebrush plant (Callistemon chisholmii), Appl. Water Sci. 4 (2014) 371-383.

[9] B. M. Jovanović, V. L. Vukašinović-Pešić, Đ. N. Veljović, LJ. V. Rajaković, Arsenic removal from water using low-cost adsorbents - a comparative study, J. Serb. Chem. Soc. 76 (10) 1437-1452 (2011).

[10] M.A. Khan, M.K. Uddin, R. Bushra, A. Ahmad, S.A. Nabi, Synthesis and characterization of polyaniline $\mathrm{Zr}(\mathrm{IV})$ molybdophosphate for the adsorption of phenol from aqueous solution, React. Kinet. Mech. Catal. 113 (2014) 499-517.

[11] R.A.K. Rao, S. Ikram, M.K. Uddin, Removal of Cr (VI) from aqueous solution on seeds of Artimisia absinthium (novel plant material), Desalin. Water Treat. 54 (2015) 3358-3371.

[12] R.A.K. Rao, S. Ikram, M.K. Uddin, Removal of Cd (II) from aqueous solution by exploring the biosorption characteristics of gaozaban (Onosma bracteatum), J. Environ. Chem. Eng. 2 (2014) 1155-1164.

[13] R.A.K. Rao, M. Kashifuddin, Adsorption properties of coriander seed powder (Coriandrum sativum): extraction and pre-concentration of $\mathrm{Pb}$ (II), $\mathrm{Cu}$ (II) and $\mathrm{Zn}$ (II) ions from aqueous solution, Adsorpt. Sci. Technol. 30 (2012) 127-146.

[14] R.A.K. Rao, F. Rehman, M. Kashifuddin, Removal of Cr (VI) from electroplating wastewater using fruit peel of Leechi (Litchi chinensis), Desalin. Water Treat. 49 (2012) 136-146.

[15] V.K. Gupta, R. Kumar, A. Nayak, T.A. Saleh, M.A. Barakat, Adsorptive removal of dyes from aqueous solution onto carbon nanotubes: a review, Adv. Colloid Interface Sci. 193 (2013) 24-34.

[16] Duarte, A.A.L.S., Cardoso, S.J.A., Alçada, A.J. Emerging and innovative techniques for arsenic removal applied to a small water supply system. Sustainability Journal, Ed. MDPIMultidisciplinary Digital Publishing Institute, Basel, Switzerland, 1 (4), pp. 1288-1307 (2009). 


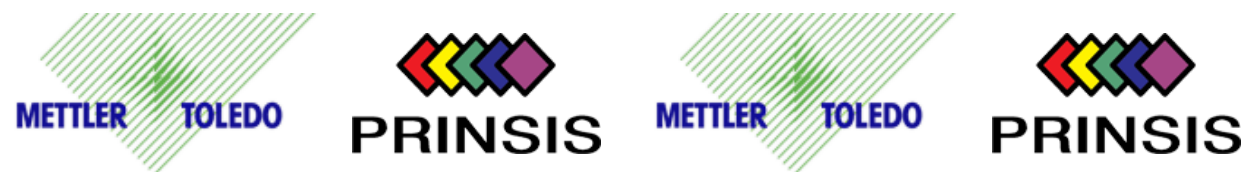

$€$ energetika ljubljana $€$ energetika ljubljana

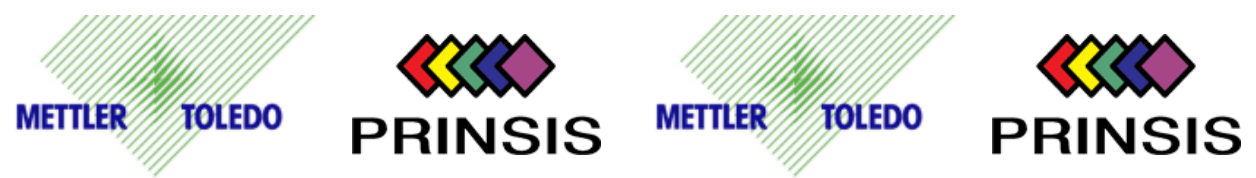

$€$ energetika ljubljana $€$ energetika ljubljana

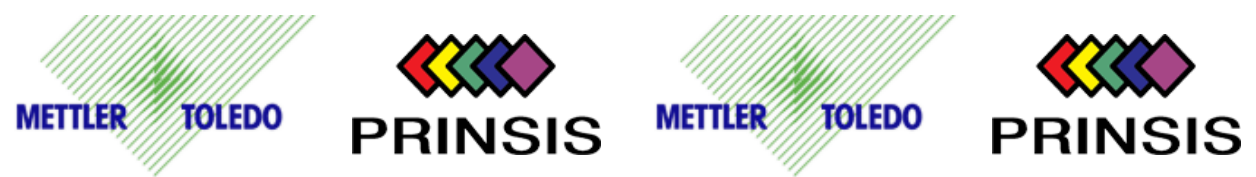

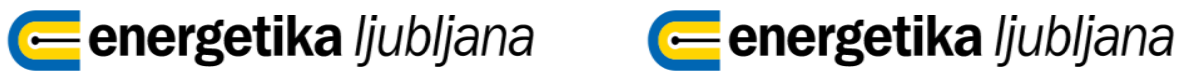

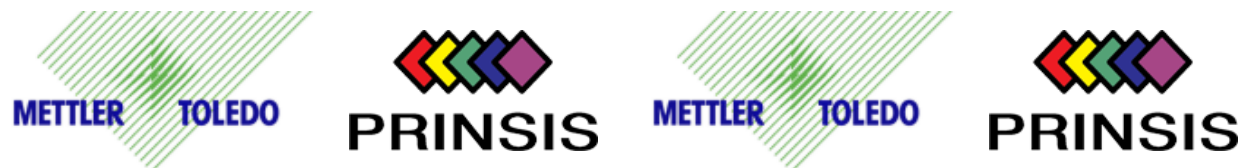

$€$ energetika ljubljana $€$ energetika ljubljana

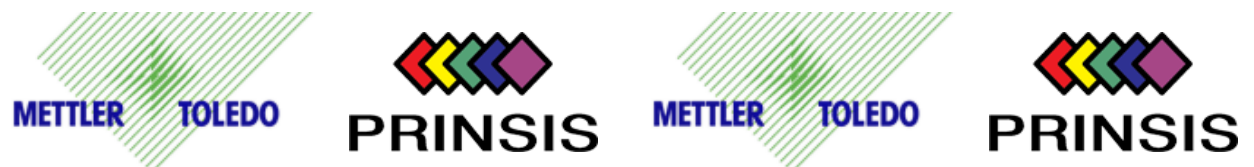

$€$ energetika ljubljana $€$ energetika ljubljana 